Fernando de Oliveira Marin

\title{
A Subcorrente Norte do Brasil ao Largo da Costa do Nordeste
}

Dissertação apresentada ao Instituto Oceanográfico da Universidade de São Paulo, como parte dos requisitos para obtenção do título de Mestre em Ciências, área de Oceanografia Física.

Orientador:

Prof. Dr. Ilson Carlos Almeida da Silveira

São Paulo

2009 


\section{UNIVERSIDADE DE SÃO PAULO INSTITUTO OCEANOGRÁFICO}

\section{A Subcorrente Norte do Brasil ao Largo da Costa do Nordeste}

Fernando de Oliveira Marin

Dissertação apresentada ao Instituto Oceanográfico da Universidade de São Paulo, como parte dos requisitos para obtenção do título de Mestre em Ciências, área de Oceanografia Física.

Julgada em

Prof. Dr.

Conceito

Prof. Dr.

Conceito

Prof. Dr.

Conceito 
"Há homens que lutam por um dia, e são bons; Há homens que lutam por um ano, e são melhores; Há homens que lutam muitos anos, $e$ são melhores ainda; Mas há aqueles que lutam a vida inteira: Estes são os imprescindíveis."

Bertold Brecht

"Um país se faz com homens e livros."

Monteiro Lobato 


\section{Sumário}

Agradecimentos iv

Resumo vii

\begin{tabular}{ll} 
Abstract & ix \\
\hline &
\end{tabular}

Lista de Siglas e Acrônimos $\quad$ xi

Lista de Figuras $\quad$ xxi

Lista de Tabelas $\quad$ xxii

\begin{tabular}{lll}
\hline & Introdução & 1
\end{tabular}

1.1 Preâmbulo . . . . . . . . . . . . . . . . . . . . 1

1.2 Síntese da Literatura $\ldots \ldots \ldots \ldots$. . . . . . . . . . . . . . . 2

1.2.1 O Giro Equatorial . . . . . . . . . . . . . . . . 2

1.2.2 Corrente Sul Equatorial (CSE) . . . . . . . . . . . . . . . 4

1.2.3 Subcorrente Norte do Brasil (SNB) . . . . . . . . . . . . . . . . . 6

1.3 Objetivos . . . . . . . . . . . . . . . . . . . . 15

1.3 .1 Objetivo Geral . . . . . . . . . . . . . . . . . 15

1.3 .2 Objetivos Específicos . . . . . . . . . . . . . . . 16

2 Conjunto de Dados 18

2.1 Preâmbulo . . . . . . . . . . . . . . . . . . . . . . . . . . . 18

2.2 Dados de Hidrografia . . . . . . . . . . . . . . . . . . . . . . 19

2.3 Dados de Velocidade de Corrente . . . . . . . . . . . . . . . . . . . 21 
3 Fundamentação Teórica 30

3.1 Preâmbulo . . . . . . . . . . . . . . . . . . . . . 30

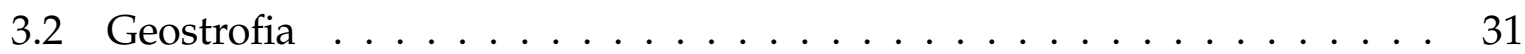

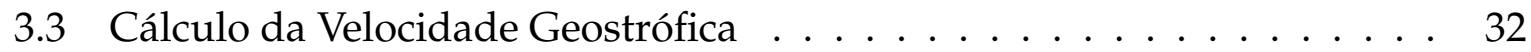

3.3 .1 Método Dinâmico . . . . . . . . . . . . . . . 32

3.4 Função de Corrente Geostrófica . . . . . . . . . . . . . . . . . . . . . . 34

$3.4 .1 \quad$ Função de Corrente Geostrófica Absoluta . . . . . . . . . . . . . . 36

$4 \quad$ Padrões de Circulação Geostrófica Baroclínica Relativa 38

4.1 Preâmbulo . . . . . . . . . . . . . . . . . . . . . . . . . 38

4.2 Metodologia . . . . . . . . . . . . . . . . . . 39

4.2 .1 Tratamento Básico dos Dados de Hidrografia . . . . . . . . . . . . 40

4.2 .2 Cálculo de Velocidade Geostrófica Baroclínica Relativa . . . . . . 45

4.2 .3 Gradeamento e Interpolação . . . . . . . . . . . . . . . . . . . 45

4.2.4 Mapas de Função de Corrente Geostrófica Baroclínica Relativa 45

4.3 Resultados e Discussão . . . . . . . . . . . . . . . . . . . . . . . . 50

4.3 .1 Seções Verticais de Velocidade Geostrófica - ONEI e ONEII . . . . 50

4.3 .2 Mapas de Função de Corrente Geostrófica - ONEI e ONEII . . . . 58

5 Padrões de Circulação Derivados de ADCP 64

5.1 Preâmbulo . . . . . . . . . . . . . . . . . . . . . . . . . . . . . 64

5.2 Metodologia . . . . . . . . . . . . . . . . 65

5.2.1 Tratamento dos Dados de Velocidade Observada . . . . . . . . 65

5.2 .2 Seções Verticais de Velocidade Observada . . . . . . . . . . . . . . 73

5.2 .3 Mapas de Função de Corrente Observada . . . . . . . . . . . . . . 74

5.3 Resultados e Discussão . . . . . . . . . . . . . . . . . 76

$5.3 .1 \quad$ Qualidade dos Dados de ADCP . . . . . . . . . . . . . 78

5.3 .2 Seções Verticais de Velocidade Observada - ONEI . . . . . . . . . 81

5.3 .3 Seções Verticais de Velocidade Observada - ONEII . . . . . . . . . 86

5.3.4 Mapa de Função de Corrente Observada - ONEI e ONEII. . . . . . 93

6 Padrões Horizontais Geostróficos Absolutos 99

6.1 Preâmbulo . . . . . . . . . . . . . . . . . . . . . . . . . . . . 99 
6.2 Resultados e Discussão . . . . . . . . . . . . . . . . . . . . . . . . . . . 100

\begin{tabular}{lll}
\hline 7 & Considerações Finais & 107
\end{tabular}

7.1 Síntese e Conclusões . . . . . . . . . . . . . . . . . . . . . . 107

7.2 Sugestões para Trabalhos Futuros . . . . . . . . . . . . . . . . . . 110

\begin{tabular}{ll}
\hline Referências Bibliográficas & 111
\end{tabular} 


\section{Agradecimentos}

A Deus, por tudo que tenho e sou.

Aos meus pais, Oswaldo e Clarice, que me prepararam para a vida com dedicação e amor incondicional. Tudo que sou devo a vocês.

Aos meus irmãos, Elisângela e Orlando, pelo imenso amor e apoio inconteste.

À minha mulher Andréa, pelo amor, carinho e paciência. Meu porto seguro em momentos tempestuosos.

Aos amigos do "2nd Floor", pela ambiência fraterna, camaradagem e respeito, que trarei sempre em meu coração. Deus me permitiu formar uma família com duas pessoas grandiosas: Felipe e Rafael. Nosso convívio harmonioso, em busca de um ideal comum, possibilitou-nos suportar de forma mais amena o afastamento dos laços familiares.

Felipe, sou grato desde o início de nossas carreiras, quando pude contar com sua ajuda em momentos significativos, dos quais você provavelmente já nem se lembra mais. Mas eu jamais esquecerei. Rafael, não consigo mensurar o quanto lhe sou grato. Com conduta profissional, amiga, serena e firme, seu apoio foi de extrema importância para a minha trajetória na USP. É inegável a imensa contribuição para o meu trabalho. É uma honra ser seu amigo.

Ao amigo Márcio Borges que, conhecedor das dificuldades decorrentes do longo tempo de afastamento dos bancos escolares e da fase avançada da carreira, sempre contribuiu com gestos e palavras de amizade. Sua resiliência nutriu-me de motivação nos momentos difícieis. Márcio, sou grato pela elevada estima e aprêço.

Ao amigo e orientador Prof. Dr. Ilson Carlos Almeida da Silveira, por colocar à disposição não apenas experiência e conhecimento, mas amizade e imenso apoio, sem os quais nem sequer sonharia em lograr êxito. Suas preciosas horas dispendidas co- 
migo, com zelo e dedicação, foram fundamentais para a conclusão do trabalho. Ilson, sou imensamente grato.

À amiga Juliana, membra honorária do "2nd Floor", pela amizade sincera e por me permitir conhecer uma bela família.

Aos amigos recém-chegados ao "2nd Floor", Fabrício e Rafael, pelo convívio agradável.

Aos membros da banca examinadora, Prof. Dr. Luiz Bruner de Miranda e CMG (RRm) José Helvécio Moraes de Rezende, pela fidalguia ao aceitar o convite. Sinto-me honrado.

Aos professores do curso, Prof. Dr. Belmiro Mendes de Castro Filho, Prof. Dr. Edmo José Dias Campos, Prof. Dr. Paulo Simionatto Polito e Profa. Dra. Sueli Susana de Godoi, pelos preciosos conhecimentos transmitidos.

À Dra. Olga Tiemi Sato, pela cordialidade e apoio.

Ao Dr. Luiz Vianna Nonnato, pela imensa contribuição, e aos demais membros do Laboratório de Instrumentação Oceanográfica (LIO), pela cordialidade e predisposição em ajudar.

À CC (T) Ana Cláudia que, com profissionalismo e boa vontade, proveu o apoio necessário através de uma relação amistosa, deixando-me bastante tranqüilo para compartilhar êxitos e dificuldades.

Ao amigo Sandro que, com postura exemplar e espírito de camaradagem, colaborou sobremaneira para a minha adaptação à cidade de São Paulo e ao ambiente acadêmico da USP.

Ao almirante Newton Cardoso, por ser favorável à minha vinda para São Paulo, não obstante a carência de recursos humanos na região amazônica.

Ao almirante Edison Lawrence Mariath Dantas, por autorizar minha participação no processo seletivo.

Aos oficiais do CCEMSP, CMG (EN) Luciano, CMG (EN) Álvaro, CMG (EN) Joaquim, CF (EN) Sarquis Attié e CT (EN) Botto, bem como à guarnição, por fazerem do CCEMSP muito mais que uma OM de apoio.

Aos profissionais do CHM, CF Marcelo, CT (T) Márcia Helena, CT (T) Vladimir, FC Jorge, pelo esforço em sempre nos atender nas diversas solicitações. 
Ao amigo Cesar Barbedo, pela grande ajuda ao final do trabalho.

Aos amigos do Laboratório de Dinâmica Oceânica (LaDO), Cayo Prado, André Schmidt, Leandro Ponsoni, Leandro Calado, Diogo, Paulo, Thiago Podadera, Herminio, Hélio Teruo, Marcelo Franco, Ronaldo Sato e Leilane Gonçalves, pela colaboração e pelos bons momentos.

Aos amigos do curso de mestrado, Gabriela Cassiano, Wellington Ceccopieri, Gustavo Mastrorocco, Victor Daher, Piero Mazzini, Alexandre Lopes, Bruno Ferrero, Marcos Tonelli e Hélvio Prevelatto, pelo ambiente de cooperação e estímulo.

Aos amigos da Pós-Graduação, França, Francisco José, Lucas Cardoso, Cássia, Melissa, Raquel, Hebe Queiroz, Ana Amélia, Mariana, Mariana Coppedê, Ruth e Fabíola. Existem pessoas que nos deixam felizes pelo simples fato de cruzarem nosso caminho.

Às amigas Angélica, Vanilde, Eliete, Mirian e Ademildes, pelo carinho e cordialidade. Trarei sempre na lembraça o apoio e os preciosos momentos de conversas agradáveis.

Aos funcionários da biblioteca, da seção de manutenção geral, da seção de copa e limpeza, da gráfica, da seção de informática, enfim, a todos os funcionários do Instituto Oceanográfico que, de alguma forma, contribuíram para a minha jornada do mestrado. Devo meu agradecimento a muita gente. Várias pessoas colaboraram e me ensinaram durante a minha trajetória na USP. Peço perdão aos que não citei. Sentirei muita falta dos amigos que fiz em São Paulo, dos inúmeros momentos felizes, e de fazer parte de um ambiente acadêmico de elevado nível. 


\section{Resumo}

A Subcorrente Norte do Brasil (SNB) é a corrente de contorno oeste que fecha o Giro Equatorial do Oceano Atlântico em sua porção austral. É uma corrente vigorosa, com núcleo atingindo $1 \mathrm{~m} \mathrm{~s}^{-1}$ em profundidades de $150 \mathrm{~m}$ a $250 \mathrm{~m}$. Trabalhos pretéritos reportam que esta corrente transporta mais de $20 \mathrm{~Sv}\left(1 \mathrm{~Sv}=10^{6} \mathrm{~m}^{3} \mathrm{~s}^{-1}\right)$. Ao receber o aporte de volume de ramos da Corrente Sul Equatorial (CSE), em torno de $4^{\circ} \mathrm{S}-5^{\circ}$ S, a SNB adquire núcleo em superfície e passa a ser denominada Corrente Norte do Brasil (CNB). Entretanto, não há relato do padrão contínuo da SNB entre $11^{\circ} \mathrm{S}$ e as proximidades da linha do equador, por observações de velocidade, na literatura.

O objetivo desta dissertação é justamente o mapeamento sinótico e descrição da SNB e das estruturas de mesoescala associadas na faixa latitudinal supracitada. Para tanto, combinamos dados de ADCP de casco e de hidrografia. Os dados são oriundos das comissões OCEANO NORDESTE I (ONEI, verão 2002) e OCEANO NORDESTE II (ONEII, primavera 2004), realizadas a bordo do NOc Antares da Marinha do Brasil.

Através de cálculo de velocidades geostróficas relativas a $1.150 \mathrm{~m}$, análise dos dados de velocidades perfiladas pelo ADCP de casco e cálculo de velocidades geostróficas absolutas referenciadas pelos dados de ADCP a 160 m, obtivemos uma descrição da SNB que confirma e estende esforços anteriores de pesquisa. A SNB aparece como uma corrente robusta e presente ao longo de todas as radiais analisadas. Entre $11^{\circ} \mathrm{S}$ e as proximidades do Cabo Calcanhar (RN), o comportamento da corrente revela pouco meandramento, seguindo o talude continental nordestino. A exceção é um ramo ciclônico em torno de $4^{\circ} \mathrm{S}$ que cede volume para originar a Subcorrente Sul Equatorial (SSE) em nível subpicnoclínico.

A SNB, provalvemente tentando conservar vorticidade potencial, frente à abrupta mudança de orientação da margem continental em $5^{\circ} \mathrm{S}$, também desenvolve 
um meandro anticiclônico frontal centrado na longitude da cidade de Macau (RN) e com cerca de $150 \mathrm{~km}$ de raio. Como há evidência do anticiclone nas duas comissões, especulamos tratar-se de uma estrutura semipermanente. Por tratar-se de um relato original, decidimos denominá-lo Vórtice de Macau (VM). Outro resultado relevante foi a documentação do processo de "transformação" da SNB em CNB, com avaliação do núcleo se tornando mais raso em direção ao equador. No cenário da ONEII, observamos a retroflexão picnoclínica da $\mathrm{CNB}$, ocorrida no hemisfério boreal e a origem da Subcorrente Equatorial (SE) na área de estudo. Também como resultado inédito, os dados de velocidade observada mostraram que também há cessão de volume pela SNB para SE em torno de $1^{\circ} \mathrm{S}$. 


\section{Abstract}

The North Brazil Undercurrent (NBUC) is the western boundary current that closes the Equatorial Gyre of the Atlantic Ocean in its austral portion. The NBC is a vigorous current with a core that reaches $1 \mathrm{~m} \mathrm{~s}^{-1}$ at depth of $150 \mathrm{~m}$ to $250 \mathrm{~m}$. Previous works reported that this current transports more than $20 \mathrm{~Sv}\left(1 \mathrm{~Sv}=10^{6} \mathrm{~m}^{3} \mathrm{~s}^{-1}\right)$. As branches of the South Equatorial Current (SEC) reaches the western boundary at around $4^{\circ} \mathrm{S}-5^{\circ} \mathrm{S}$, the NBUC core surfaces and the new current is referred as the North Brazil Current (NBC). However, there is no report in the literature about a continuous pattern of the NBUC in the latitude range between $11^{\circ} \mathrm{S}$ and the vicinities of the equator from observed velocities.

The main goal of this thesis is just to obtain a synoptic map of NBUC and the associated mesoscale features in the latitude range mentioned above. In order to do so, we combined vessel-mount ADCP and hydrographic data from two cruises conducted by the R/V Antares of the Brazilian Navy: the OCEANO NORDESTE I (ONEI, summer 2002) and the OCEANO NORDESTE II (ONEII, spring 2004).

We calculated geostrophic velocities relative to $1.150 \mathrm{~m}$, analyzed ADCP observed velocity data as well computed absolute geostrophic velocities, referenced by the ADCP data at $160 \mathrm{~m}$. Hence, we were able to obtain a NBC description that corroborated and extended the findings of previous research in the area. The NBUC was depicted as a robust nearly non-meandering current between $11^{\circ} \mathrm{S}$ and Cape Calcanhar (RN) present in all transects of both cruises. At $4^{\circ} \mathrm{S}$, the NBUC develops a cyclonic branch and originates the South Equatorial Undercurrent (SEUC).

Possibly as an attempt to conserve potential vorticity as the NBUC faces the abrupt change in the continental margin orientation at $5^{\circ} \mathrm{S}$, the current develops a $150 \mathrm{~km}$ radius anticyclonic frontal meander. As there are evidence of the anticyclone 
in both cruises, we speculate that it can be a semipermanent feature. As it is a original description, we named it the Macau Eddy. Another result that deserves to be mentioned is that the process of the "transformation" of the NBUC in NBC was well documented for the first time through a continuous surfacing process of the current core. Finally, in the ONEII scenario, we observed the pycnoclinic retroflection of the NBC that occurs in northern hemisphere and returns to the equator to originate the Equatorial Undercurrent (EUC). We also depicted that the NBUC feeds the forming EUC from the southern hemisphere from a cyclonic branch around $1^{\circ} \mathrm{S}$. 


\section{Lista de Siglas e Acrônimos}

ACAS Água Central do Atlântico Sul

ADCP Acoustic Doppler Current Profiler

AO Análise Objetiva

AOV Análise Objetiva Vetorial

APAN Água Profunda do Atlântico Norte

BNDO Banco Nacional de Dados Oceanográficos

CA Corrente das Agulhas

CB Corrente do Brasil

CCI Corrente de Contorno Intermediária

CCO Corrente de Contorno Oeste

CHM Centro de Hidrografia da Marinha

$\mathrm{CM}$ Corrente das Malvinas

CNB Corrente Norte do Brasil

CCNE Contracorrente Norte Equatorial

CODAS Common Ocean Data Access System

CRM Célula de Revolvimento Meridional

CTD Conductivity, Temperature, and Depth

CSE Corrente Sul Equatorial

CSEc Ramo Central da Corrente Sul Equatorial

CSEe Ramo Equatorial da Corrente Sul Equatorial

CSEn Ramo Norte da Corrente Sul Equatorial

CSEs Ramo Sul da Corrente Sul Equatorial

DHN Diretoria de Hidrografia e Navegação

EUC Equatorial Undercurrent

EPS -78 Escala Prática de Salinidade 1978

GPS Global Positioning System

LADCP Lowered Acoustic Doppler Current Profiler

JPOTS Joint Panel On Oceanographic Tables and Standards 


$\begin{array}{ll}\text { MB } & \text { Marinha do Brasil } \\ \text { MDC } & \text { Método Dinâmico Clássico } \\ \text { MDR } & \text { Método Dinâmico Referenciado } \\ \text { NASA } & \text { National Aeronautics and Space Administration } \\ \text { NBC } & \text { North Brazil Current } \\ \text { NBUC } & \text { North Brazil Undercurrent } \\ \text { NR } & \text { Nível de Referência } \\ \text { NOc } & \text { Navio Oceanográfico } \\ \text { ONEI } & \text { Comissão Hidroceanográfica OCEANO NORDESTE I } \\ \text { ONEII } & \text { Comissão Hidroceanográfica OCEANO NORDESTE II } \\ \text { PSS-78 } & \text { Practical Salinity Scale 1978 } \\ \text { QuickSCAT } & \text { Quick Scatterometer } \\ \text { SE } & \text { Subcorrente Equatorial } \\ \text { SEC } & \text { South Equatorial Current } \\ \text { SEUC } & \text { South Equatorial Undercurrent } \\ \text { SNB } & \text { Subcorrente Norte do Brasil } \\ \text { SNE } & \text { Subcorrente Norte Equatorial } \\ \text { SSE } & \text { Subcorrente Sul Equatorial } \\ \text { VM } & \text { Vórtice de Macau } \\ \text { VM-ADCP } & \text { Vessel-Mount Acoustic Doppler Current Profiler } \\ \text { VM-DAS } & \text { Vessel-Mount Data Acquisition System } \\ \text { UNESCO } & \text { United Nations Educational, Scientific and Cultural Organization } \\ & \end{array}$




\section{Lista de Figuras}

1.1 Representação esquemática, em superfície, dos giros oceânicos do Atlântico

\begin{tabular}{|c|}
\hline Sul, entre $40^{\circ} \mathrm{S}$ e $40^{\circ} \mathrm{N}$, de acordo com os padrões de circulação forçada pelo \\
\hline vento presentes em Mayer $\mathcal{E}$ Weisberg[[1993]. Modificado de Bub \& Brown [1996].] 2
\end{tabular}

1.2 Representação esquemática do padrão de circulação de larga escala para as correntes geostróficas no Atlântico Sul, entre 0 e 100 m. São mostradas: Contracor-

rente Norte Equatorial (CCNE); Subcorrente Equatorial (SE); Corrente Norte do

Brasil (CNB); Subcorrente Sul Equatorial (SSE), Contracorrente Sul Equatorial

(CCSE); Ramos norte (CSEn), central (CSEc), sul (CSEs) e equatorial (CSEe) da

Corrente Sul Equatorial (CSE); Corrente do Brasil; Corrente do Atlântico Sul;

Corrente Circumpolar Antártica; Corrente das Malvinas (CM); Corrente das

Agulhas (CA). Modificado de Stramma \& England [1999] . . . . . . . . . . . . 4

1.3 Representação esquemática do padrão de circulação de larga escala para as correntes geostróficas no domínio da Água Central do Atlântico Sul (ACAS), de

100 a 500 m. Além das correntes apresentadas na Figura 1.2 , são mostradas:

Subcorrente norte do Brasil (SNB); Subcorrente Norte Equatorial (SNE). Modi-

ficado de Stramma $\&$ England $[1999] . \ldots$. . . . . . . . . . . . . . . . . . . 5 
1.4 Distribuições verticais de velocidade geostrófica referentes às radiais 1 e 12 da comissão analisada por Silveira et al. [1994|. Na radial $1\left(\backsim 10^{\circ} 30^{\prime}\right.$ S) pode-se observar a SNB com núcleo de subsuperfície de $\backsim 50 \mathrm{~cm} \mathrm{~s}^{-1}$ em $150 \mathrm{~m}$. Na radial $12\left(\backsim 4^{\circ} \mathrm{S}\right)$ pode-se observar a SNB com núcleo de subsuperfície de $\backsim$ $100 \mathrm{~cm} \mathrm{~s}^{-1}$ entre 100 e $150 \mathrm{~m}$, verificando-se também a presença da SSE, com velocidade máxima para sul da ordem de $30-40 \mathrm{~cm} \mathrm{~s}^{-1}$ entre $200-300 \mathrm{~m}$, bem como a estrutura vertical da bifurcação do ramo CSEc para norte. O retângulo sombreado indica região sem estimativas de velocidade devido às rasas perfilagens hidrográficas. Valores de velocidade positivos para norte. Modificado de Silveira et al. [1994]. . . . . . . . . . . . . . . . . . . . . . . . 8

1.5 Distribuições verticais de velocidades correspondentes à SNB, nas latitudes de $5^{\circ} 30^{\prime} \mathrm{S}$ e $10^{\circ} \mathrm{S}$. Essas velocidades foram obtidas por LADCP durante a primavera austral (novembro/1992). O intervalo entre as isotacas é de $10 \mathrm{~cm} \mathrm{~s}^{-1}$. Reproduzido de Stramma et al.[1995]. . . . . . . . . . . . . . . . . . . . 9

1.6 Distribuições, ao largo da costa brasileira, das velocidades médias de corrente $\left(\mathrm{cm} \mathrm{s}^{-1}\right)$ e dos transportes médios (Sv) calculados a partir de dados de ADCP/LADCP. coletados nos 9 cruzeiros realizados durante o período de 1990-2004, nas proximidades da latitude $5^{\circ} \mathrm{S}$, e nas 5 seções realizadas durante o período de 20002004 , nas proximidades da latitude $11^{\circ} \mathrm{S}$. Valores de velocidade positivos para norte. Reproduzida de Schott et al. [2005]. . . . . . . . . . . . . . . . . . . . . 11

1.7 Mapas de topografia dinâmica (relativa a $1.000 \mathrm{~m}$ ) referentes aos dados analisados por Silveira et al.[1994]. A partir dos mapas (a) e (b), níveis 0 e 100 m, respectivamente, pode-se constatar um fluxo para sul, resultante da bifurcação do ramo CSEc, podendo ser observado também o ramo CSEs girando no sentido horário em aproximadamente $9^{\circ} 30^{\prime} \mathrm{S}$, alimentando a SNB. A partir do mapa (c), nível $200 \mathrm{~m}$, pode-se constatar a SSE sendo alimentada pelo ramo CSEc e, provavelmente, pela SNB, em aproximadamente $4^{\circ} \mathrm{S}-5^{\circ} \mathrm{S}$ e $34^{\circ} \mathrm{W} . \quad$. 12 
1.8 Distribuições horizontais de função de corrente apresentados por Goes et al. [2005]. Esses campos foram construídos a partir de dados de LADCP, para as superfícies isopicnais de $24,5 \mathrm{~kg} \mathrm{~m}^{-3}(\backsim 75 \mathrm{~m})$ e $26,8 \mathrm{~kg} \mathrm{~m}^{-3}$ ( $\left.300 \mathrm{~m}\right)$. No campo correspondente à camada $0-24,5 \mathrm{~kg} \mathrm{~m}^{-3}$ (painel superior), a CSE é representada como fluxo largo em direção a oeste, estendendo-se de cerca de $6^{\circ} \mathrm{S}$ ao equador, transformando-se em CNB nas proximidades de $44^{\circ} \mathrm{W}$, ocorrendo retroflexão para originar a CCNE. No campo correspondente à camada $24,5 \mathrm{~kg} \mathrm{~m}^{-3}-26,8 \mathrm{~kg} \mathrm{~m}^{-3}$ (painel inferior), pode-se observar a retroflexão da SNB, para originar a SE/SNE. . . . . . . . . . . . . . . . . . . 14

2.1 Representação esquemática das posições de lançamento de CTD, referentes às comissões hidroceanográficas ONEI (painel superior) e ONEII (painel inferior), realizadas pelo NOc Antares, da MB. . . . . . . . . . . . . . . . . . . 20

2.2 Representação esquemática dos trechos de navegação nos quais foram obtidos perfis de velocidade através de ADCP, referentes à comissão ONEI (painel superior) e à comissão ONEII (painel inferior). . . . . . . . . . . . . . . . . . . . 22

2.3 Representação esquemática da face de emissão do módulo transdutor do ADCP

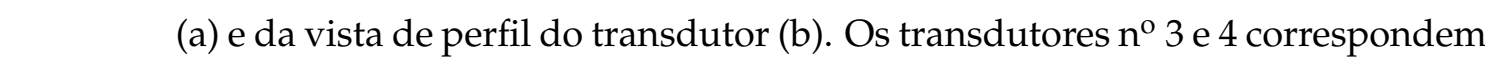
ao eixo longitudinal ( $\mathrm{n}^{\mathrm{o}} 3$ para vante), e os feixes $\mathrm{n}^{\mathrm{o}} 1$ e 2 correspondem ao eixo

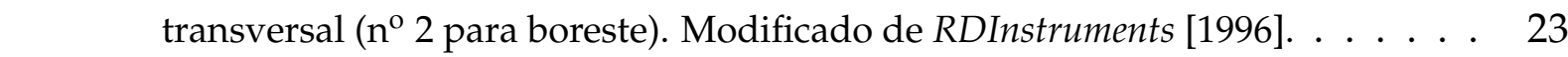

2.4 Representação esquemática dos ângulos de rotação que influenciam os dados de ADCP: balanço (roll), caturro (pitch) e guinada (heading). . . . . . . . . . . . 26

2.5 Representação esquemática das células de profundidade que dividem a perfilagem do ADCP. Modificado de RDInstruments [1996]. . . . . . . . . . . . . . 27

2.6 Representação esquemática da propagação dos feixes acústicos emitidos pelo transdutor do ADCP. Modificado de RDInstruments [1996]. . . . . . . . . . . . 28

4.1 Detalhe dos primeiros $100 \mathrm{~m}$ dos perfis de $T$ (painel esquerdo) e $S$ (painel direito) referentes à estação ${ }^{\circ} 42$ (ONEI), sendo mostrado os dados brutos (linha tracejada azul) e os dados filtrados (linha vermelha contínua), exemplificando os resultados obtidos após o tratamento básico dos dados. A profundidade máxima amostrada na estação foi de $2.337 \mathrm{~m} . \ldots \ldots \ldots \ldots$. . . . . . . . . . . . . . . . . 42 
4.2 Perfil de densidade potencial $\left(\sigma_{\theta}\right)$, parâmetro derivado dos dados de $T$ e $S$ resultantes do processamento, referente à estação hidroceanográfica $\mathrm{n}^{\circ} 42$ da comissão ONEI. . . 42

4.3 Seções verticais de $T, S$ e $\sigma_{\theta}$ até $2.000 \mathrm{~m}$ de profundidade, referentes à radial 1 da comissão ONEI. Os triângulos na parte superior de cada seção indicam as estações hidroceanográficas. . . . . . . . . . . . . . . . . . . . . . . . . . . 43

4.4 Seções verticais de $T, S$ e $\sigma_{\theta}$ até $2.000 \mathrm{~m}$ de profundidade, referentes à radial 5 da comissão ONEI. Os triângulos na parte superior de cada seção indicam as estações hidroceanográficas. . . . . . . . . . . . . . . . . . . . . 44

4.5 Grades curvilineares usadas na interpolação dos dados para elaboração das distribuições horizontais dos dados termohalinos e das funções de corrente, referente às comissões ONEI e ONEII. . . . . . . . . . . . . . . . . . . . . . . 46

4.6 Função de correlação gaussiana isotrópica (linha vermelha), calculada de acordo com a Eq. 4.2 e os valores de variância do erro $\left(\epsilon^{2}\right)$ e comprimento de correlação $\left(l_{c}\right)$, relativos aos dados hidrográficos da comissão ONEI $\left(\epsilon^{2}=0,2678\right.$ e $l_{c} \approx$

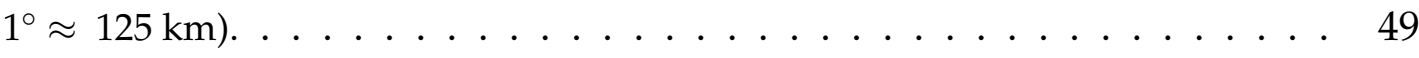

4.7 Seção vertical de velocidade de corrente geostrófica baroclínica $\left(\vec{V}_{g}\right)$, obtida a partir do $\mathrm{MDC}$, com $\mathrm{NR}=1.150 \mathrm{~m}$, referente à radial $1\left(\sim 11^{\circ} \mathrm{S}\right)$ da comissão ONEI. Os triângulos na parte superior da seção indicam as estações oceanográficas e os asteriscos, os pontos médios entre estações, para os quais são calculados as velocidades geostróficas. O intervalo entre as isotacas é de $0,1 \mathrm{~m} \mathrm{~s}^{-1}$. Valores positivos para norte. . . . . . . . . . . . . . 53

4.8 Seção vertical de velocidade de corrente geostrófica baroclínica $\left(\vec{V}_{g}\right)$, obtida a partir do $\mathrm{MDC}, \mathrm{com} \mathrm{NR}=1.150 \mathrm{~m}$, referente à radial $5\left(\sim 5^{\circ} \mathrm{S}\right)$ da comissão ONEI. Os triângulos na parte superior da seção indicam as estações oceanográficas e os asteriscos, os pontos médios entre estações, para os quais são calculados as velocidades geostróficas. O intervalo entre as isotacas é de $0,1 \mathrm{~m} \mathrm{~s}^{-1}$. Valores positivos para norte. . . . . . . . . . . . . . . 54 
4.9 Seção vertical de velocidade de corrente geostrófica baroclínica $\left(\vec{V}_{g}\right)$, obtida a partir do MDC, com NR $=1.150 \mathrm{~m}$, referente à radial $1\left(\sim 11^{\circ} \mathrm{S}\right)$ da comissão ONEII. Os triângulos na parte superior da seção indicam as estações oceanográficas e os asteriscos, os pontos médios entre estações, para os quais são calculados as velocidades geostróficas. O intervalo entre as isotacas é de $0,1 \mathrm{~m}$ $\mathrm{s}^{-1}$. Valores positivos para norte. . . . . . . . . . . . . . . 55

4.10 Seção vertical de velocidade de corrente geostrófica baroclínica $\left(\vec{V}_{g}\right)$, obtida a partir do $\mathrm{MDC}$, com NR $=1.150 \mathrm{~m}$, referente à radial $5\left(\sim 5^{\circ} \mathrm{S}\right)$ da comissão ONEII. Os triângulos na parte superior da seção indicam as estações oceanográficas e os asteriscos, os pontos médios entre estações, para os quais são calculados as velocidades geostróficas. O intervalo entre as isotacas é de $0,1 \mathrm{~m}$ $\mathrm{s}^{-1}$. Valores positivos para norte. . . . . . . . . . . . . . 56

4.11 Mapas de função de corrente geostrófica baroclínica $\left(\psi_{g}\right)$ para os níveis de 32 $\mathrm{m}$ e $100 \mathrm{~m}$, referentes às velocidades calculadas pelo MDC, com NR $=1.150$ $\mathrm{m}$, a partir dos dados da comissão ONEI. Os vetores de velocidade $\left(\mathrm{m} \mathrm{s}^{-1}\right)$ estão sobrepostos aos campos de $\psi_{g}$. A máscara cinza junto à costa representa a região sobre a plataforma continental limitada pela isóbata de $100 \mathrm{~m}$ (contorno dinâmico). Linha vermelha: isóbata de $1000 \mathrm{~m}$. . . . . . . . . . . . . . . . 60

4.12 Mapas de função de corrente geostrófica baroclínica $\left(\psi_{g}\right)$ para os níveis de 160 $\mathrm{m}$ e $200 \mathrm{~m}$, referentes às velocidades calculadas pelo MDC, com NR = 1.150 m, a partir dos dados da comissão ONEI. Os vetores de velocidade $\left(\mathrm{m} \mathrm{s}^{-1}\right)$ estão sobrepostos aos campos de $\psi_{g}$. A máscara cinza junto à costa representa a região sobre a plataforma continental limitada pela isóbata de $100 \mathrm{~m}$ (contorno dinâmico). Linha vermelha: isóbata de $1.000 \mathrm{~m}$. . . . . . . . . . . . . . . 61

4.13 Mapas de função de corrente geostrófica baroclínica $\left(\psi_{g}\right)$ para os níveis de 32 m e $100 \mathrm{~m}$, referentes às velocidades calculadas pelo MDC, com NR = 1.150 $\mathrm{m}$, a partir dos dados da comissão ONEII. Os vetores de velocidade $\left(\mathrm{m} \mathrm{s}^{-1}\right)$ estão sobrepostos aos campos de $\psi_{g}$. A máscara cinza junto à costa representa a região sobre a plataforma continental limitada pela isóbata de $100 \mathrm{~m}$ (contorno dinâmico). Linha vermelha: isóbata de $1.000 \mathrm{~m}$. . . . . . . . . . . . . . . 62 
4.14 Mapas de função de corrente geostrófica baroclínica $\left(\psi_{g}\right)$ para os níveis de 160 $\mathrm{m}$ e $200 \mathrm{~m}$, referentes às velocidades calculadas pelo MDC, com NR $=1.150$ m, a partir dos dados da comissão ONEII. Os vetores de velocidade $\left(\mathrm{m} \mathrm{s}^{-1}\right)$ estão sobrepostos aos campos de $\psi_{g}$. A máscara cinza junto à costa representa a região sobre a plataforma continental limitada pela isóbata de $100 \mathrm{~m}$ (contorno dinâmico). Linha vermelha: isóbata de $1.000 \mathrm{~m}$. . . . . . . . . . . . . . . . . . 63

5.1 Representação esquemática dos ângulos do módulo transdutor em relação ao navio, no plano horizontal (a) e no plano vertical (b), aos quais estão relacionados os parâmetros $\alpha$ e $1+\beta$, respectivamente, de acordo com Joyce[1989]. . . . . 67

5.2 Representação esquemática dos três sistemas com origem O no centro do módulo \begin{tabular}{|c|c|}
\hline transdutor do ADCP: OX'Y' (coordenadas ADCP), OXY (coordenadas do na- \\
\hline
\end{tabular} vio) e OEN (coordenadas terrestres). $\gamma$ representa a defasagem entre os sistemas OXY e OEN, $\lambda$ representa a defasagem entre OXY e OX'Y' e $\phi$ entre OX'Y' e OEN. Obtido de Osiński[[2000]. . . . . . . . . . . . . . . . . . . . . . . . . 70

5.3 Posições dos pontos de calibração water-track, do processamento dos dados de ADCP pelo sistema CODAS, e os valores ângulo de fase médio obtidos na calibração: $\alpha$ médio $=0,98^{\circ}$, para a comissão ONEI, e $\alpha$ médio $=1,95^{\circ}$, para a comissão ONEII . . . . . . . . . . . . . . . . . . . . . 72

5.4 Seções verticais de velocidade observada $\left(\mathrm{m} \mathrm{s}^{-1}\right)$ obtidas a partir dos dados brutos de ADCP (painel superior) e a partir dos dados processados pelo sistema CODAS (painel inferior), exemplificando a diferença significativa entre dados brutos e processados e ressaltando a importância do processamento. Os dados processados (painel inferior) foram interpolados por $\mathrm{AO}$, e os valores com erro de interpolação superior a 30\% foram desconsiderados. O intervalo entre isotacas é de $0,1 \mathrm{~m} \mathrm{~s}^{-1}$. Valores positivos para norte. Dados referentes à radial 5 da comissão ONEI. . . . . . . . . . . . . . . . . . . . . . . . . . . . 77 
5.5 Distribuições horizontais dos vetores de velocidade observada da comissão ONEI, resultantes do processamento pelo CODAS, sem a utilização da interpolação por AOV. Esses vetores correspondem aos dados de velocidade que apresentaram percent good superiores a 50\% nas profundidades de $32 \mathrm{~m}, 96 \mathrm{~m}$, 144 m e 192 m. Esses níveis correspondem aos níveis amostrados pelo ADCP de acordo com a "célula de profundidade" de $8 \mathrm{~m}$, utilizada em ambas as comissões. Não há interpolação vertical. . . . . . . . . . . . . . . . . . . . . . 79

5.6 Distribuições horizontais dos vetores de velocidade observada da comissão ONEII, resultantes do processamento pelo CODAS, sem a utilização da interpolação por AOV. Esses vetores correspondem aos dados de velocidade que apresentaram percent good superiores a 50\% nas profundidades de $32 \mathrm{~m}, 96 \mathrm{~m}$, $144 \mathrm{~m}$ e $192 \mathrm{~m}$. Esses níveis correspondem aos níveis amostrados pelo ADCP de acordo com a "célula de profundidade" de $8 \mathrm{~m}$, utilizada em ambas as comissões. Não há interpolação vertical. . . . . . . . . . . . . . . . . . . . . . 80

5.7 Mapas de erro de interpolação (\%) associados às seções verticais de velocidade observada referentes às radiais 1, 5, 6 e 8 da comissão ONEI. As seções verticais foram obtidas a partir da interpolação por AO dos dados de ADCP processados pelo CODAS. . . . . . . . . . . . . . . . . . 82

5.8 Seções verticais de velocidade observada $\left(\mathrm{m} \mathrm{s}^{-1}\right)$ obtidas a partir dos dados processados pelo sistema CODAS, referentes às radiais 1 (painel superior) e 5 (painel inferior) da comissão ONEI. As seções foram obtidas a partir de AO dos dados de ADCP processados pelo CODAS, e os valores com erro de interpolação superior a $30 \%$ foram retirados. O intervalo entre isotacas é de $0,1 \mathrm{~m} \mathrm{~s}^{-1}$. Valores positivos para norte. . . . . . . . . . . . . . . . . . 84

5.9 Seções verticais de velocidade observada $\left(\mathrm{m} \mathrm{s}^{-1}\right)$ obtidas a partir dos dados processados pelo sistema CODAS, referentes às radiais 6 (painel superior) e 8 (painel inferior) da comissão ONEI. As seções foram obtidas a partir de AO dos dados de ADCP processados pelo CODAS, e os valores com erro de interpolação superior a $30 \%$ foram retirados. O intervalo entre isotacas é de $0,1 \mathrm{~m} \mathrm{~s}^{-1}$. Valores positivos para norte. . . . . . . . . . . . . . . . . 85 
5.10 Mapas de erro de interpolação (\%) associados às seções de velocidade observada das radiais 1, 5, 6, 9 e 12 da comissão ONEII. As seções foram obtidas a partir da interpolação por AO dos dados de ADCP processados pelo CODAS. . 89

5.11 Seções verticais de velocidade observada $\left(\mathrm{m} \mathrm{s}^{-1}\right)$ obtidas a partir dos dados processados pelo sistema CODAS, referentes às radiais 1 (painel superior) e 5 (painel inferior) da comissão ONEII. As seções foram obtidas a partir de $\mathrm{AO}$ dos dados de ADCP processados pelo CODAS, e os valores com erro de interpolação superior a 30\% foram retirados (áreas na cor branca). O intervalo entre isotacas é de $0,1 \mathrm{~m} \mathrm{~s}^{-1}$. Valores positivos para norte. . . . . . . . . . . . 90

5.12 Seções verticais de velocidade observada $\left(\mathrm{m} \mathrm{s}^{-1}\right)$ obtidas a partir dos dados processados pelo sistema CODAS, referentes às radiais 6 (painel superior) e 9 (painel inferior) da comissão ONEII. As seções foram obtidas a partir de $\mathrm{AO}$ dos dados de ADCP processados pelo CODAS, e os valores com erro de interpolação superior a 30\% foram retirados (áreas na cor branca). O intervalo entre isotacas é de $0,1 \mathrm{~m} \mathrm{~s}^{-1}$. Valores positivos para norte. . . . . . . . . . . . 91

5.13 Seção vertical de velocidade observada $\left(\mathrm{m} \mathrm{s}^{-1}\right)$ obtida a partir dos dados pro-

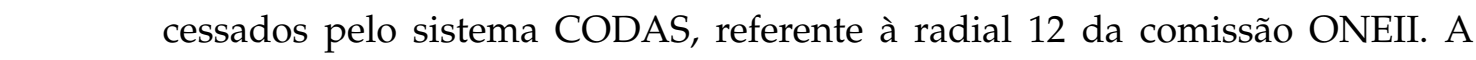
seção foi obtida a partir de AO dos dados de ADCP processados pelo CODAS, e os valores com erro de interpolação superior a 30\% foram retirados (áreas na cor branca). O intervalo entre isotacas é de $0,1 \mathrm{~m} \mathrm{~s}^{-1}$. Valores positivos para norte . . . . . . . . . . . . . . . . . . . 92

5.14 Mapas de $\psi_{\text {obs }}$, para $32 \mathrm{~m}$ e $96 \mathrm{~m}(\mathrm{ONEI})$. Vetores de $\vec{V}_{o b s}\left(\mathrm{~m} \mathrm{~s}^{-1}\right)$ sobrepostos aos campos de $\psi_{\text {obs }}\left(\mathrm{m}^{2} \mathrm{~s}^{-1}\right)$. Máscara cinza junto à costa: região sobre a plataforma continental limitada pela isóbata de $100 \mathrm{~m}$ (contorno dinâmico). Linha vermelha: isóbata de $1.000 \mathrm{~m}$. . . . . . . . . . . . . . . . . . . . 95

5.15 Mapa de $\psi_{\text {obs }}$ para $160 \mathrm{~m}(\mathrm{ONEI})$. Vetores de $\vec{V}_{\text {obs }}\left(\mathrm{m} \mathrm{s}^{-1}\right)$ sobrepostos aos campos de $\psi_{o b s}\left(\mathrm{~m}^{2} \mathrm{~s}^{-1}\right)$. Máscara cinza junto à costa: região sobre a plataforma continental limitada pela isóbata de 100 m (contorno dinâmico). Linha vermelha: isóbata de $1.000 \mathrm{~m}$. . . . . . . . . . . . . . . . . . . . 96 
5.16 Mapas de $\psi_{o b s}$, para $32 \mathrm{~m}$ e $96 \mathrm{~m}$ (ONEII). Vetores de $\vec{V}_{o b s}\left(\mathrm{~m} \mathrm{~s}^{-1}\right)$ sobrepostos aos campos de $\psi_{o b s}\left(\mathrm{~m}^{2} \mathrm{~s}^{-1}\right)$. Máscara cinza junto à costa: região sobre a plataforma continental limitada pela isóbata de $100 \mathrm{~m}$ (contorno dinâmico). Linha vermelha: isóbata de $1.000 \mathrm{~m}$. . . . . . . . . . . . . . . . . . . . . . 97

5.17 Mapa de $\psi_{\text {obs }}$, para $160 \mathrm{~m}$ (ONEII). Vetores de $\vec{V}_{\text {obs }}\left(\mathrm{m} \mathrm{s}^{-1}\right)$ sobrepostos aos campos de $\psi_{\text {obs }}\left(\mathrm{m}^{2} \mathrm{~s}^{-1}\right)$. Máscara cinza junto à costa: região sobre a plataforma continental limitada pela isóbata de $100 \mathrm{~m}$ (contorno dinâmico). Linha vermelha: isóbata de $1.000 \mathrm{~m}$. . . . . . . . . . . . . . . . . . . . 98

6.1 Mapas de $\psi_{g_{a b s}}$ calculados a partir do MDR com NR = $160 \mathrm{~m}$, para os níveis de $32 \mathrm{~m}$ (painel superior) e $100 \mathrm{~m}$ (painel inferior). Vetores de $\vec{V}_{g_{a b s}}\left(\mathrm{~m} \mathrm{~s}^{-1}\right)$ sobrepostos aos campos de $\psi_{g_{a b s}}\left(\mathrm{~m}^{2} \mathrm{~s}^{-1}\right)$. Dados da comissão ONEI. . . . . . . 101

6.2 Mapas de $\psi_{g_{a b s}}$ calculados a partir do MDR com NR = $160 \mathrm{~m}$, para os níveis de $200 \mathrm{~m}$ (painel superior) e $500 \mathrm{~m}$ (painel inferior). Vetores de $\vec{V}_{g_{a b s}}\left(\mathrm{~m} \mathrm{~s}^{-1}\right)$ sobrepostos aos campos de $\psi_{g_{a b s}}\left(\mathrm{~m}^{2} \mathrm{~s}^{-1}\right)$. Dados da comissão ONEI. ... 102

6.3 Mapas de $\psi_{g_{a b s}}$ calculados a partir do MDR com NR $=160 \mathrm{~m}$, para os níveis de $32 \mathrm{~m}$ (painel superior) e $100 \mathrm{~m}$ (painel inferior). Vetores de $\vec{V}_{g_{a b s}}\left(\mathrm{~m} \mathrm{~s}^{-1}\right)$ sobrepostos aos campos de $\psi_{g_{a b s}}\left(\mathrm{~m}^{2} \mathrm{~s}^{-1}\right)$. Dados da comissão ONEII. . . . . . . 104

6.4 Mapas de $\psi_{g_{a b s}}$ calculados a partir do MDR com NR $=160 \mathrm{~m}$, para os níveis de $200 \mathrm{~m}$ (painel superior) e $500 \mathrm{~m}$ (painel inferior). Vetores de $\vec{V}_{g_{a b s}}\left(\mathrm{~m} \mathrm{~s}^{-1}\right.$ ) sobrepostos aos campos de $\psi_{g_{a b s}}\left(\mathrm{~m}^{2} \mathrm{~s}^{-1}\right)$. Dados da comissão ONEII. . . . . . 105 


\section{Lista de Tabelas}

4.1 Valores de transporte de volume (Sv) e de velocidade máxima $\left(\mathrm{m} \mathrm{s}^{-1}\right)$ das seções de velocidade geostrófica baroclínica relativa (MDC com NR = 1.150 m), referentes às radiais 1 e 5 das comissões ONEI e ONEII. . . . . . . . . . . . 51

4.2 Valores de transporte de volume $(\mathrm{Sv})$ e de velocidade máxima $\left(\mathrm{m} \mathrm{s}^{-1}\right)$ das seções de velocidade geostrófica baroclínica relativa (MDC com NR =1.000 m),

5.1 Valores de transporte de volume (Sv) e de velocidade máxima $\left(\mathrm{m} \mathrm{s}^{-1}\right)$ referentes à assinatura da SNB observada nas 8 seções das radiais da comissão ONEI. $\quad 81$

5.2 Valores de transporte de volume (Sv) e de velocidade máxima $\left(\mathrm{m} \mathrm{s}^{-1}\right)$ referentes à assinatura da SNB observada nas 9 seções das radiais da comissão ONEII. Os dados relativos às radiais 2, 3, 4 e 8, foram insuficientes para elaboração das respectivas seções. . . . . . . . . . . . . . . . . . . 87

5.3 Valores de transporte de volume (Sv) calculados por Schott et al. [2005] a partir de dados de LADCP. . . . . . . . . . . . . . . . . . 87

6.1 Valores máximos de magnitude de velocidade não-divergente $\left(\mathrm{m} \mathrm{s}^{-1}\right)$ referentes ao núcleo da SNB nos campos de $\psi_{g}, \psi_{o b s}$ e $\psi_{g_{a b s}}$, para os níveis de 32m, 96 m e 200 m. Dados da comissão ONEI. . . . . . . . . . . . . . . . . . 106 


\section{Capítulo 1}

\section{Introdução}

\subsection{Preâmbulo}

O Brasil possui um litoral consideravelmente extenso (aproximadamente 8.000 $\mathrm{km}$ ). Entretanto, ainda é escasso o conhecimento acerca dos processos dinâmicos que ocorrem nas águas oceânicas adjacentes à costa brasileira. Diversos fenômenos de mesoescala e larga escala carecem de investigação. De acordo com Munk [2000], mais de 99\% da energia cinética das correntes oceânicas está associada a processos de mesoescala (escala espacial em torno de $100 \mathrm{~km}$ e escala temporal de até 100 dias).

Dentre os fenômenos de mesoescala que carecem de investigação podemos citar, por exemplo, os processos de formação e a origem da Subcorrente Norte do Brasil (SNB). Sabe-se que a SNB se origina em nível picnoclínico, a partir da bifurcação do ramo sul da Corrente Sul Equatorial (CSEs), que encontra o continente brasileiro próximo à $20^{\circ} \mathrm{S}$, dividindo-se em uma parte mais fraca, que alimenta a $\mathrm{CB}$, e uma parte mais forte, que flui em direção ao norte como núcleo de subsuperfície da SNB. Contudo, a origem da SNB não é bem definida em escala sinótica.

No presente capítulo, será apresentada uma síntese da literatura acerca dos escoamentos associados à SNB, bem como os objetivos que nortearam os procedimentos e resultados relatados na presente dissertação. 


\subsection{Síntese da Literatura}

\subsubsection{O Giro Equatorial}

A circulação forçada pelo vento forma células de circulação praticamente fechadas, de distribuição meridional, as quais denominamos giros oceânicos [Sverdrup. 1947]. A Figura 1.1 modificada de Bub E Brown [1996], representa esquematicamente, em superfície, os giros oceânicos do Atlântico Sul, entre $40^{\circ} \mathrm{S}$ e $40^{\circ} \mathrm{N}$, de acordo com os padrões de circulação forçada pelo vento presentes em Mayer E Weisberg [1993].

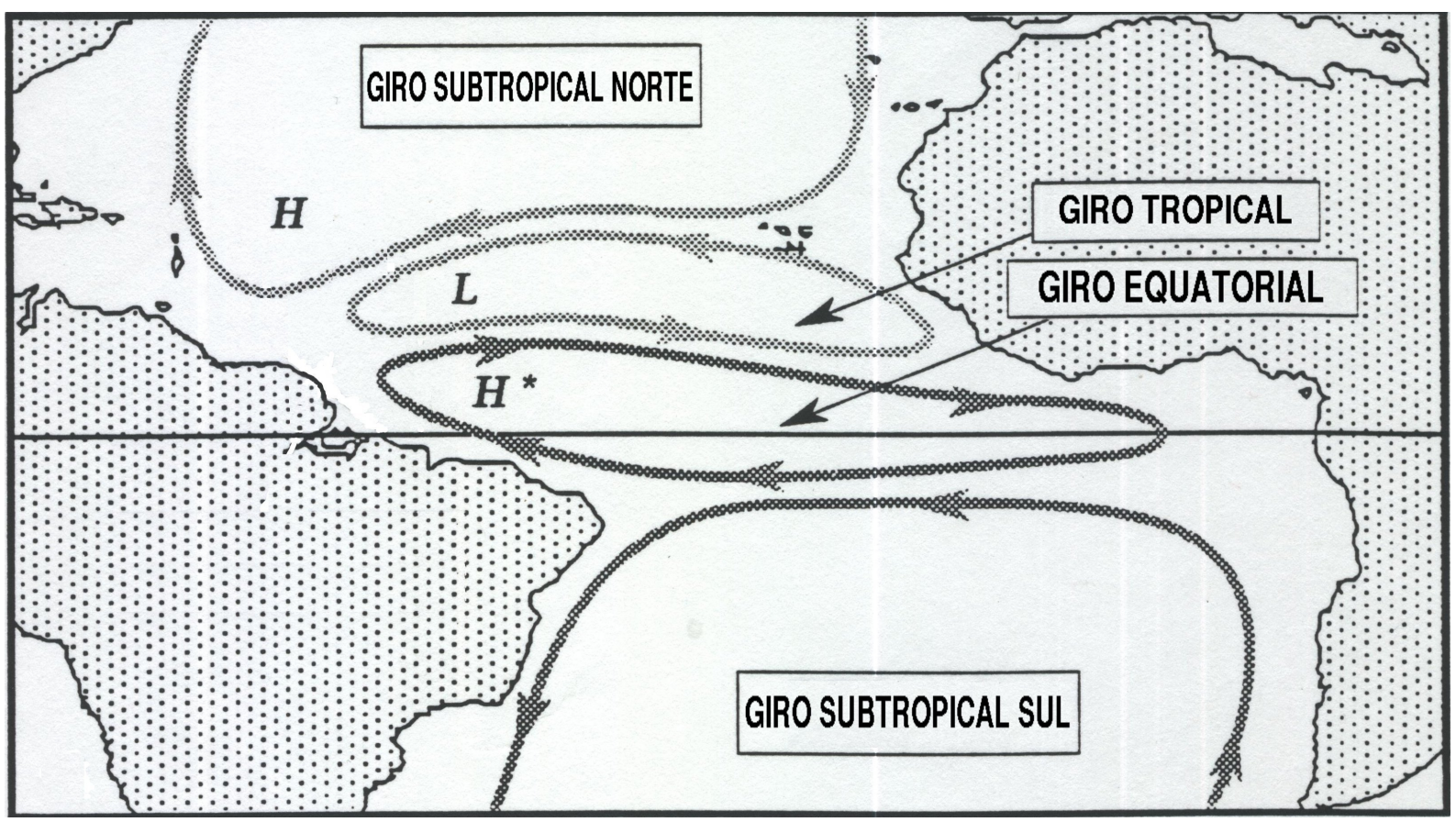

Figura 1.1: Representação esquemática, em superfície, dos giros oceânicos do Atlântico Sul, entre $40^{\circ} \mathrm{S}$ e $40^{\circ} \mathrm{N}$, de acordo com os padrões de circulação forçada pelo vento presentes em Mayer \& Weisberg [1993]. Modificado de Bub \& Brown [1996].

Observacionalmente é comprovado que as correntes no lado oeste dos giros oceânicos são bem mais intensas que suas correspondentes do lado leste. Através de um estudo sobre a circulação dirigida pelo vento, considerando um oceano retangular e homogêneo, Stommel [1948] explicou o fato das correntes oceânicas serem mais intensas no lado oeste, demonstrando que a assimetria dos giros oceânicos é devida à variação do parâmetro de Coriolis com a latitude. Essas correntes mais intensas no lado oeste dos giros oceânicos são denominadas de Correntes de Contorno Oeste (CCOs). 
De acordo com Silveira et al. [2003], as CCOs são jatos geofísicos caracterizados como fluxos intensos, estreitos e bem definidos, fluindo ao largo das margens continentais oeste das bacias oceânicas. Segundo Silveira et al. [2000b], as CCOs podem ser pensadas como fluxo de retorno do transporte de Sverdrup. Este último pode ser estimado pelos campos de tensão de cisalhamento do vento em larga escala.

O sistema de CCOs do giro equatorial é composto pela SNB, que tem núcleo em cerca de $150-200 \mathrm{~m}$ e se estende da latitude de $20^{\circ} \mathrm{S}$ a latitudes inferiores a $5^{\circ} \mathrm{S}$, e pela Corrente Norte do Brasil (CNB), ao norte da latitude de $5^{\circ} \mathrm{S}$. A CNB apresenta núcleo em superfície devido ao aporte adicional de água pela Corrente Sul Equatorial (CSE) em seus ramos central (CSEc) e equatorial (CSEe) [Silveira et al., 1994; Stramma $\mathcal{E}$ England, 1999]. Ao sul, o ramo sul da CSE (CSEs) delimita os giros equatorial e subtropical do Atlântico Sul. Ao norte, a Contracorrente Norte Equatorial (CCNE) separa os giros equatorial e tropical [Peterson $\mathcal{E}$ Stramma, 1991; Stramma E England, 1999]. Ao leste, a Corrente de Angola fecha o giro equatorial [Stramma E England, 1999].

Os detalhes descritos no parágrafo anterior se referem a uma visão integrada e sverdrupiana dos giros oceânicos. Na realidade, os padrões de escoamento são resultantes da combinação entre a circulação forçada pelo vento e a circulação termohalina. De acordo com Urbano $\mathcal{E}$ Silveira [2003], as CCOs desempenham um importante papel como elo de ligação na circulação termohalina global, e isto é extremamente relevante no caso do giro equatorial. Stramma E England [1999], através de estimativas de fluxo geostrófico, no oceano superior, apresentam um padrão mais realístico para a circulação no Oceano Atlântico Sul. As Figuras 1.2 e 1.3, modificadas de Stramma E England [1999], representam os padrões de circulação de larga escala para as correntes geostróficas no Atlântico Sul, nos níveis de 0 - 100 m e 100 - 500 m, respectivamente. Em face desse padrão mais complexo, cumpre discutir em maior detalhe as correntes componentes do giro equatorial, em particular a CSE, a SNB e a CNB. 


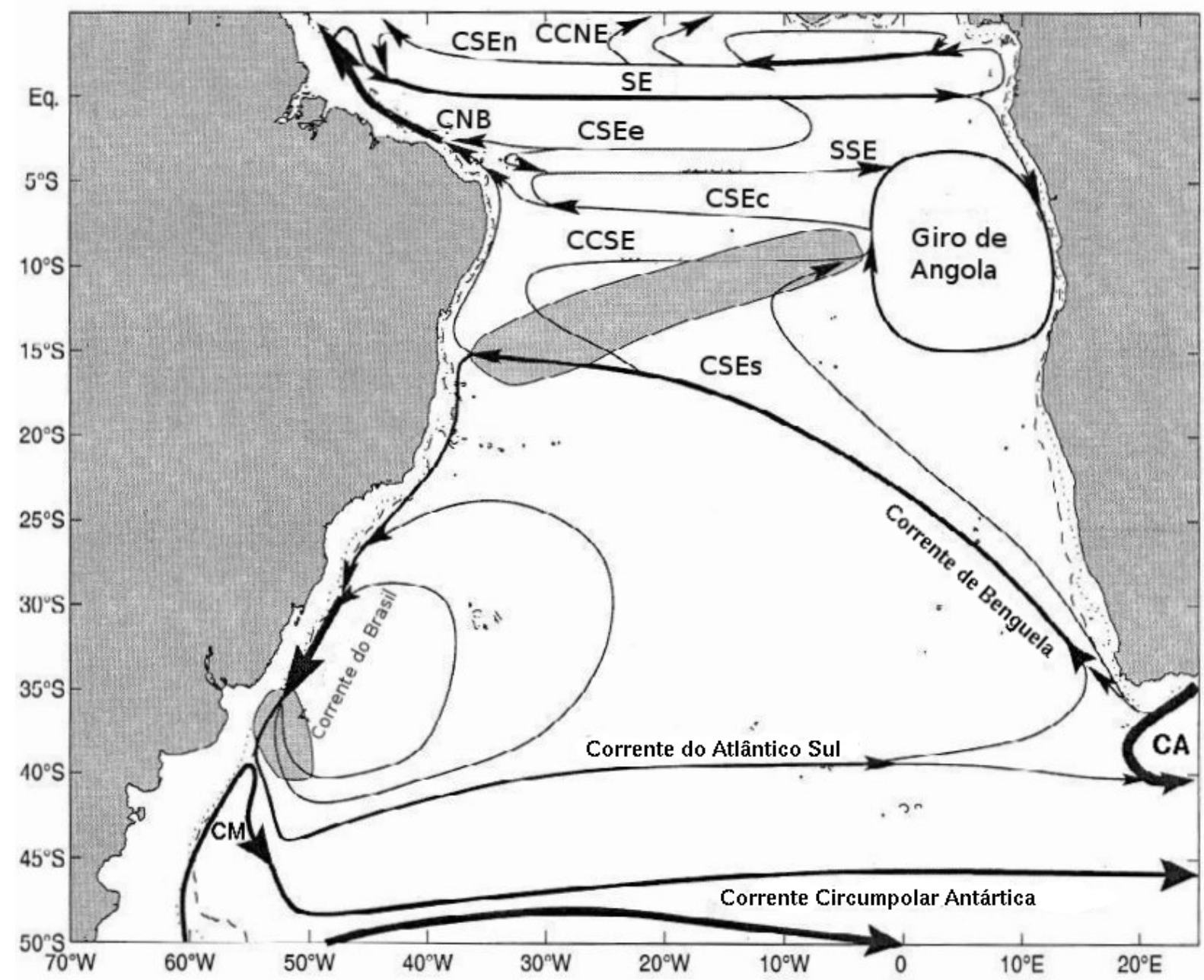

Figura 1.2: Representação esquemática do padrão de circulação de larga escala para as correntes geostróficas no Atlântico Sul, entre 0 e 100 m. São mostradas: Contracorrente Norte Equatorial (CCNE); Subcorrente Equatorial (SE); Corrente Norte do Brasil (CNB); Subcorrente Sul Equatorial (SSE), Contracorrente Sul Equatorial (CCSE); Ramos norte (CSEn), central (CSEc), sul (CSEs) e equatorial (CSEe) da Corrente Sul Equatorial (CSE); Corrente do Brasil; Corrente do Atlântico Sul; Corrente Circumpolar Antártica; Corrente das Malvinas (CM); Corrente das Agulhas (CA). Modificado de Stramma E England [1999]

\subsubsection{Corrente Sul Equatorial (CSE)}

A CSE é uma corrente que flui de leste para oeste e se bifurca ao se aproximar da costa brasileira. Os estudos de Molinari [1982] e Stramma [1991] descreveram a CSE como um fluxo para oeste com três ramos distintos: sul (CSEs), central (CSEc) e norte (CSEn), onde os ramos CSEn e CSEc estariam separados pela Subcorrente Sul Equatorial (SSE), e os ramos CSEc e CSEs pela Contracorrente Sul Equatorial (CCSE). Sendo o ramo CSEn adicionalmente separado pela Subcorrente Equatorial (SE), a descrição 


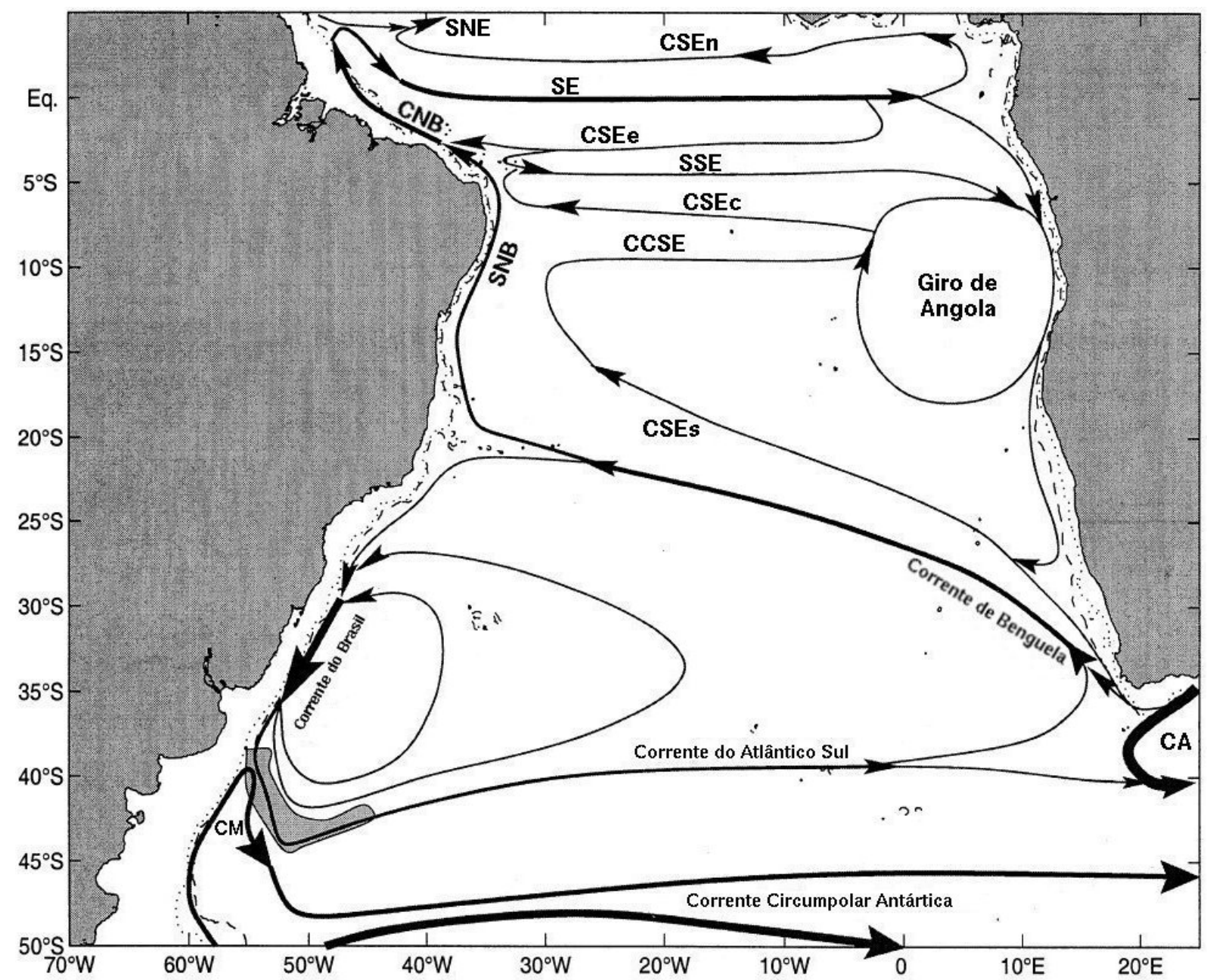

Figura 1.3: Representação esquemática do padrão de circulação de larga escala para as correntes geostróficas no domínio da Água Central do Atlântico Sul (ACAS), de 100 a 500 m. Além das correntes apresentadas na Figura 1.2, são mostradas: Subcorrente norte do Brasil (SNB); Subcorrente Norte Equatorial (SNE). Modificado de Stramma \& England [1999].

apresentada por Stramma E Schott [1999] considera o fluxo entre a SE e a SSE como mais um ramo, o ramo equatorial (CSEe), e somente a parte ao norte do equador como o ramo CSEn. As Figuras 1.2 e 1.3, modificadas de Stramma E England [1999], ilustram os ramos da CSE.

A bifurcação da CSE foi descrita por Stramma E England [1999] como um fenômeno complexo e estratificado, ocorrendo em diferentes profundidades, para diferentes latitudes. Segundo os estudos de Stramma E England [1999], a bifurcação da CSE, em nível de superfície, ocorre em torno de $15^{\circ} \mathrm{S}$, resultando nas duas CCOs que fluem junto à costa brasileira: a porção superficial da SNB e a Corrente do Brasil (CB). Em níveis picnoclínicos, no domínio vertical da Água Central do Atlântico Sul (ACAS), a 
bifurcação ocorre em torno de $20^{\circ} \mathrm{S}$, onde parte flui para norte, acompanhando a Corrente de Contorno Intermediária (CCI) e contribuindo com a região do núcleo da SNB, e parte flui para sul, espessando verticalmente o fluxo da CB.

De acordo com Rodrigues et al. [2007], a CSE forma a parte norte do giro subtropical do Oceano Atlântico Sul, carregando água subtropical da região da Corrente de Benguela em direção à margem continental brasileira. Segundo esses autores, a bifurcação da CSE pode ter implicações na variabilidade climática, porque o sistema CSE/SNB é o principal condutor tanto para o fluxo de retorno, no oceano superior, da Célula de Revolvimento Meridional (CRM) [Talley, 2003; Ganachaud, 2003; Lumpkin E Speer, 2003], quanto para a troca de massa subtropical-tropical.

Rodrigues et al. [2007] mencionam que a latitude de bifurcação pode ser indicativa da quantidade de água subtropical conduzida para os trópicos e para o Atlântico Norte, através do sistema SNB/CNB, e da quantidade que recircula no giro subtropical. Para esses autores, a variabilidade na latitude de bifurcação e no transporte de correntes pode impactar regiões remotas como, por exemplo, a região dos anéis da CNB $\left(6^{\circ}-9^{\circ} \mathrm{N}\right)$ e a região da confluência Brasil-Malvinas $\left(38^{\circ}-40^{\circ} \mathrm{S}\right)$. O conhecimento da variabilidade e estrutura vertical da assinatura de bifurcação da CSE, em mesoescala, ainda permanece obscura e é objeto de investigação pela comunidade científica.

\subsubsection{Subcorrente Norte do Brasil (SNB)}

A primeira descrição da estrutura vertical e dos padrões horizontais da SNB foi realizada por Silveira et al. [1994]. Esses autores analisaram dados de hidrografia obtidos por garrafa de Nansen, coletados ao largo da costa nordeste brasileira pelo NOc Almirante Saldanha, da Marinha do Brasil, durante a comissão oceanográfica NORDESTE III (NEIII), no período de 4 de maio a 12 de julho de 1986. Através desses dados, os referidos autores descreveram a presença da SNB em termos de cálculo dinâmico relativo a $1.000 \mathrm{~m}$.

Historicamente, estimativas de direção de correntes por deriva do navio e por derivadores lagrangeanos sugeriam que a porção superficial da SNB e a CB eram formadas a partir da bifurcação do ramo CSEc. Segundo Rennell [1832], a bifurcação da CSE ocorreria próximo ao Cabo de São Roque, nas proximidades da latitude $5^{\circ} 30^{\prime}$ S. 
Stramma et al. [1990] e Stramma [1991] descobriram que a CB e a porção superficial da SNB eram resultantes da bifurcação do ramo CSEs. Os resultados de Silveira et al. [1994] indicaram a presença do núcleo da SNB entre 100 e 200 m, revelando também que a SNB é formada ao sul de $10^{\circ} 30^{\prime} \mathrm{S}$, corroborando os resultados de Stramma et al. [1990] e Stramma [1991]. Contudo, a exata localização da origem da SNB não é bem definida porque a CSE tem uma complexa estrutura nessa região. Silveira et al. [1994] também constataram a presença da SSE em aproximadamente $4^{\circ} \mathrm{S}-5^{\circ} \mathrm{S}$, verificando que a bifurcação do ramo CSEc resulta em um ramo norte que segue superficialmente para oeste, juntando-se ao escoamento de subsuperfície da SNB para formar a CNB, efetuando, posteriormente, uma curva ciclônica para reforçar a SSE.

A Figura 1.4 representa as seções verticais de velocidade geostrófica (relativa a $1.000 \mathrm{~m}$ ) referentes às radiais 1 e 12 da comissão NEIII analisada por Silveira et al. [1994]. Na seção correspondente à radial 1 ( $\sim 10^{\circ} 30^{\prime}$ S), pode-se observar a SNB como uma corrente com núcleo de subsuperfície de aproximadamente $50 \mathrm{~cm} \mathrm{~s}^{-1}$ em $150 \mathrm{~m}$, cujo transporte de volume foi de $23,7 \mathrm{~Sv}\left(1 \mathrm{~Sv} \equiv 10^{6} \mathrm{~m}^{3} \mathrm{~s}^{-1}\right)$. Na seção correspondente à radial $12\left(\backsim 4^{\circ} \mathrm{S}\right)$, pode-se observar a SNB com núcleo de subsuperfície de aproximadamente $100 \mathrm{~cm} \mathrm{~s}^{-1}$ entre 100 e $150 \mathrm{~m}$, com transporte de 24,9 Sv. Nessa seção pode-se verificar a presença da SSE, com velocidade máxima para sul da ordem de $30-40$ $\mathrm{cm} \mathrm{s}^{-1}$ entre $200-300 \mathrm{~m}$, verificando-se também a estrutura vertical da porção norte resultante da bifurcação do ramo CSEc, com transporte médio calculado de 15,7 Sv.

As observações por LADCP (Lowered Acoustic Doppler Current Profiler) conduzidas por Stramma et al. [1995], confirmaram a presença da SNB, que foi observada com um núcleo em subsuperfície em torno de $200 \mathrm{~m}$, com velocidades de até $90 \mathrm{~cm}$ $\mathrm{s}^{-1}$, resultando em intensos transportes para norte (superiores a $22 \mathrm{~Sv}$ ) acima de 1.000 m. Esses autores investigaram a região de origem da SNB ao largo da costa nordeste do Brasil, entre as latitudes de $5^{\circ} 30^{\prime} \mathrm{S}$ e $10^{\circ} \mathrm{S}$, durante a primavera austral (novembro/1992), e compararam com observações realizadas em outubro/1990. Em ambas as latitudes o núcleo de subsuperfície foi observado em cerca de $200 \mathrm{~m}$, com velocidade máxima de $90 \mathrm{~cm} \mathrm{~s}^{-1}$ para a latitude de $5^{\circ} 30^{\prime} \mathrm{S}$, e de $80 \mathrm{~cm} \mathrm{~s}^{-1}$ para a latitude de $10^{\circ}$ S. A Figura 1.5, reproduzida de Stramma et al. [1995], representa as seções verticais de velocidades correspondentes à SNB, nas latitudes de $5^{\circ} 30^{\prime} \mathrm{S}$ e $10^{\circ} \mathrm{S}$. 

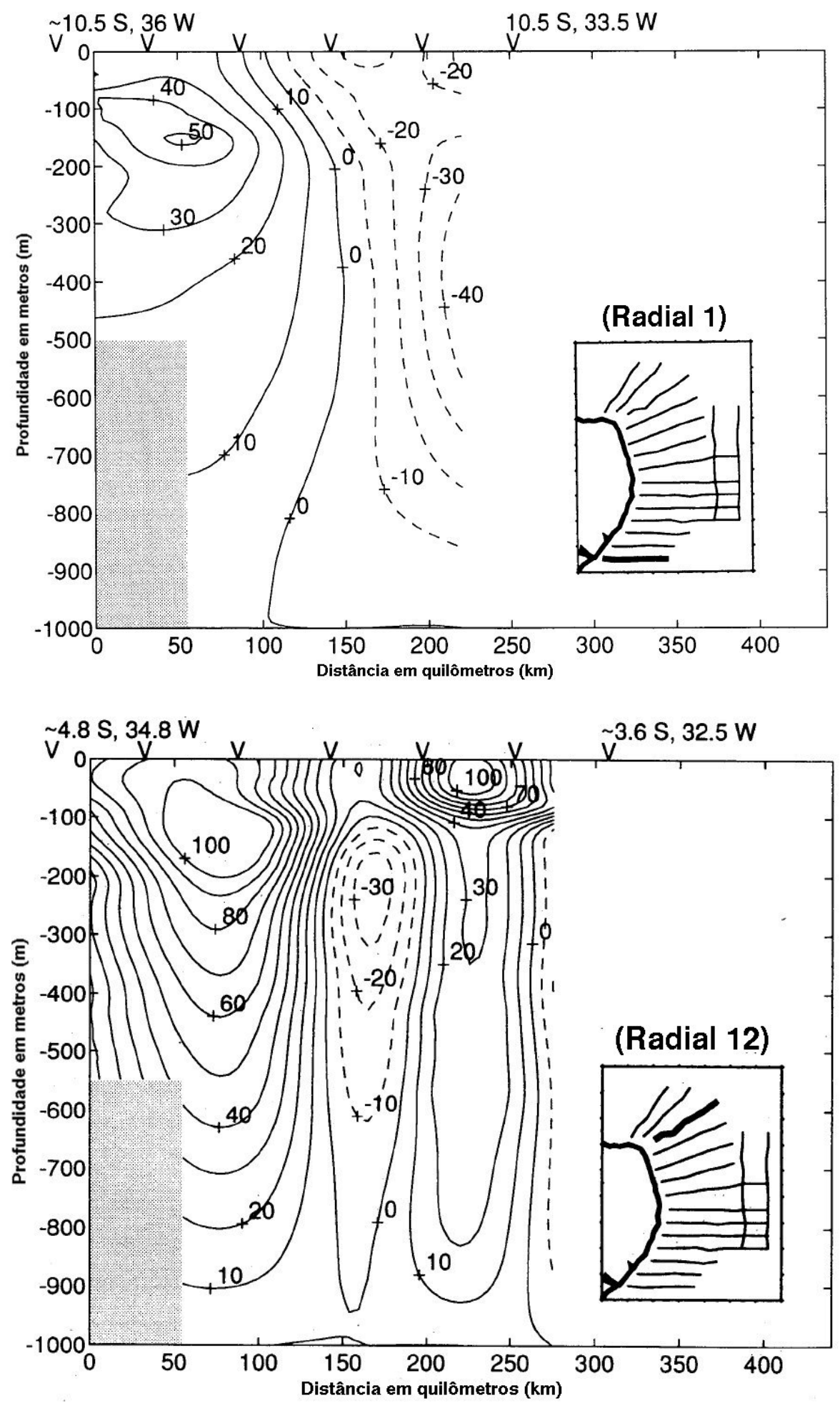

Figura 1.4: Distribuições verticais de velocidade geostrófica referentes às radiais 1 e 12 da comissão analisada por Silveira et al. [1994]. Na radial 1 ( $\sim 10^{\circ} 30^{\prime}$ S) pode-se observar a SNB com núcleo de subsuperfície de $\backsim 50 \mathrm{~cm} \mathrm{~s}^{-1} \mathrm{em} 150 \mathrm{~m}$. Na radial $12\left(\backsim 4^{\circ} \mathrm{S}\right)$ pode-se observar a SNB com núcleo de subsuperfície de $\sim 100 \mathrm{~cm} \mathrm{~s}^{-1}$ entre 100 e $150 \mathrm{~m}$, verificando-se também a presença da SSE, com velocidade máxima para sul da ordem de $30-40 \mathrm{~cm} \mathrm{~s}^{-1}$ entre $200-300 \mathrm{~m}$, bem como a estrutura vertical da bifurcação do ramo CSEc para norte. O retângulo sombreado indica região sem estimativas de velocidade devido às rasas perfilagens hidrográficas. Valores de velocidade positivos para norte. Modificado de Silveira et al. [1994]. 

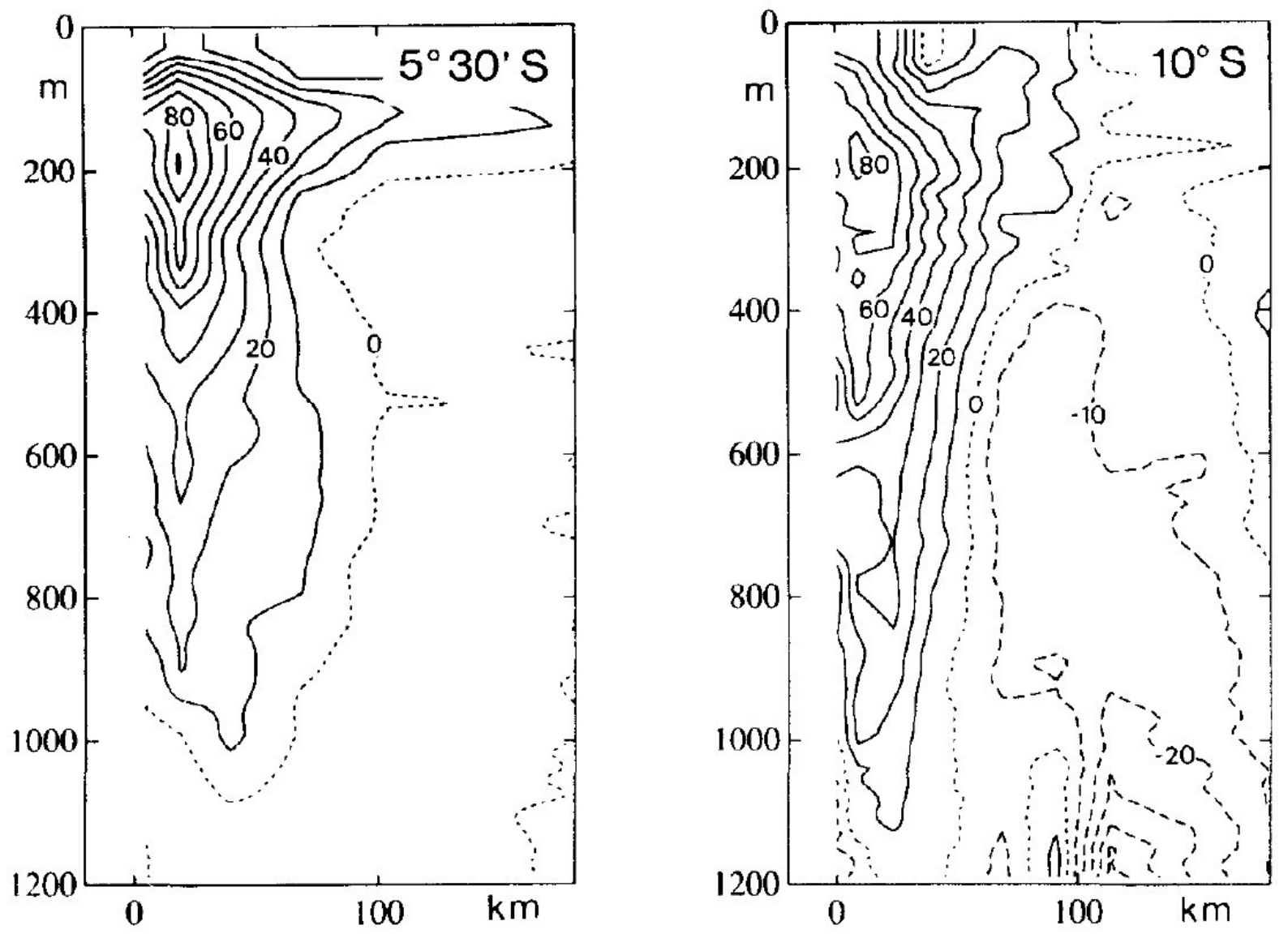

Figura 1.5: Distribuições verticais de velocidades correspondentes à SNB, nas latitudes de $5^{\circ} 30^{\prime} \mathrm{S}$ e $10^{\circ} \mathrm{S}$. Essas velocidades foram obtidas por LADCP durante a primavera austral (novembro/1992). O intervalo entre as isotacas é de $10 \mathrm{~cm} \mathrm{~s}^{-1}$. Reproduzido de Stramma et al. [1995].

Segundo Schott et al. [1998], ao norte de $5^{\circ}$ S, a CSE faz a SNB perder a sua característica de subcorrente e se transformar na CNB. De acordo com Stramma E England [1999], a ACAS (Água Central do Atlântico Sul) flui com a Corrente de Benguela e a CSE em direção à margem continental brasileira, onde é transportada em direção ao equador pela SNB. Próximo ao equador, ao largo da costa brasileira, o ramo CSEe se sobrepõe ao núcleo de subsuperfície da SNB, formando a CNB intensificada em superfície, que cruza o equador como a maior fonte de água quente transferida do hemisfério sul para o hemisfério norte.

Schott et al. [2002] citam a margem oeste do Atlântico Sul tropical como uma região particularmente interessante para observação da circulação termohalina. Segundo esses autores, boa parte da água quente que é transferida do hemisfério sul em direção ao equador (em níveis superiores) é contida na SNB, cujo transporte seria resul- 
tante de duas diferentes componentes: uma com origem na Célula de Revolvimento Meridional (CRM), na qual aproximadamente 20 Sv da Água Profunda do Atlântico Norte (APAN) segue em direção ao sul através da zona equatorial, e outra com origem na célula subtropical.

Schott et al. [2005] analisaram o fluxo de águas quentes para norte através da SNB, confirmando que a SNB é bem desenvolvida em $11^{\circ} \mathrm{S}$ e constatando que são pequenas as variações interanuais do transporte da SNB. Esses autores contruíram, com base em seções de ADCP/LADCP, uma estrutura para a SNB estatisticamente muito mais robusta que as apresentadas por Stramma et al. [2005]. A Figura 1.6, reproduzida de Schott et al. [2005], ilustra as distribuições, ao largo da costa brasileira, das velocidades médias de corrente $\left(\mathrm{cm} \mathrm{s}^{-1}\right)$ e dos transportes médios (Sv) calculados a partir de dados de ADCP/LADCP, coletados nos 9 cruzeiros realizados durante o período de 1990 - 2004 (4 no período de 1990 - 1994 e 5 no período de 2000 - 2004), nas proximidades da latitude $5^{\circ} \mathrm{S}$, e nas 5 seções realizadas durante o período de 2000 - 2004, nas proximidades da latitude $11^{\circ} \mathrm{S}$. A SNB aparece bem desenvolvida nas duas seções médias.

Enquanto a estrutura vertical da SNB é razoavelmente bem conhecida, ao largo da costa leste e norte, informações acerca dos padrões horizontais de circulação e atividades de mesoescala associadas às correntes de contorno são escassas, e se restringem aos padrões de circulação geostrófica entre $10^{\circ} 30^{\prime} \mathrm{S}$ e $5^{\circ} \mathrm{S}$, apresentados por Silveira et al. [1994], e aos padrões obtidos a partir de dados de ADCP entre $7^{\circ} \mathrm{S}$ e $3^{\circ} \mathrm{N}$, apresentados por Goes et al. [2005] e Stramma et al. [2005].

Silveira et al. [1994] apresentaram mapas de topografia dinâmica (relativa a 1.000 m) para os níveis de 0,100 e $200 \mathrm{~m}$. A partir dos mapas referentes aos níveis de 0 e $100 \mathrm{~m}$, esses autores constataram um fluxo para sul como resultante da bifurcação do ramo central da CSE (CSEc), observando também o ramo sul da CSE (CSEs) girando no sentido horário em aproximadamente $9^{\circ} 30^{\prime} \mathrm{S}$, alimentando a SNB. A partir do mapa referente ao nível de $200 \mathrm{~m}$, eles observaram que a SSE é alimentada pelo ramo CSEc e, provavelmente, pela SNB, em aproximadamente $4^{\circ} \mathrm{S}-5^{\circ} \mathrm{S}$ e $34^{\circ} \mathrm{W}$. A Figura 1.7 representa os mapas de topografia dinâmica de acordo com Silveira et al. [1994]. 

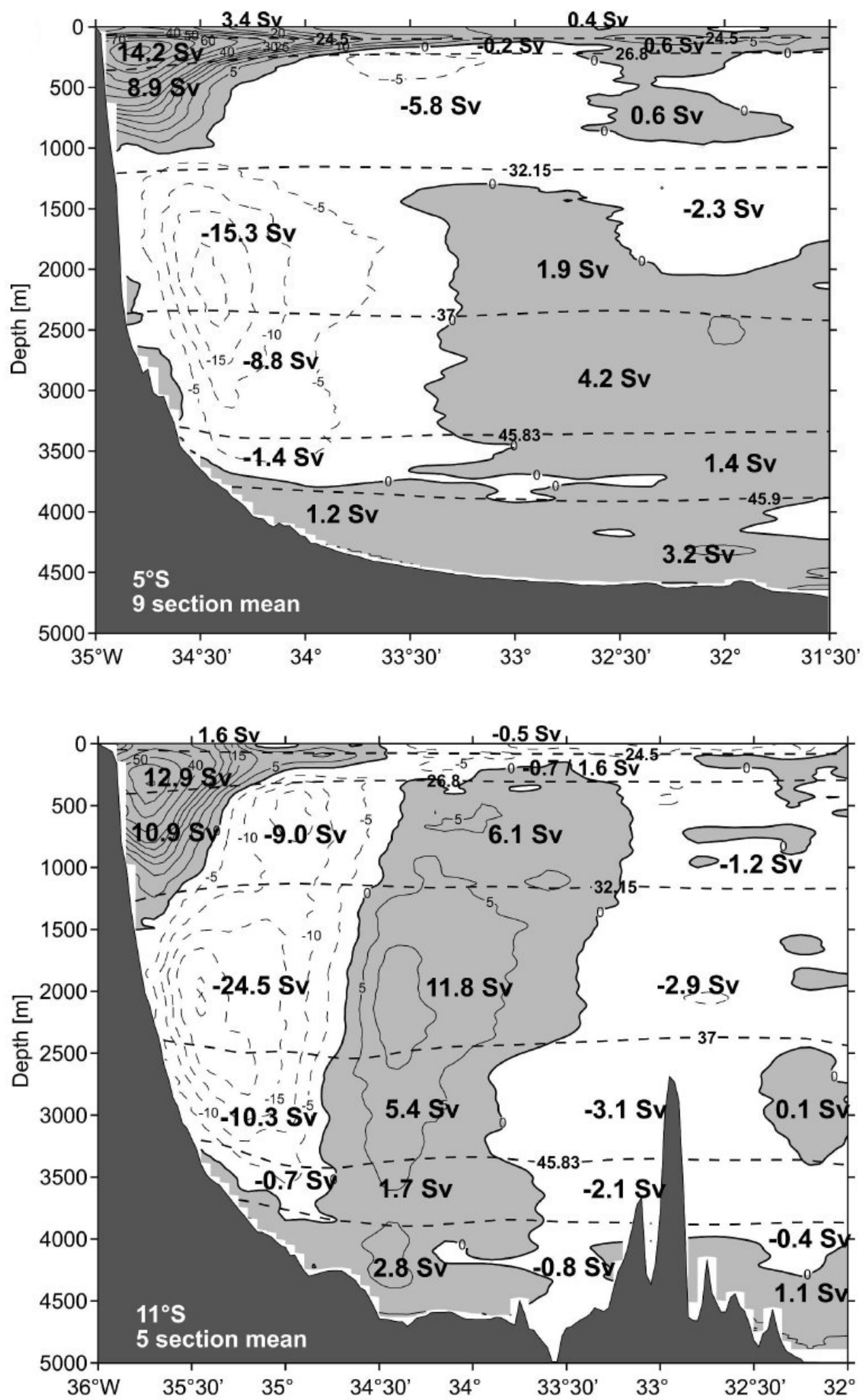

Figura 1.6: Distribuições, ao largo da costa brasileira, das velocidades médias de corrente $(\mathrm{cm}$ $\mathrm{s}^{-1}$ ) e dos transportes médios (Sv) calculados a partir de dados de ADCP/LADCP, coletados nos 9 cruzeiros realizados durante o período de 1990-2004, nas proximidades da latitude $5^{\circ} \mathrm{S}$, e nas 5 seções realizadas durante o período de 2000-2004, nas proximidades da latitude $11^{\circ} \mathrm{S}$. Valores de velocidade positivos para norte. Reproduzida de Schott et al. [2005]. 


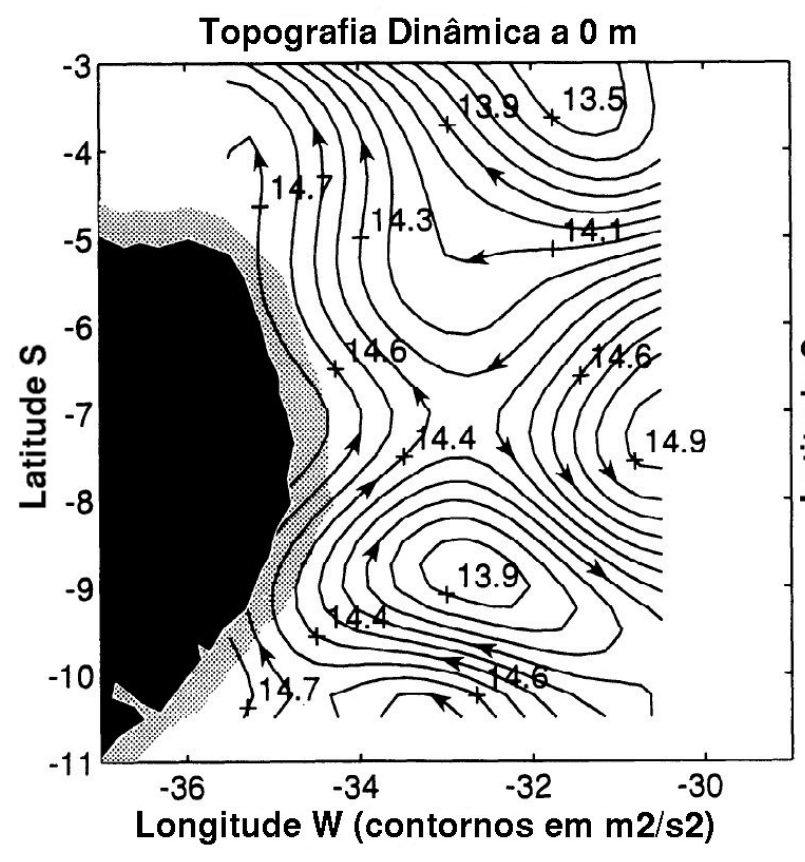

(a)

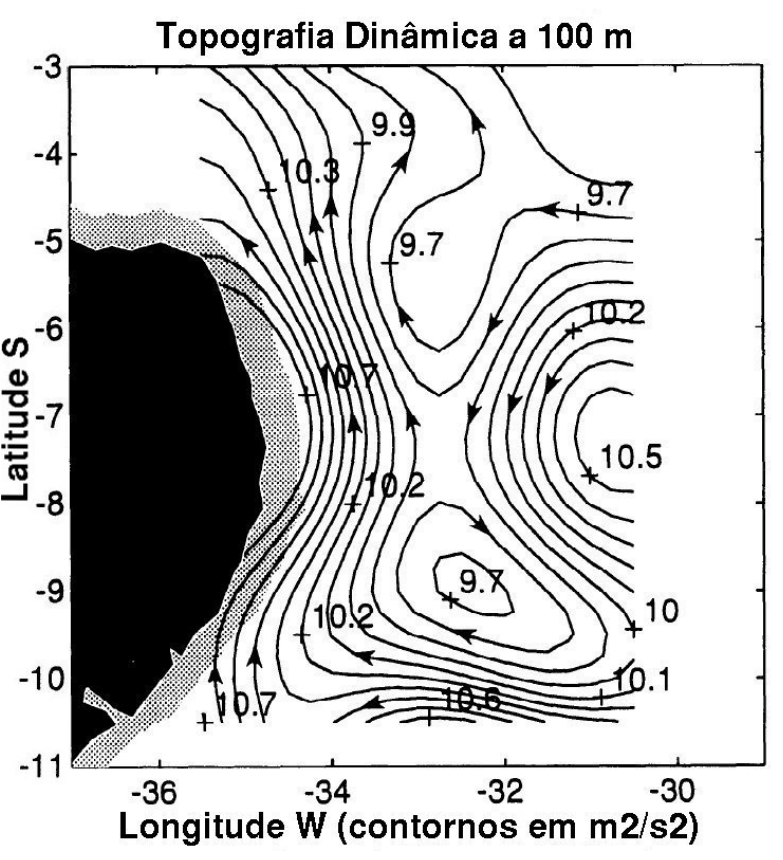

(b)

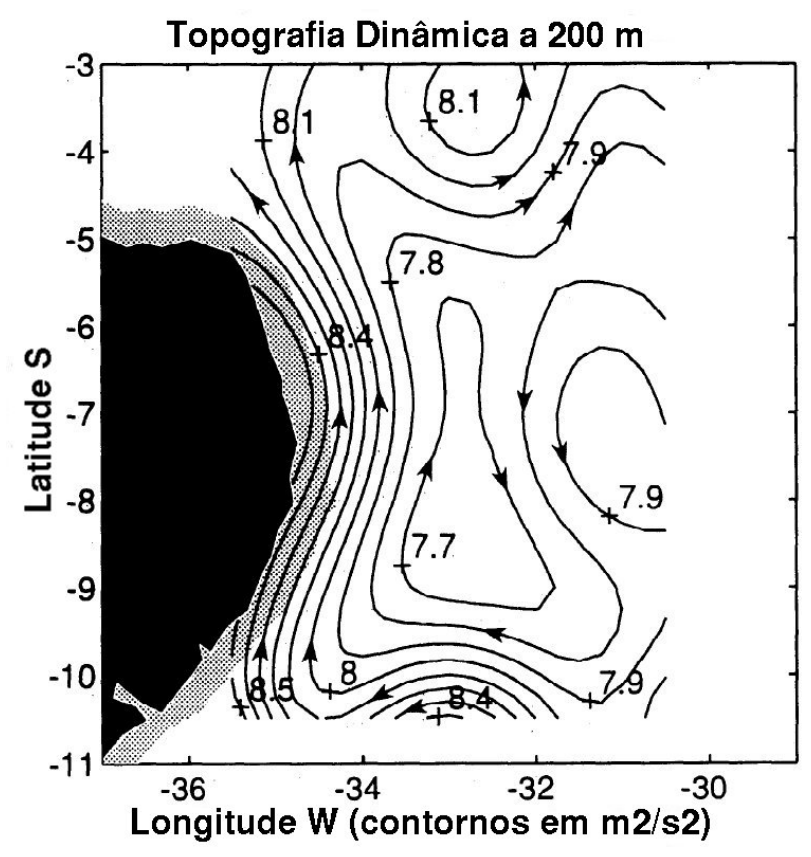

(c)

Figura 1.7: Mapas de topografia dinâmica (relativa a $1.000 \mathrm{~m}$ ) referentes aos dados analisados por Silveira et al. [1994]. A partir dos mapas (a) e (b), níveis 0 e $100 \mathrm{~m}$, respectivamente, pode-se constatar um fluxo para sul, resultante da bifurcação do ramo CSEc, podendo ser observado também o ramo CSEs girando no sentido horário em aproximadamente $9^{\circ} 30^{\prime} \mathrm{S}$, alimentando a SNB. A partir do mapa (c), nível $200 \mathrm{~m}$, pode-se constatar a SSE sendo alimentada pelo ramo CSEc e, provavelmente, pela SNB, em aproximadamente $4^{\circ} \mathrm{S}-5^{\circ} \mathrm{S}$ e $34^{\circ} \mathrm{W}$. 
Goes et al. [2005] apresentaram mapas de função de corrente construídos a partir de dados de LADCP. Esses autores consideraram a coluna d'água separada em duas camadas, uma entre a superfície e a isopicnal de $24,5 \mathrm{~kg} \mathrm{~m}^{-3}$, estando inserida nessa camada o núcleo da CNB, e a outra entre as isopicnais de $24,5 \mathrm{~kg} \mathrm{~m}^{-3}$ e $26,8 \mathrm{~kg} \mathrm{~m}^{-3}$, estando inserida nessa camada o núcleo da SNB. A Figura 1.8, modificada de Goes et al. [2005], representa as distribuições horizontais de função de corrente construídas a partir de dados de LADCP, para as superfícies isopicnais de $24,5 \mathrm{~kg} \mathrm{~m}^{-3}(\backsim 75 \mathrm{~m}$ ) e $26,8 \mathrm{~kg} \mathrm{~m}^{-3}(\backsim 300 \mathrm{~m})$. Esses campos de função de corrente possuem grande incerteza entre $40^{\circ} \mathrm{W}$ e $36^{\circ} \mathrm{W}$, devido à ausência de dados. No campo correspondente à camada superior $\left(0-24,5 \mathrm{~kg} \mathrm{~m}^{-3}\right)$, em cerca de $35^{\circ} \mathrm{W}$, a CSE é representada como fluxo largo em direção a oeste, estendendo-se de cerca de $6^{\circ} \mathrm{S}$ ao equador, transformando-se em CNB nas proximidades de $44^{\circ} \mathrm{W}$. A CNB é mostrada com uma largura de aproximadamente $3^{\circ}$, e está em retroflexão em superfície para originar a CCNE, como já verificado por Johns et al. [1990], Bub E Brown [1996] e Silveira et al. [2000a]. No campo correspondente à camada inferior $\left(24,5 \mathrm{~kg} \mathrm{~m}^{-3}-26,8 \mathrm{~kg} \mathrm{~m}^{-3}\right)$, a SNB é representada em retroflexão para originar a SE/SNE, confirmando os resultados anteriores de [Silveira et al., 2000a].

Cumpre observar a controvérsia existente na literatura a respeito da caracterização da CNB e SNB ao norte de $5^{\circ}$ S. Enquanto Stramma \& England [1999], Schott et al. [2005] e Stramma et al. [2005] tratam o fluxo ao norte de $5^{\circ} \mathrm{S}$ como CNB, considerando a CNB e a SNB como uma estrutura única nessa região, Goes et al. [2005] consideram o fluxo dessas duas correntes de forma independente, usando a isopicnal de $24,5 \mathrm{~kg}$ $\mathrm{m}^{-3}$ para separar estes fluxos. Entretanto, ao norte de $5^{\circ} \mathrm{S}$, as duas correntes fluem como uma estrutura contínua em direção ao equador. O presente trabalho irá considerar como CNB o escoamento que apresenta núcleo de velocidades em superfície resultantes da fusão entre a SNB e os ramos CSEc e CSEe. 

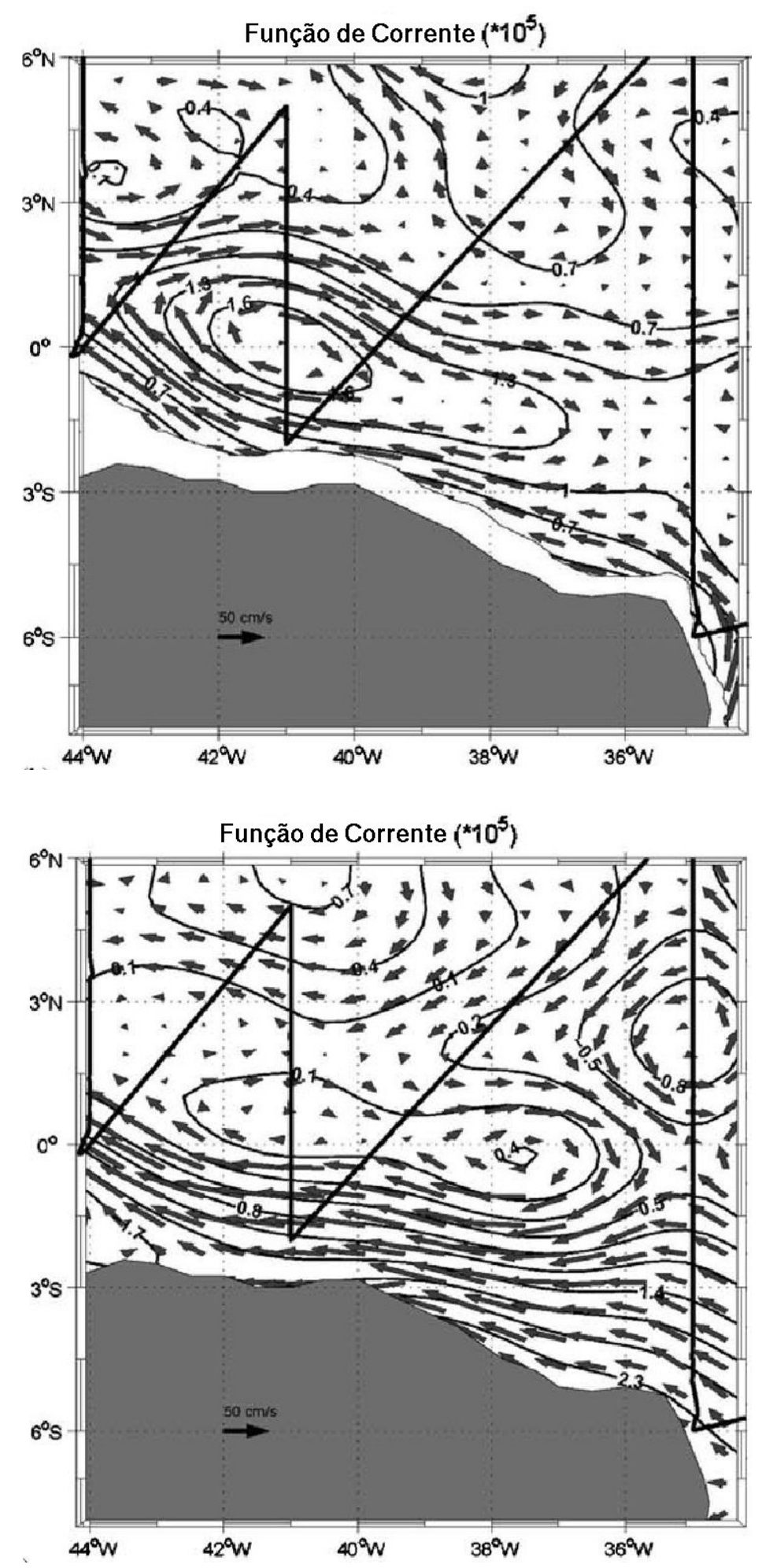

Figura 1.8: Distribuições horizontais de função de corrente apresentados por Goes et al. [2005]. Esses campos foram construídos a partir de dados de LADCP, para as superfícies isopicnais de $24,5 \mathrm{~kg} \mathrm{~m}^{-3}(\backsim 75 \mathrm{~m})$ e $26,8 \mathrm{~kg} \mathrm{~m}^{-3}(\backsim 300 \mathrm{~m})$. No campo correspondente à camada $0-24,5 \mathrm{~kg}$ $\mathrm{m}^{-3}$ (painel superior), a CSE é representada como fluxo largo em direção a oeste, estendendo-se de cerca de $6^{\circ} \mathrm{S}$ ao equador, transformando-se em CNB nas proximidades de $44^{\circ} \mathrm{W}$, ocorrendo retroflexão para originar a CCNE. No campo correspondente à camada $24,5 \mathrm{~kg} \mathrm{~m}^{-3}-26,8 \mathrm{~kg}$ $\mathrm{m}^{-3}$ (painel inferior), pode-se observar a retroflexão da SNB, para originar a SE/SNE. 
Os trabalhos de Stramma et al. [1995] e Schott et al. [2005] apresentaram análises, de caráter seccional, de medições diretas de correntes por LADCP realizadas na margem continental brasileira leste e nordeste, indicando a presença do escoamento da SNB. Excetuando Goes et al. [2005], que examinaram dados coletados entre as longitudes de $35^{\circ} \mathrm{W}-44^{\circ} \mathrm{W}$ e entre as latitudes de $11^{\circ} \mathrm{S}-7^{\circ} \mathrm{N}$, inexistem descrições de padrões horizontais de mesoescala associados à $\mathrm{SNB}$, em termos de velocidade absoluta. Essa lacuna na literatura nos conduz a formular as seguintes questões:

1. Os padrões de circulação geostrófica absoluta diferem muito dos padrões obtidos para as correntes geostróficas baroclínicas relativas a um nível de referência escolhido arbitrariamente?

2. Os padrões de circulação geostrófica absoluta reproduzem satisfatoriamente os padrões de circulação observada?

3. Existe atividade de mesoescala associada à SNB ao norte de $7^{\circ} \mathrm{S}$ ?

\subsection{Objetivos}

\subsubsection{Objetivo Geral}

O objetivo central da presente dissertação é obter uma descrição sinótica dos padrões horizontal e vertical de escoamento da Subcorrente Norte do Brasil (SNB) ao largo da costa do nordeste, bem como de outras estruturas de mesoescala associadas à SNB, através da elaboração de distribuições verticais de velocidade e da construção de campos horizontais de função de corrente a serem apresentados em vários níveis.

Esses padrões serão construídos a partir de dados de temperatura e salinidade, obtidos através de CTD, e dados de velocidade de corrente, obtidos por ADCP de casco de navio, coletados na área oceânica adjacente à costa do nordeste brasileiro, em duas comissões hidroceanográficas realizadas pelo Navio Oceanográfico Antares (NOc Antares), da Marinha do Brasil: comissão OCEANO NORDESTE I (ONEI), no período de 26 de fevereiro a 21 de março de 2002, e comissão OCEANO NORDESTE II (ONEII), no período de 26 de outubro a 20 de dezembro de 2004. 


\subsubsection{Objetivos Específicos}

Os objetivos específicos desta dissertação consistem em:

1. Obter uma descrição sinótica do padrão horizontal de circulação geostrófica baroclínica relativa, associado ao escoamento da SNB, através da construção de campos horizontais de função de corrente geostrófica baroclínica relativa a um nivel de referência, a partir de dados de temperatura e salinidade, a fim de comparar os resultados com padrões já descritos na literatura;

2. Obter uma descrição sinótica da circulação observada, associada ao escoamento da SNB, através da elaboração de distribuições verticais de velocidade medida por ADCP de casco nas proximidades das latitudes de $5^{\circ} \mathrm{S}$ e $11^{\circ} \mathrm{S}$, a fim de comparar os resultados com duas seções de controle, apresentadas nos estudos de Schott et al. [2005];

3. Obter uma descrição sinótica dos padrões verticais de circulação observada associados ao escoamento da SNB;

4. Obter uma descrição sinótica do padrão horizontal de circulação geostrófica absoluta, associada ao escoamento da SNB, através da construção de campos horizontais de função de corrente geostrófica absoluta referenciada por dados de ADCP de casco, a fim de se obter resultados em profundidades maiores que as de alcance do perfilador de velocidade acústico.

A disponibilidade de dados de temperatura e salinidade e de dados de velocidade de corrente, coletados simultaneamente, possibilitou que realizássemos estimativas de circulação geostrófica baroclínica relativa, através do Método Dinâmico Clássico, e de circulação geostrófica absoluta, através do Método Dinâmico Referenciado, com base na técnica desenvolvida por Sutton $\mathcal{E}$ Chereskin [2002]. Foram elaboradas distribuições verticais de velocidade geostrófica baroclínica relativa e de velocidade observada, bem como distribuições horizontais de função de corrente geostrófica baroclínica relativa, de função de corrente observada e de função de corrente geostrófica absoluta, com o intuito de atingir os objetivos delineados para o presente trabalho. 
No Capítulo 2, serão apresentados os dados que serviram de base para a presente dissertação. No Capítulo3, serão descritos os principais conceitos aplicados nos cálculos realizados a partir desses dados. No Capítulo 4, serão apresentados os procedimentos metodológicos, resultados e discussões referentes aos cálculos geostróficos realizados para a construção dos campos de velocidade geostrófica baroclínica relativa e de função de corrente geostrófica baroclínica relativa, a partir dos dados de CTD das comissões ONEI e ONEII. No Capítulo 5, serão apresentados os procedimentos metodológicos, resultados e discussões referentes aos cálculos realizados para a construção dos campos de velocidade observada e de função de corrente observada, a partir dos dados de $\mathrm{ADCP}$ de ambas as comissões. No Capítulo 6 , serão apresentados os resultados e discussões sobre as estimativas de escoamento geostrófico absoluto. E, finalmente, no Capítulo 7, será apresentado um sumário dos resultados, bem como as conclusões e sugestões para trabalhos futuros. 


\section{Capítulo 2}

\section{Conjunto de Dados}

\subsection{Preâmbulo}

Um conceito primário na maioria de trabalhos observacionais é a exatidão dos equipamentos de medição. Uma exatidão alta requer uma calibração freqüente do instrumento para detectar e corrigir qualquer variação no seu desempenho. A qualidade das observações depende fortemente do cuidado conduzido na calibração e no processamento dos dados [Emery \& Thomson, 1998].

De acordo com Miranda et al. [2002], medições das propriedades hidrográficas (salinidade, temperatura e pressão) e dos movimentos (correntes) são fundamentais na área de Oceanografia Física. Os dados que serviram de base para a presente dissertação são dados de hidrografia (temperatura e salinidade), obtidos através de um perfilador CTD (Conductivity, Temperature and Depth) e de velocidade de corrente, obtidos através de um perfilador ADCP de casco de navio. Esses dados foram coletados na área oceânica adjacente à costa do nordeste brasileiro, em duas comissões hidroceanográficas realizadas pelo NOc Antares, da Marinha do Brasil: ONEI (fevereiromarço/2002) e ONEII (outubro-dezembro/2004). Os dados foram disponibilizados pelo Centro de Hidrografia da Marinha (CHM), organização militar subordinada à Diretoria de Hidrografia e Navegação (DHN), e fazem parte do Banco Nacional de Dados Oceanográficos (BNDO).

Cabe à DHN, por intermédio do CHM e pelo BNDO, cadastrar, recuperar e disseminar informações e dados oceanográficos em níveis nacional e internacional, 
valendo-se das comissões realizadas por navios da MB, da Marinha Mercante, navios estrangeiros (em águas sob jurisdição brasileira) e pela comunidade científica nacional, bem como manter o intercâmbio com os centros de dados.

A seguir serão apresentados os dados que serviram de base para a presente dissertação, bem como os equipamentos utilizados na coleta desses dados. Devido à diferença de características entre os dados de hidrografia (grandezas escalares) e os dados de velocidade de corrente (grandezas vetoriais), os processamentos desses dados serão apresentados separadamente, nos Capítulos 4 e 5 , respectivamente.

\subsection{Dados de Hidrografia}

Os dados de temperatura e salinidade foram coletados por um perfilador CTD de modelo SBE 9Plus, do fabricante Sea-Bird Electronics, Inc., adequado a perfilagens até $6.000 \mathrm{~m}$ de profundidade (camâra estanque de alumínio). O perfilador CTD foi utilizado conectado a uma unidade de bordo SBE 11Plus, possibilitando o monitoramento dos dados em tempo real, tendo sido utilizada a freqüência de operação de 24 Hz. O CTD é um perfilador vertical contínuo de condutividade, temperatura e pressão. Adicionalmente, outros sensores podem ser a ele acoplados, possibilitando a coleta de dados de propriedades como $\mathrm{pH}$, teor de oxigênio dissolvido, dentre outras. Possui, então, três sensores-padrão: condutividade, temperatura e pressão. A partir dos dados de condutividade pode-se inferir a salinidade.

Como descrito por Miranda et al. [2002], a salinidade é calculada com base no algoritmo da Escala Prática de Salinidade (Pratical Salinity Scale) EPS-1978 (PSS-78). A EPS-1978 (PSS-78) foi implementada com base nos estudos de Edward Lyn Lewis que, por solicitação do JPOTS (Joint Panel On Oceanographic Tables and Standards), em 1975, reviu as várias equações já existentes, tendo concluído sua revisão em 1980 [Lewis, 1980]. Em 1981 a Escala Prática de Salinidade foi formalmente publicada nos relatórios técnicos da UNESCO [UNESCO, 1981ba].

Foram obtidos 57 perfis na comissão ONEI (57 estações distribuídas em 8 radiais), e 94 perfis na comissão ONEII (94 estações distribuídas em 13 radiais). A Figura 2.1 representa esquematicamente as estações de lançamento de CTD. 

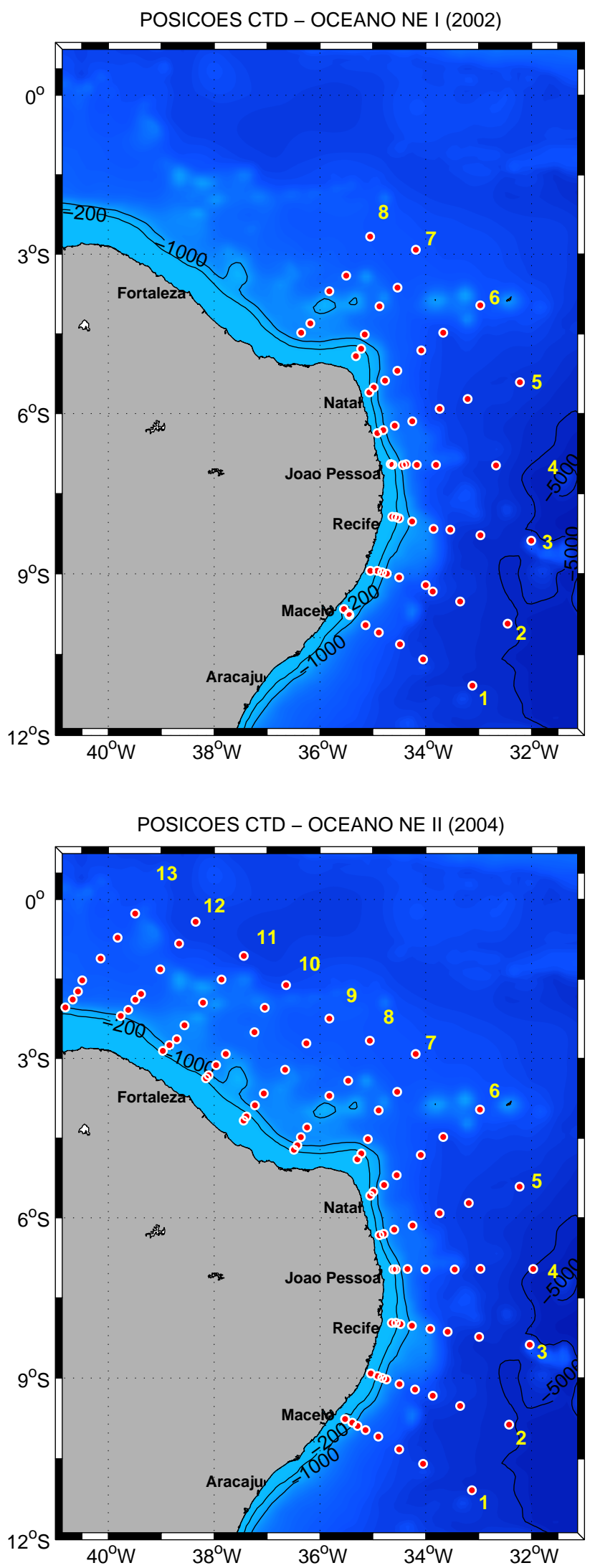

Figura 2.1: Representação esquemática das posições de lançamento de CTD, referentes às comissões hidroceanográficas ONEI (painel superior) e ONEII (painel inferior), realizadas pelo NOc Antares, da MB. 


\subsection{Dados de Velocidade de Corrente}

Dentre as propriedades físicas de interesse em Oceanografia Física, uma das mais difíceis de ser determinada experimentalmente é a velocidade de corrente, por ser uma grandeza vetorial que apresenta grande variação tanto na intensidade quanto na direção [Miranda et al., 2002]. Nas comissões em análise, os dados de velocidade de corrente foram obtidos através de um perfilador ADCP de modelo RDI BroadBand 75 $\mathbf{k H z}$, do fabricante RDI (RD Instruments), como mostrado na Figura 2.2. Esse perfilador é um ADCP de casco de navio (Vessel-Mount ADCP) e opera com tecnologia broadband ("banda larga") de transmissão de sinais acústicos, na freqüência de transmissão de 75 $\mathrm{kHz}$, com alcance nominal de 560 - $700 \mathrm{~m}$ de profundidade.

Para que seja possível se obter o vetor velocidade resultante do fluxo, é necessária a existência de, no mínimo, três feixes sonoros. O módulo transdutor do ADCP RDI BroadBand $75 \mathbf{~ k H z}$ é composto por quatro transdutores espaçados de $90^{\circ}$ na horizontal, distribuidos em dois planos ortogonais, ou seja, cada plano contendo um par de transdutores dipostos simetricamente em relação à vertical. Cada transdutor emite um feixe (beam) com largura de feixe (beam width) de $4^{\circ}$, estando estes feixes inclinados de $20^{\circ}$ em relação à vertical.

De acordo com o manual do fabricante RDInstruments [1996], a configuração do módulo transdutor do ADCP é denominada Janus configuration em alusão ao deus romano Janus, que era retratado como tendo dois rostos antepostos, podendo olhar para frente e para trás. A vantagem dessa configuração é minimizar erros na velocidade horizontal devidos a eventuais inclinações do ADCP, como caturro (pitch) e balanço (roll). Dois feixes dispostos simetricamente em relação à vertical permitem calcular uma das componentes horizontais e a componente vertical da velocidade. Ao mesmo tempo, os outros dois feixes permitem calcular a outra componente horizontal e a mesma componente vertical. A figura 2.3, é uma representação esquemática da face de emissão do módulo transdutor do ADCP (face voltada para o fundo), mostrando os 4 transdutores, e da vista de perfil de um transdutor, de acordo com o manual do fabricante RDInstruments [1996]. 

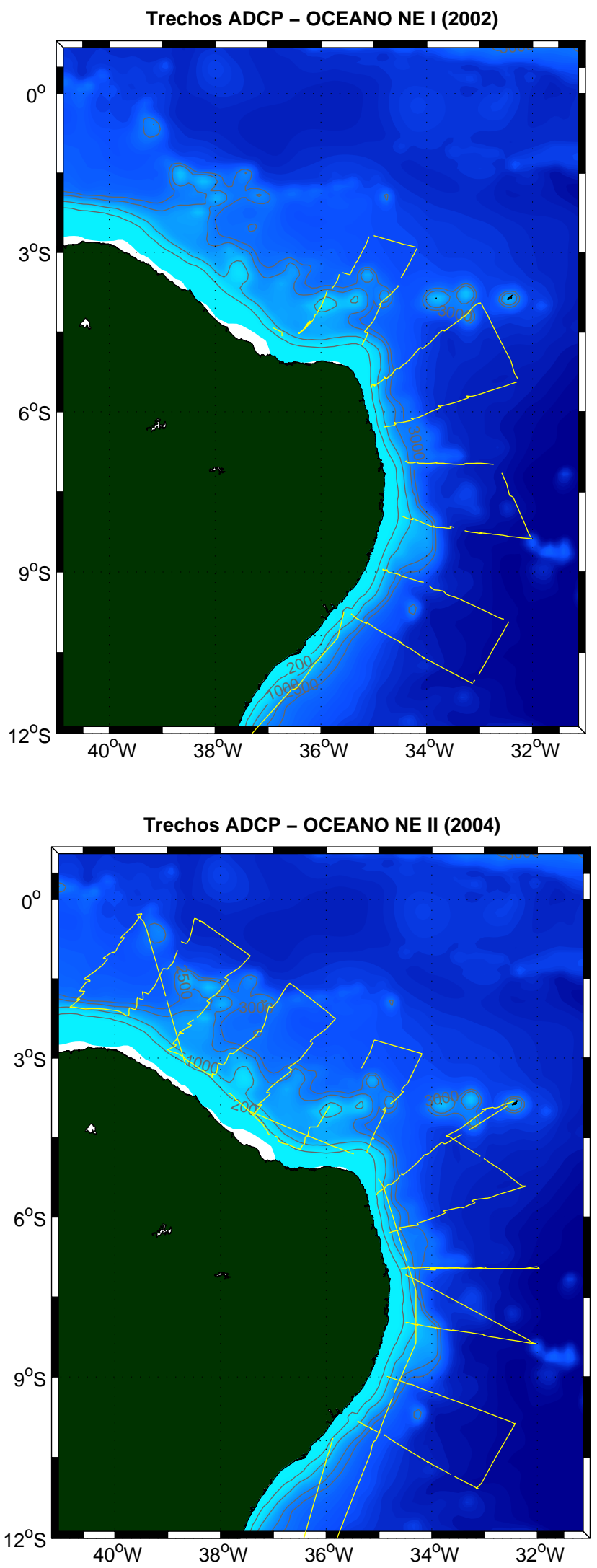

Figura 2.2: Representação esquemática dos trechos de navegação nos quais foram obtidos perfis de velocidade através de $\mathrm{ADCP}$, referentes à comissão ONEI (painel superior) e à comissão ONEII (painel inferior). 


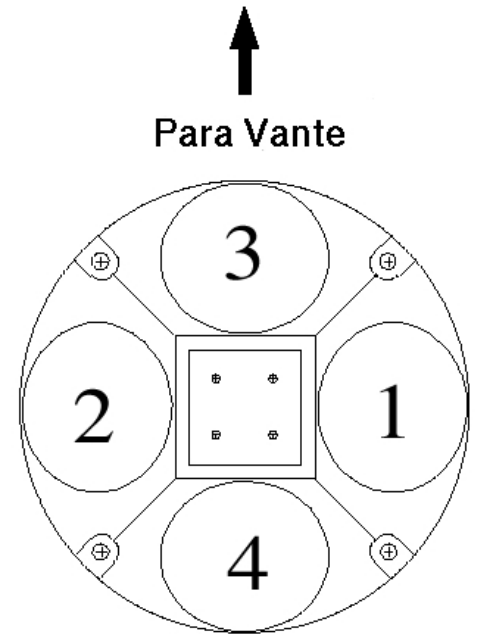

(a) Módulo transdutor

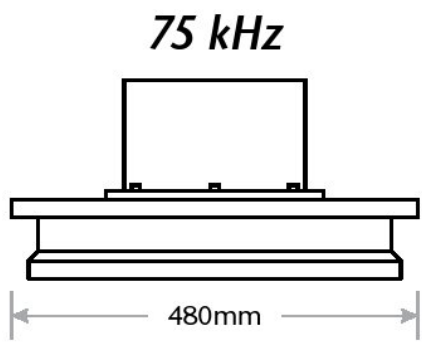

(b) Transdutor

Figura 2.3: Representação esquemática da face de emissão do módulo transdutor do ADCP (a) e da vista de perfil do transdutor (b). Os transdutores $n^{0} 3$ e 4 correspondem ao eixo longitudinal ( $\mathrm{n}^{\mathrm{o}} 3$ para vante), e os feixes $\mathrm{n}^{\mathrm{o}} 1$ e 2 correspondem ao eixo transversal ( $\mathrm{n}^{\mathrm{o}} 2$ para boreste). Modificado de RDInstruments [1996].

O perfilador ADCP é um perfilador acústico que tem como princípio de funcionamento o efeito Doppler. O equipamento emite sinais ultra-sônicos em feixes estreitos em uma freqüência conhecida. Esses pulsos acústicos são refletidos por partículas em suspensão presentes na coluna d'água, as quais acompanham o movimento do fluido. A diferença entre as freqüências dos pulsos emitidos e recebidos (desvio Doppler) é proporcional à velocidade relativa entre o navio e as partículas em suspensão na água. Dessa forma, é possivel se obter dados de velocidade de corrente horizontal em várias profundidades. Em regiões rasas, dentro do alcance do equipamento, a velocidade do navio também pode ser medida pelo ADCP, através do processo denominado bottomtracking. Na opção bottom-track, o ADCP transmite um pulso acústico específico para medir o movimento do fundo.

O efeito Doppler é um fenômeno que se caracteriza pela alteração de freqüência de uma onda, acústica ou eletromagnética, quando há movimento relativo entre uma fonte e o meio de propagação da onda e/ou entre o receptor e o meio de propagação. Consideremos, por exemplo, o caso de um navio dotado de um transdutor acústico de ADCP. O pulso acústico emitido pelo transdutor, ao ser refletido por um alvo (partículas em suspensão ou o fundo submarino, por exemplo), retorna ao instrumento com ou- 
tra freqüência. Essa diferença entre as freqüências emitida e recebida (desvio Doppler), servirá de base para o calculo da velocidade relativa entre o emissor (navio) e o receptor (alvo). Essa velocidade pode ser calculada, de acordo com o manual do fabricante RDInstruments [1996], a partir da seguinte equação:

$$
f_{D}=f_{R}-f_{T}=\frac{2 f_{T} \cdot V_{A} \cdot \cos \theta}{V_{S}},
$$

onde:

$$
\begin{aligned}
-f_{D} & \equiv \text { desvio Doppler (freqüência de desvio Doppler); } \\
-f_{T} \equiv & \text { freqüência do sinal transmitido; } \\
- & f_{R} \equiv \text { freqüência do sinal recebido; } \\
-V_{A} \equiv & \text { velocidade do alvo em relação ao emissor (navio); } \\
-V_{S} \equiv & \text { velocidade de propagação do som no meio; } \\
-\theta \quad & \text { ângulo entre a direção de propagação da onda } \\
& \text { transmitida e a direção de deslocamento do alvo. }
\end{aligned}
$$

A velocidade do alvo é, então, obtida pela manipulação da equação 2.1.

$$
V_{A}=\frac{f_{D} \cdot V_{S}}{2 f_{T} \cdot \cos \theta}
$$

Se o alvo é constituído por partículas em suspensão, a velocidade relativa obtida corresponde à velocidade do fluido. Se o alvo é o fundo submarino (bottom-tracking), a velocidade relativa obtida é a própria velocidade do navio. Considerando, então, um referencial fixo (Terra) e um referencial móvel (navio) temos:

$$
\vec{V}_{F L U I D O} / \text { REF.FIXO }=\vec{V}_{F L U I D O} / \text { REF.MOVEL }+\vec{V}_{R E F . M O V E L} / \text { REF.FIXO }
$$

Ou seja,

$$
\vec{V}_{f}=\vec{V}_{d}+\vec{V}_{n}
$$


onde:

- $\vec{V}_{f} \equiv$ velocidade do fluido em relação ao referencial fixo.

(velocidade "absoluta" do fluido);

- $\vec{V}_{d} \equiv$ velocidade do fluido em relação ao referencial móvel.

(velocidade do fluido medida pelo ADCP);

- $\vec{V}_{n} \equiv$ velocidade do referencial móvel em relação ao referencial fixo.

(velocidade "absoluta" do navio).

A velocidade "absoluta" do navio $\left(\vec{V}_{n}\right)$ pode ser obtida de duas formas:

- Através do método bottom-track; ou

- Através de uma navegação precisa (navigation), utilizando um sistema de posicionamento como o GPS (Global Positioning System), por exemplo.

De acordo com o manual do fabricante RDInstruments [1996], as velocidades obtidas por ADCP podem ser fornecidas com as seguintes coordenadas:

- Coordenadas do feixe: a velocidade é orientada paralelamente à cada feixe;

- Coordenadas terrestres: a velocidade é referenciada a um sistema de coordenadas cartesianas com um eixo orientado para LESTE (E), um eixo orientado para NORTE (N) e um eixo coincidente com a direção da vertical do lugar, orientado para CIMA;

- Coordenadas do ADCP: a velocidade é referenciada a um sistema de coordenadas cartesianas com um eixo coincidente com a direção dos transdutores $n^{\circ} 3$ e 4 (eixo longitudinal) e orientado para o transdutor $n^{\circ} 3$, um eixo coincidente com a direção dos transdutores $n^{\circ} 1$ e 2 (eixo transversal) e orientado para o trandutor $\mathrm{n}^{\mathrm{o}} 2$, e um eixo coincidente com a direção da vertical do lugar, orientado para CIMA;

- Coordenadas do navio: similar às coordenadas do ADCP exceto pelo fato de que os eixos longitudinal e transversal são os eixos do próprio navio. Se os eixos 
longitudinais do módulo transdutor e do navio coincidirem, o transdutor $\mathrm{n}^{\mathrm{o}} 3$ estará para a proa, o $\mathrm{n}^{\mathrm{O}} 2$ estará para boreste (BE), e as coordenadas do navio serão iguais às coordenadas do ADCP.

O manual do fabricante RDInstruments [1996] menciona que os dados de ADCP devem ser corrigidos dos erros ocasionados por dois tipos de movimento:

- Rotação: caturro (pitch), balanço (roll) e guinada (heading);

- Translação: deslocamento do navio durante a navegação.

Dos ângulos de rotação obtidos a partir dos sensores de atitude, o ângulo que mais acarreta erro aos dados de ADCP é o ângulo de guinada. Geralmente esse ângulo é obtido a partir de uma agulha giroscópica, que tem como característica uma resposta mais lenta do que a necessária para a freqüência em que se tomam os perfis de velocidade através do ADCP. Isso fica mais evidente nos momentos em que o navio tem o seu rumo alterado bruscamente durante a navegação, geralmente durante as paradas para execução de estações hidrográficas, ou quando se é necessário adotar angulações elevadas para alteração de rumo. A Figura 2.4 representa esquematicamente os 3 ângulos de rotação que influenciam os dados de ADCP.

Figura 2.4: Representação esquemática dos ângulos de rotação que influenciam os dados de ADCP: balanço (roll), caturro (pitch) e guinada (heading).

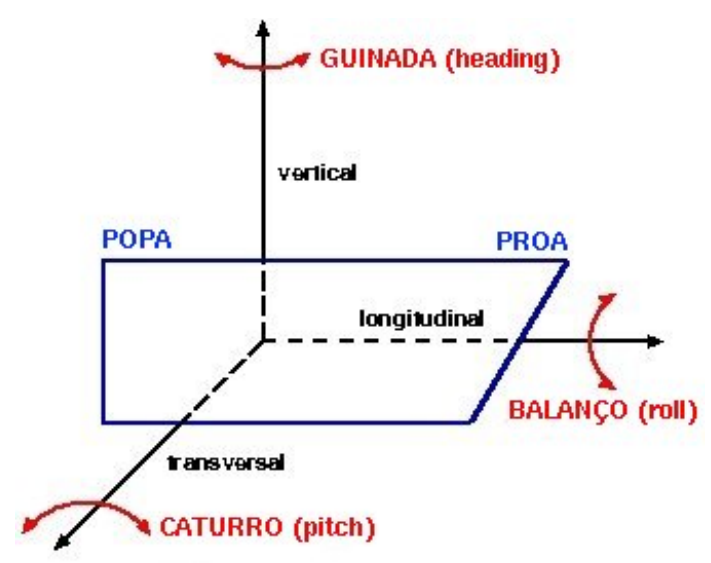

Dentre as formas de se medir os movimentos sofridos pelo equipamento podemos citar:

- Para medir a guinada: agulha giroscópica;

- Para medir o caturro e o balanço: compensador de ondas; 
- Para medir a translação: método bottom-tracking, navegação precisa (navigation) ou assumindo-se um nível de referência de movimento nulo.

Quando o módulo transdutor do ADCP é instalado a bordo de um navio, por maior que seja o cuidado em mantê-lo alinhado com os eixos do navio, há sempre desvios de montagem resultantes. O erro na determinação do valor do ângulo horizontal de montagem somado ao erro associado à informação da agulha giroscópica (GIRO), resultam no ângulo horizontal de desalinhamento do módulo transdutor, que deve ser determinado através de calibração, em cada cruzeiro oceanográfico [Joyce, 1989: Pollard E Read, 1989]. Os métodos de calibração serão abordados na Seção 5.2 do Capítulo 5.

O ADCP permite a configuração de diversos parâmetros de operação, que influenciam a qualidade dos dados. Dentre estes parâmetros está a "célula de profundidade" (depth cell ou bin). A escolha do tamanho da célula depende da profundidade de operação, da freqüência do $\mathrm{ADCP}$, do modo de operação selecionado, da precisão e da resolução desejada. O tamanho da célula corresponde ao valor de espaçamento que será utilizado para dividir a a coluna d'água em intervalos iguais. O ADCP calcula uma média das várias velocidades que são amostradas em cada célula. O número de células de profundidade, para o equipamento considerado, pode variar de 1 a 128 . A Figura 2.5 representa esquematicamente as células de profundidade, de acordo com o manual do fabricante RDInstruments [1996].
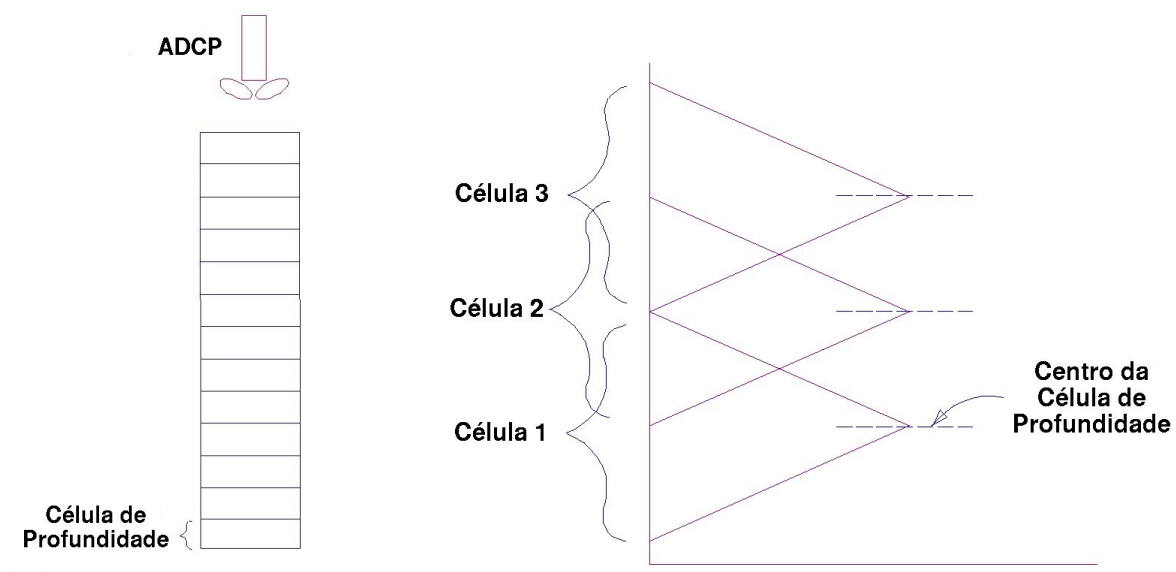

Figura 2.5: Representação esquemática das células de profundidade que dividem a perfilagem do ADCP. Modificado de RDInstruments [1996. 
Os sinais acústicos emitidos pelo transdutor de um ADCP, ao se propagarem no mar, sofrem menor desvio devido à refração quando comparados com os sinais emitidos pelo transdutor do sonar, pois os feixes do ADCP possuem menor angulação em relação à vertical. Dessa forma, os feixes do ADCP podem penetrar a termoclina. A Figura 2.6 representa esquematicamente a propagação dos feixes acústicos emitidos pelo transdutor do ADCP, de acordo com o manual do fabricante RDInstruments [1996].

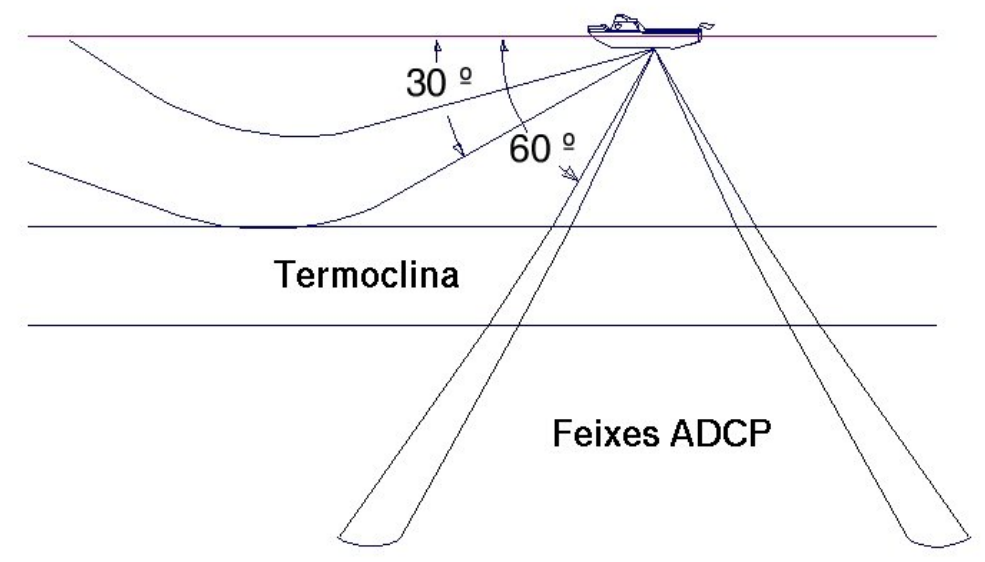

Figura 2.6: Representação esquemática da propagação dos feixes acústicos emitidos pelo transdutor do ADCP. Modificado de RDInstruments [1996].

A aquisição de dados por ADCP fabricados pela RDI é feita através de um software denominado VmDAS (Vessel-Mount Data Acquisition System). Para a coleta de dados, são necessários os arquivos de configuração (.TXT) e de inicialização (.INI). Dentre os arquivos gerados pelo ADCP, destacamos os que possuem as seguintes extensões:

- ENR (Raw Binary ADCP Data): arquivo de dados brutos;

- ENS (Binary ADCP Data): arquivo de dados brutos após terem sido retiradas informações sem consistência;

- ENX (Binary Ensemble Data): arquivo pronto para o cálculo das médias;

- STA (Short Term Averaged Data): arquivo de dados com navegação após ter sido realizada a média curta no período especificado;

- LTA (Long Term Averaged Data): arquivo de dados com navegação após ter sido realizada a média longa no período especificado; 
- N1R (Raw NMEA ASCII Data): arquivo de dados brutos NMEA (National Marine Electronics Association) que possui informações de latitude e longitude. O NMEA é um protocolo padrão para transmissão de dados;

- N2R (Raw NMEA ASCII Data): arquivo de dados brutos NMEA que possui as informações de balanço (roll), caturro (pitch), e ângulo de proa (heading), caso haja o sensor de atitude;

- NMS (Averaged Nav Data): arquivos de navegação no formato binário após ter sido realizada a média.

Nos arquivos de configuração das comissões ONEI e ONEII, consta que foram recebidas informações da agulha giroscópica e do compensador de ondas. A aquisição de dados foi realizada de modo a operar automaticamente em bottom-track e navigation, além dos seguintes parâmetros de configuração, dentre outros:

- Desalinhamento horizontal do módulo transdutor: $48,5^{\circ}$;

- Intervalo de transmissão: $3 \mathrm{~s}$;

- Intervalo entre o pulso para medição da velocidade do fluido (water ping) e o pulso para o fundo (bottom ping): 1,5 s;

- Profundidade máxima de busca do fundo: 900 m;

- Célula de profundidade: $8 \mathrm{~m}$;

- No de células de profundidade: 100;

- First Time Interval (relacionado aos arquivos .STA): 300 s (5min);

- Second Time Interval (relacionado aos arquivos .LTA): $600 \mathrm{~s}$ (10 min).

Optamos por realizar o processamento dos arquivos .LTA (intervalo de $10 \mathrm{~min}$ ), cujas etapas serão descritas no Capítulo 5. 


\section{Capítulo 3}

\section{Fundamentação Teórica}

\subsection{Preâmbulo}

De acordo com Gill [1982], o oceano e a atmosfera tendem a se aproximarem do equilíbrio geostrófico a todo instante. Segundo Holton [1992], movimentos em escala sinótica nas latitudes médias estão, aproximadamente, em balanço geostrófico. $\mathrm{O}$ fluxo geostrófico é um movimento teórico que fornece uma boa aproximação para escoamentos de larga e mesoescala. A validade desta aproximação pode ser avaliada pelo número de Rossby associado ao movimento. Como os tipos de escoamento investigados no presente trabalho têm escalas temporais e espaciais que se aproximam do balanço geostrófico, utilizou-se a geostrofia como arcabouço teórico.

O escoamento geostrófico é tipicamente inferido a partir do campo de densidade, quando no uso de dados de estações hidroceanográficas, através do método denominado Método Dinâmico. A velocidade geostrófica obtida a partir desse método é relativa a um nível onde o movimento é nulo (Método Dinâmico Clássico) ou a um nível onde as velocidades são conhecidas (Método Dinâmico Referenciado).

O Método Dinâmico Clássico apresenta como desvantagem o fato de possibilitar a determinação apenas da componente baroclínica da velocidade geostrófica relativa a um nível arbitrariamente estabelecido. A disponibilidade de dados de hidrografia (obtidos através de CTD) e dados de velocidade de corrente (obtidos através de ADCP) possibilitou que realizássemos estimativas de circulação geostrófica absoluta, através do Método Dinâmico Referenciado, com base na técnica desenvolvida por Sut- 
ton $\mathcal{E}$ Chereskin [2002], que utilizaram um nível de velocidades conhecidas, oriundas de ADCP, para referenciar o cálculo de correntes geostróficas.

Partindo da consideração de velocidade não-divergente, utilizamos o conceito de função de corrente para análise dos escoamentos. Foram construídos mapas de função de corrente geostrófica baroclínica relativa, de corrente observada e de corrente geostrófica absoluta, como somatório das outras duas. Como as equações governantes para a simulação de escoamento de fluidos podem apresentar resultados diferentes, dependendo das condições de contorno e condições iniciais, foram estabelecidas as condições de contorno de Dirichlet, determinando-se fluxo normal à costa nulo (função de corrente constante no contorno sólido), para atender ao comportamento esperado das linhas de corrente na região de estudo. Os cálculos realizados para a elaboração dos mapas de função de corrente geostrófica baroclínica relativa, de função de corrente observada e de função de corrente geostrófica absoluta serão apresentados nos Capítulos 4, 5e 6, respectivamente. No presente capítulo, apresentaremos os principais conceitos teóricos que nortearam o desenvolvimento do trabalho.

\subsection{Geostrofia}

De acordo com Gill [1982], o nome geostrophic (geostrófico) se deve a Shaw (1916). Segundo Cushman-Roisin [1994], o termo geostrophic (geostrófico) é derivado das palavras gregas $\gamma \eta=$ "geo" (earth) e $\sigma \tau \rho o \varphi \eta=$ "strophe" (turn). Portanto, o termo geostrofia está relacionado ao movimento de rotação da Terra. O equilíbrio geostrófico é o balanço entre a força de Coriolis e a força de gradiente de pressão:

$$
\begin{aligned}
-f v_{g} & =-\frac{1}{\rho_{0}} \frac{\partial p}{\partial x} \Rightarrow v_{g}=\frac{1}{\rho_{0} f} \frac{\partial p}{\partial x} \\
f u_{g} & =-\frac{1}{\rho_{0}} \frac{\partial p}{\partial y} \Rightarrow u_{g}=-\frac{1}{\rho_{0} f} \frac{\partial p}{\partial y} .
\end{aligned}
$$

As Eqs. 3.1 e 3.2 correspondem às componentes zonal $\left(u_{g}\right)$ e meridional $\left(v_{g}\right)$ do vetor velocidade geostrófica $\vec{V}_{g}$, permitindo-nos concluir que o vetor $\vec{V}_{g}$ é perpendicu- 
lar ao vetor gradiente de pressão horizontal $\nabla_{H} p$ :

$$
\left(u_{g}, v_{g}\right) \perp\left(\frac{\partial p}{\partial x}, \frac{\partial p}{\partial y}\right) \quad \Rightarrow \quad \vec{V}_{g} \perp \nabla_{H} p \quad \Rightarrow \quad \vec{V}_{g}=\frac{1}{\rho_{0} f} \vec{k} \times \nabla_{H} p
$$

O fluxo geostrófico é caracterizado por um movimento ao longo das isóbaras [Tomczak E Godfrey, 1994]. Todo fluxo geostrófico é isobárico [Cushman-Roisin, 1994].

\subsection{Cálculo da Velocidade Geostrófica}

As velocidades geostróficas podem ser calculadas apenas de forma indireta, através da relação existente entre os gradientes de profundidade e as diferenças de geopotencial, que estão associadas aos campos de densidade. O geopotencial ( $\Phi$ ) é uma função escalar que corresponde à energia potencial do campo gravitacional terrestre, referente a uma parcela de massa unitária. A partir da anomalia do geopotencial $\Delta \Phi$ (função de $S, T$ e $p$ ), é possível calcular a velocidade geostrófica, através do método dinâmico. De acordo com Pond E Pickard [1983] temos a definição para a anomalia do geopotencial:

$$
\Delta \Phi=\int_{p_{0}}^{p} \delta d p
$$

onde $\delta$ é a anomalia do volume específico e $p_{0}$, o nível isobárico de referência.

\subsubsection{Método Dinâmico}

A corrente geostrófica é comumente calculada pelo método clássico, deduzido independentemente em 1903 pelos oceanógrafos físicos escandinavos, Johan Sandström e Bjorn Helland-Hansen, a partir do teorema da circulação de Bjerknes. Esse método, que posteriormente foi denominado Método Dinâmico e analisado criticamente por Fomin (1964), permite a estimativa das componentes do movimento geostrófico relativamente a superfícies isobáricas convenientemente selecionadas [Miranda \& Castro FiIho, 1979]. 
O método desenvolvido por Sandström e Helland-Hansen consiste na integração vertical da equação do vento térmico

$$
\frac{\partial \vec{V}_{g}}{\partial z}=-\frac{g}{\rho f} \vec{k} \times(\nabla \rho)
$$

permitindo inferir a componente baroclínica da velocidade geostrófica usando o campo de massa, calculado a partir dos dados de temperatura e salinidade. Considerando, então, a equação do vento térmico na forma escalar:

$$
\begin{aligned}
& \frac{\partial v_{g}}{\partial z}=-\frac{g}{\rho f} \frac{\partial \rho}{\partial x} \\
& \frac{\partial u_{g}}{\partial z}=\frac{g}{\rho f} \frac{\partial \rho}{\partial y} .
\end{aligned}
$$

Se tomarmos dois níveis $z$ e $-H_{0}$ (eixo $z$ apontando para cima e $z>-H_{0}$ ), correspondentes às pressões $p$ e $p_{0}$, respectivamente, teremos, para a componente meridional:

$$
\int_{-H_{0}}^{z} v_{g}=\int_{-H_{0}}^{z}-\frac{g}{\rho f} \frac{\partial \rho}{\partial x} d z \Rightarrow v_{g}(z)-v_{g}\left(-H_{0}\right)=-\frac{g}{\rho f} \int_{-H_{0}}^{z} \frac{\partial \rho}{\partial x} d z
$$

Expressando a Eq. 3.8 em termos da anomalia do geopotencial $(\Delta \Phi)$ :

$$
v_{g}(p)-v_{g}\left(p_{0}\right)=-\frac{1}{f} \int_{p_{0}}^{p} \frac{\partial \delta}{\partial x} d p \quad \Rightarrow \quad v_{g}(p)-v_{g}\left(p_{0}\right)=\frac{1}{f} \frac{\partial}{\partial x} \Delta \Phi
$$

O nível $p_{0}$ é o nível isobárico de referência (NR), correspondente a uma região em que a velocidade é muito pequena quando comparada à velocidade máxima. A rigor, o NR deve corresponder ao nível de movimento nulo. Nesse caso, o método é denominado Método Dinâmico Clássico (MDC). Quando o NR é um nível onde as velocidades são conhecidas (oriundas de ADCP, por exemplo), o método é denominado Método Dinâmico Referenciado (MDR). 
Para o caso do MDC, consideremos duas estações oceanográficas A e B separadas de uma distância $\Delta x$. Por meio da aproximação por acréscimos finitos de distância, podemos aplicar $\partial x \sim \Delta x$ na Eq. 3.9. obtendo então a equação da velocidade geostrófica baroclínica pelo MDC:

$$
v_{g}(p)=\frac{1}{f} \frac{\Delta \Phi_{B}-\Delta \Phi_{A}}{\Delta x}+\underbrace{v_{g}\left(p_{0}\right)}_{\sim 0} .
$$

A utilidade do Método Dinâmico Clássico tem sido demonstrada ao longo dos anos. Contudo, podemos citar duas desvantagens inerentes a esse método: a estimativa, nem sempre correta, de um nível de movimento nulo, e a determinação apenas da componente baroclínica da velocidade geostrófica.

\subsection{Função de Corrente Geostrófica}

A equação que relaciona a variação de densidade com o movimento é deduzida a partir do princípio da conservação de massa, sendo tradicionalmente denominada de equação da continuidade, por referir-se a uma propriedade intrínseca dos meios contínuos. Essa equação é de fundamental importância para o estudo de todos os problemas relacionados ao movimento dos fluidos [Miranda et al., 2002].

De acordo com Kundu [1990], a equação da continuidade para escoamentos bidimensionais é dada por

$$
\frac{\partial u}{\partial x}+\frac{\partial v}{\partial y}=0
$$

e garante a existência de uma função de corrente $\psi(x, y, t)$, que se relaciona com as componentes de velocidade através das equações

$$
u=-\frac{\partial \psi}{\partial y} \quad \text { e } \quad v=\frac{\partial \psi}{\partial x}
$$

Ao longo de uma linha de corrente, a derivada total da função de corrente é nula, ou seja, $\psi(x, y, t)=$ cte. A família de curvas $\psi(x, y, t)=$ cte. define as linhas de 
corrente representativas do escoamento. Combinando as Eqs. $3.1 \mathrm{e} 3.2$ com as equações definidas em 3.12 , obtemos:

$$
\begin{aligned}
& u_{g}=-\frac{1}{\rho_{0} f} \frac{\partial p}{\partial y}=-\frac{\partial}{\partial y}\left(\frac{p}{\rho_{0} f}\right)=-\frac{\partial \psi_{g}}{\partial y} \\
& v_{g}=\frac{1}{\rho_{0} f} \frac{\partial p}{\partial x}=\frac{\partial}{\partial x}\left(\frac{p}{\rho_{0} f}\right)=\frac{\partial \psi_{g}}{\partial x} .
\end{aligned}
$$

Ou na forma vetorial,

$$
\vec{V}_{g}=\vec{k} \times \nabla\left(\frac{p}{\rho_{0} f}\right)=\vec{k} \times \nabla \psi_{g}
$$

Considerando $\vec{V}_{g}$ expressa em coordenadas isobáricas:

$$
\vec{V}_{g}=\frac{g}{f} \vec{k} \times(\nabla z)_{p}=\frac{\vec{k}}{f} \times \nabla_{p} \Phi \Rightarrow\left\{\begin{array}{l}
v_{g}=\frac{1}{f} \frac{\partial \Delta \Phi}{\partial x} \\
u_{g}=-\frac{1}{f} \frac{\partial \Delta \Phi}{\partial y}
\end{array}\right.
$$

ao combinarmos as equações de $u_{g}$ e $v_{g}$ em 3.16 com as Eqs. 3.13 e 3.14. obtemos:

$$
\psi_{g}=\frac{p}{\rho_{0} f}=\frac{\Delta \Phi}{f} \equiv \text { função de corrente geostrófica. }
$$

O teorema de Helmholtz permite a separação do campo de velocidade em uma componente não-divergente (e rotacional, relacionada à função de corrente $\psi$ ) e uma componente irrotacional (e divergente, relacionada ao potencial de velocidade $\chi$ )

$$
\vec{V}=\vec{k} \times \nabla \psi+\nabla \chi
$$

Como os escoamentos analisados no presente trabalho estão em escalas que apresentam pequena divergência, considerou-se como negligenciável a componente 
irrotacional (divergente)

$$
\vec{V} \approx \vec{k} \times \nabla \psi
$$

A condição de não-divergência permite a utilização da propriedade física $\psi$ como ferramenta importante para análise dos escoamentos. Tendo em vista que os escoamentos analisados estão em escalas temporais e espaciais que se aproximam da geostrofia, foram calculados campos de função de corrente geostrófica em vários níveis, para obtenção de feições representativas dos escoamentos.

\subsubsection{Função de Corrente Geostrófica Absoluta}

Num oceano barotrópico, não há cisalhamento vertical da corrente geostrófica, significando que a velocidade é igual em toda a coluna d'água. A componente barotrópica da força de gradiente de pressão depende unicamente da elevação da superfície do mar. A componente barotrópica é responsável pela geração das correntes geostróficas barotrópicas.

A componente baroclínica da força de gradiente de pressão depende dos gradientes horizontais de densidade (avaliado a partir das propriedades termohalinas). Em campos baroclínicos, onde se considera a densidade variando horizontal e verticalmente, há cisalhamento vertical da corrente horizontal, ou seja, a velocidade varia ao longo da coluna d'água. A componente baroclínica é responsável pela geração das correntes geostróficas baroclínicas (vide Eq. 3.5.

Portanto, no oceano real devemos considerar, para a análise das correntes geostróficas, a existência da componente barotrópica e da componente baroclínica. Entretanto, correntes como as CCOs em um oceano tropical têm, em sua componente baroclínica, a maior parte da energia, devido à forte estratificação da coluna de água observada nestas latitudes. Por esse motivo, numerosos trabalhos descrevem esses escoamentos, quantitativamente ou qualitativamente, com base apenas na componente baroclínica.

A disponibilidade de dados de hidrografia e de dados de velocidade, coletados simultaneamente, possibilitou que realizássemos estimativas de circulação ge- 
ostrófica absoluta, através do MDR, com base na técnica desenvolvida por Sutton $\mathcal{E}$ Chereskin [2002]. Para tanto, foram calculados campos de função de corrente como base na seguinte expressão:

$$
\psi_{g_{a b s}}=\psi_{g}+\psi_{o b s}
$$

onde:

- $\psi_{g} \equiv$ função de corrente geostrófica baroclínica (dados de hidrografia);

- $\psi_{o b s} \equiv$ função de corrente observada (dados de velocidade de corrente);

- $\psi_{g_{a b s}} \equiv$ função de corrente geostrófica absoluta (somatório das outras duas).

Com base em princípios físicos da hidrodinâmica sabe-se que o transporte de volume e de massa são iguais ao volume e a massa de água que passa, por unidade de tempo, através de uma seção transversal [Miranda et al., 2002]. Os transportes de volume dos escoamentos analisados, considerando-se uma área de seção transversal A, foram calculados a partir da equação

$$
T_{V}=\iint_{A} \vec{V} \cdot \vec{n} d A
$$

onde $\overrightarrow{\boldsymbol{V}} \cdot \overrightarrow{\boldsymbol{n}}$ corresponde ao produto escalar entre o vetor velocidade do escoamento $(\vec{V})$ e o versor normal ao incremento de área $d A(\vec{n})$. 


\section{Capítulo 4}

\section{Padrões de Circulação Geostrófica Baroclínica Relativa}

\subsection{Preâmbulo}

Conforme comentamos no capítulo anterior, a disponibilidade de dados de hidrografia e de dados de velocidade de corrente possibilitou que realizássemos estimativas de velocidades geostróficas absolutas $\left(\vec{V}_{g_{a b s}}\right)$, através do MDR, com base na técnica desenvolvida por Sutton E Chereskin [2002]. No presente capítulo serão apresentados os padrões geostróficos obtidos através da aplicação do MDC, a partir dos dados de temperatura e salinidade das comissões ONEI e ONEII. Esses padrões foram obtidos com o intuito de serem comparados com padrões já existentes na literatura, particularmente os apresentados por Silveira et al. [1994]. Para tanto, foram elaboradas distribuições verticais de velocidade geostrófica baroclínica relativa $\left(\vec{V}_{g}\right)$ e distribuições horizontais de função de corrente geostrófica baroclínica relativa $\left(\psi_{g}\right)$, a partir da aplicação do MDC com NR = $1.150 \mathrm{~m}$. Esse NR, apesar de ligeiramente diferente do valor utilizado por Silveira et al. [1994], foi escolhido em função de representar a média da base da SNB observada por LADCP nos estudos de Stramma et al. [1995]. A seguir, iremos descrever os procedimentos metodológicos utilizados na elaboração das seções verticais de $\vec{V}_{\boldsymbol{g}}$ e na construção dos campos de $\boldsymbol{\psi}_{\boldsymbol{g}}$ para ambas as comissões, bem como os respectivos resultados e análises. 


\subsection{Metodologia}

Os perfis verticais de propriedades hidrográficas e de velocidade de corrente devem ser discretizados em um número finito de profundidades equidistantes entre a superfície e o fundo. Essa discretização pode ser feita por métodos de interpolação gráfica ou numérica, sendo este último preferível para minimizar erros e quando o número de perfis a serem reduzidos for muito grande [Miranda et al., 2002].

Os dados de hidrografia (temperatura e salinidade) das comissões ONEI e ONEII foram obtidos através de um perfilador CTD, que pode coletar dados tanto durante a descida quanto durante a subida. Normalmente são utilizados os dados de descida, tendo em vista que, durante a descida, a coluna de água encontra-se pouco influenciada pelo peso do instrumento. Consideramos, para o presente trabalho, o tratamento numérico e a análise dos dados de descida de ambas as comissões. Para obtenção dos resultados experimentais, realizamos os seguintes procedimentos:

1. Tratamento básico dos dados de hidrografia;

2. Cálculo de velocidade geostrófica baroclínica e elaboração de seções verticais de velocidade geostrófica baroclínica;

3. Construção de uma grade curvilinear;

4. Construção de mapas de função de corrente geostrófica baroclínica, através da interpolação dos dados sobre a grade curvilinear gerada, usando o método da Análise Objetiva (AO).

Esses procedimentos foram executados com base em programas desenvolvidos no ambiente MathWorks MATLAB e com o auxílio das sub-rotinas da biblioteca SEAWATER [Morgan, 1994], além de outras sub-rotinas deste software. Através desses programas, obtivemos valores de densidade, de volume específico e de anomalia do geopotencial, dentre outros. Esses procedimentos serão descritos a seguir. Na Seção 4.3. apresentaremos os resultados e discussões. 


\subsubsection{Tratamento Básico dos Dados de Hidrografia}

O processamento dos dados de temperatura e salinidade foi realizado de acordo com o documento UNESCO [1988], que estabelece os procedimentos para aquisição, calibração e análise de dados obtidos através de um perfilador CTD. São três os procedimentos realizados no tratamento básico dos dados:

- Eliminação de "Picos" (Spikes);

- Média em Caixas ou “Binagem" (Bin Averaging);

- Alisamento por Janela Móvel ou “Janelamento” (Windowing).

\section{Eliminação de "Picos" (Spikes)}

Erros "acidentais" ou spikes são resultantes de falha no equipamento, alterações de energia ou outras interrupções significativas no fluxo de dados [Emery $\mathcal{E}$ Thomson, 1998]. A eliminação de "picos" (spikes) consiste na remoção de ruídos aleatórios de grande intensidade. Esse procedimento é feito com um filtro simples que remove qualquer amostra que tem seu valor aumentado ou diminuído de 3 vezes ou mais o desvio padrão do trecho de $10 \mathrm{~m}$ de coluna de água que a envolve.

\section{Média em Caixas ou "Binagem" (Bin Averaging)}

Consiste em estabelecer o equi-espaçamento vertical dos dados, uma vez que a freqüência amostral do equipamento é constante, mas sua velocidade de perfilagem não é. Como a velocidade de descida do CTD é variável, os intervalos de profundidade em que os dados são coletados não são uniformes. Para um tratamento adequado dos dados, é necessário o estabelecimento de um intervalo regular de amostragem. Esse intervalo é obtido através de um processo denominado média em caixas. Como o perfilador CTD foi utilizado com freqüência de amostragem de $24 \mathrm{~Hz}$, e uma velocidade média de descida de $1 \mathrm{~m} \mathrm{~s}^{-1}$, podemos considerar que existem, em média, 24 amostras por metro. Estabelecendo-se, então, uma "caixa" de $\mathbf{1} \mathbf{~ m}$, obtemos a média de 24 valores, permitindo o equi-espaçamento vertical dos dados, com conseqüente alisamento do perfil. 


\section{Alisamento por Janela Móvel ou “Janelamento" (Windowing)}

A aplicação de uma função janela deslizante faz com que cada bloco de dados analisado compartilhe uma certa quantidade de dados com seus blocos vizinhos, garantindo-se que haja alguma relação entre os blocos adjacentes. Esse procedimento resulta em uma variação suave dos valores do sinal. O espectro do sinal janelado é a convolução do espectro do sinal original com o espectro da janela. A Janela aplicada foi a do tipo Hanning. O tamanho da janela espectral (N) é determinado em função da profundidade local, de forma a não alterar os gradientes verticais básicos do perfil. Foram adotados os seguintes valores para o tamanho da janela (N ímpar):

$-\mathrm{N}=5$, para profundidades até $100 \mathrm{~m}$;

- $\mathrm{N}=11$, para profundidades entre 100 e $500 \mathrm{~m}$;

$-\mathrm{N}=21$, para profundidades superiores a $500 \mathrm{~m}$.

Após o tratamento básico dos dados, foram construídos perfis de temperatura $(T)$, salinidade $(S)$, densidade in situ $(\sigma)$ e densidade potencial $\left(\sigma_{\theta}\right)$, bem como seções verticais de $T, S$ e $\sigma_{\theta}$, para visualização da coerência dos dados. Os valores de densidade foram inferidos a partir dos dados termohalinos, através da equação de estado da água do mar. As seções verticais de $T, S$ e $\sigma_{\theta}$ foram obtidas a partir de interpolação linear. A assinatura da SNB pôde ser notada nessas seções, verificando-se a intensificação das isohalinas nas proximidades da margem continentental e início do talude. A Figura 4.1 representa os primeiros $100 \mathrm{~m}$ dos perfis de temperatura e salinidade referentes à estação hidroceanográfica $n^{\circ} 42$ da comissão ONEI, exemplificando os resultados obtidos após o tratamento básico dos dados, e a Figura 4.2, referente à mesma estação, representa o perfil de $\sigma_{\theta}$.

Um dos objetivos específicos do presente trabalho foi o de elaborar seções verticais de velocidade geostrófica absoluta referenciada por dados de ADCP de casco, nas proximidades das latitudes de $5^{\circ} \mathrm{S}$ e $11^{\circ} \mathrm{S}$, onde existem informações pretéritas na literatura [Stramma et al., 1995; Schott et al., 2005]. Para tanto, analisamos mais detalhadamente as distribuições verticais de $T, S$ e $\sigma_{\theta}$ referentes aos dados das radiais 1 ( $\left.11^{\circ} \mathrm{S}\right)$ e $5\left(\sim 5^{\circ} \mathrm{S}\right)$, de ambas as comissões. As Figuras 4.3 e 4.4 representam as seções verticais de $T, S$ e $\sigma_{\theta}$, referentes às radiais 1 e 5 da comissão ONEI, respectivamente. 

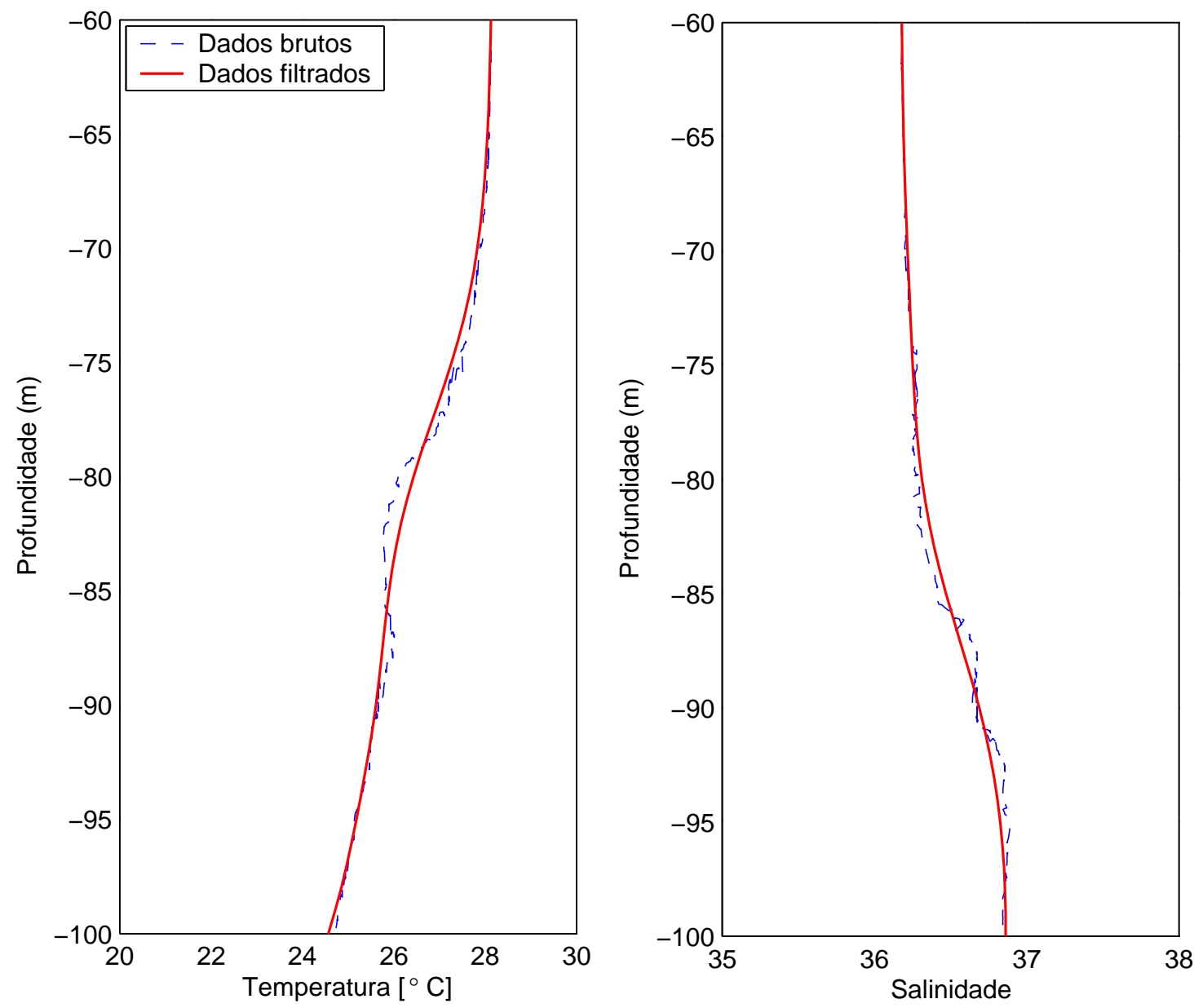

Figura 4.1: Detalhe dos primeiros $100 \mathrm{~m}$ dos perfis de $T$ (painel esquerdo) e $S$ (painel direito) referentes à estação $\mathrm{n}^{\circ} 42$ (ONEI), sendo mostrado os dados brutos (linha tracejada azul) e os dados filtrados (linha vermelha contínua), exemplificando os resultados obtidos após o tratamento básico dos dados. A profundidade máxima amostrada na estação foi de $2.337 \mathrm{~m}$.

Figura 4.2: Perfil de densidade potencial $\left(\sigma_{\theta}\right)$, parâmetro derivado dos dados de $T$ e $S$ resultantes do processamento, referente à estação hidroceanográfica ${ }^{\circ} 42$ da comissão ONEI.

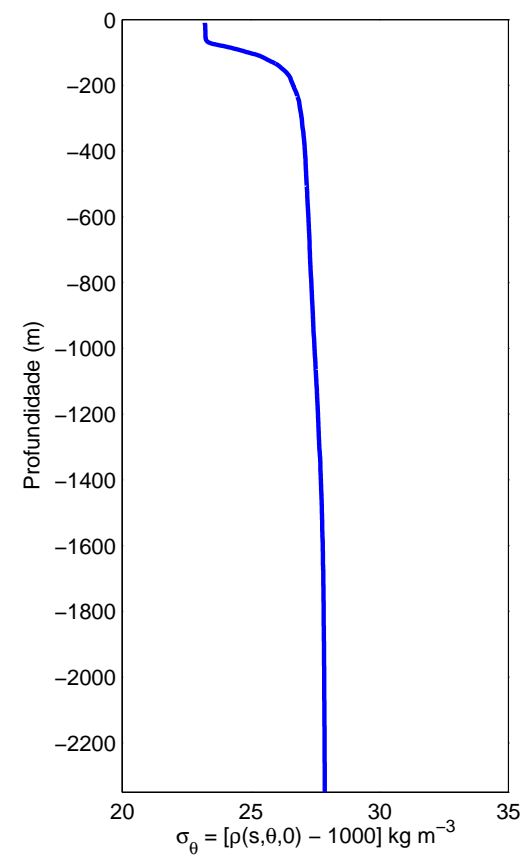



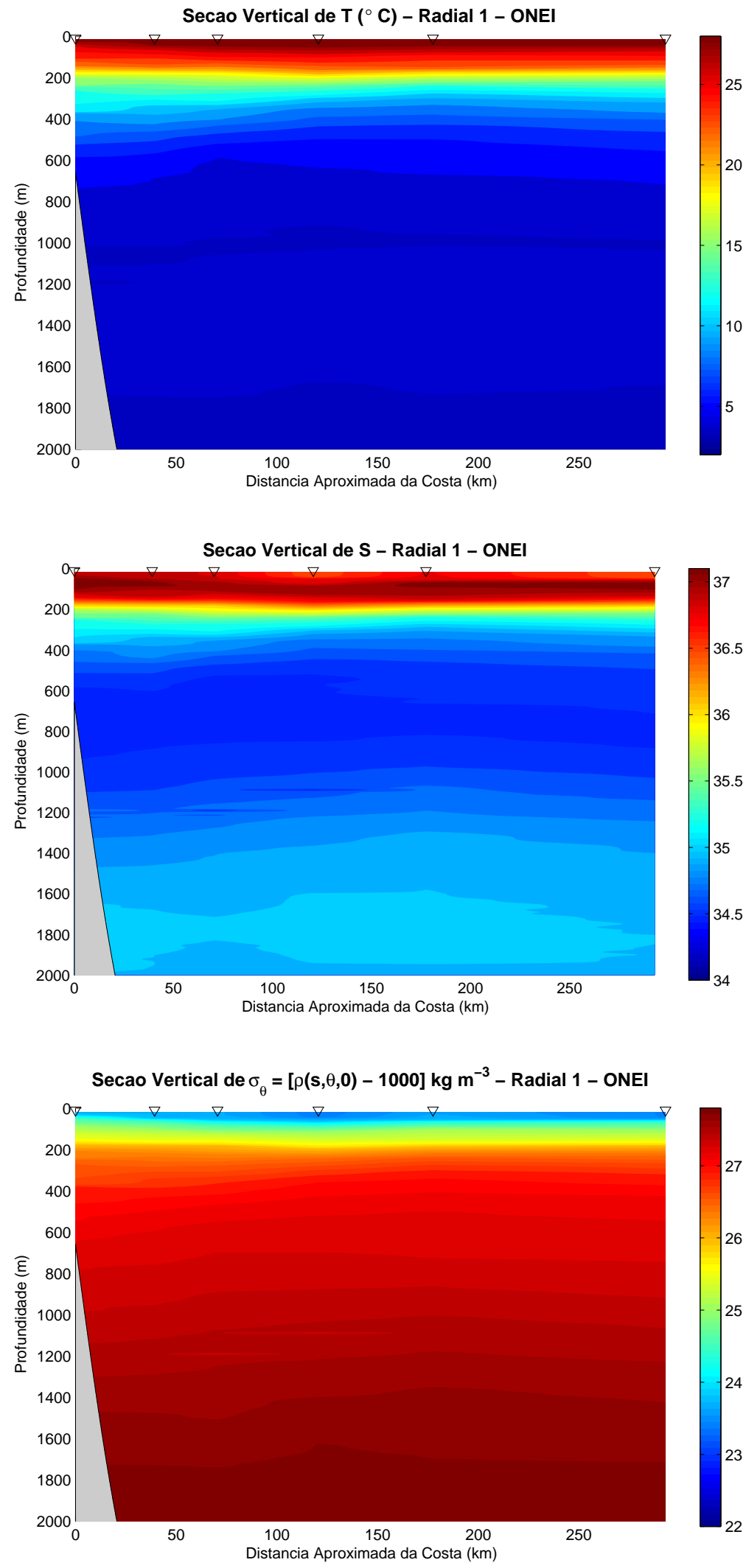

Figura 4.3: Seções verticais de $T, S$ e $\sigma_{\theta}$ até $2.000 \mathrm{~m}$ de profundidade, referentes à radial 1 da comissão ONEI. Os triângulos na parte superior de cada seção indicam as estações hidroceanográficas. 

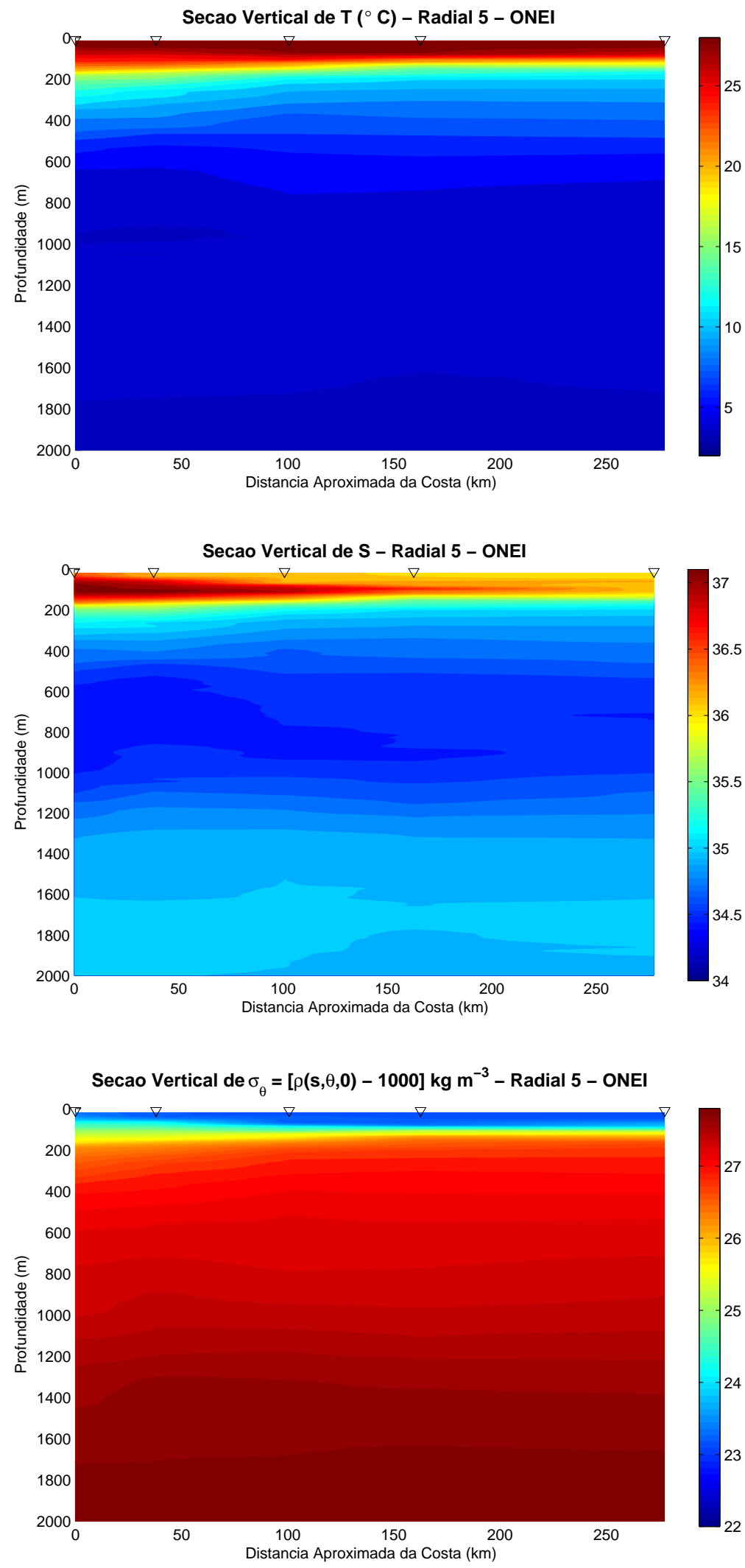

Figura 4.4: Seções verticais de $T, S$ e $\sigma_{\theta}$ até $2.000 \mathrm{~m}$ de profundidade, referentes à radial 5 da comissão ONEI. Os triângulos na parte superior de cada seção indicam as estações hidroceanográficas. 


\subsubsection{Cálculo de Velocidade Geostrófica Baroclínica Relativa}

A partir do processamento dos dados de temperatura e salinidade, obtivemos valores de anomalia do geopotencial $(\Delta \Phi)$ que foram aplicados na Eq. 3.10 apresentada na Seção 3.3 do Capítulo 3 , para o cálculo das velocidades geostróficas baroclínicas relativas $\left(\vec{V}_{g}\right)$. Foram descartadas todas as estações com profundidades inferiores a 250 $\mathrm{m}$, para se evitar erros de extrapolação do geopotencial.

As velocidades geostróficas baroclínicas relativas foram calculadas através do MDC com um NR = $1.150 \mathrm{~m}$, valor igual ao utilizado nos estudos de Stramma et al. [1995], correspondente à base média da SNB observada por esses autores através de dados de LADCP.

\subsubsection{Gradeamento e Interpolação}

As interpolações dos dados de temperatura e salinidade, bem como dos valores de função de corrente, para a elaboração das distribuições horizontais, foram feitas sobre grades curvilineares, construídas através do programa seagrid. O seagrid é uma aplicação do software MATLAB que permite a construção de grades curvilineares ortogonais, adequadas para mapeamentos de dados oceanográficos. Foram construídas duas grades, uma para cada comissão hidroceanográfica, sendo uma grade 30 x 50 pontos para a comissão ONEI e uma grade $30 \times 60$ pontos para a comissão ONEII. A Figura 4.5 representa as grades curvilineares construídas para as duas comissões.

\subsubsection{Mapas de Função de Corrente Geostrófica Baroclínica Relativa}

Os valores de $\Delta \Phi$ resultantes do processamento dos dados, foram aplicados na Eq. 3.17, definida na Seção 3.4 do Capítulo 3, para a construção dos campos de função de corrente geostrófica baroclínica $\left(\psi_{g}\right)$. Para a construção dos mapas de $\psi_{g}$ sobre as grades curvilineares geradas, realizou-se a interpolação dos dados através de uma técnica estatística denominada Análise Objetiva (AO), descrita no contexto oceanográfico primeiramente por Bretherton et al. [1976]. 
GRADE DE INTERPOLACAO - OCEANO NE I (FEV-MAR/2002)

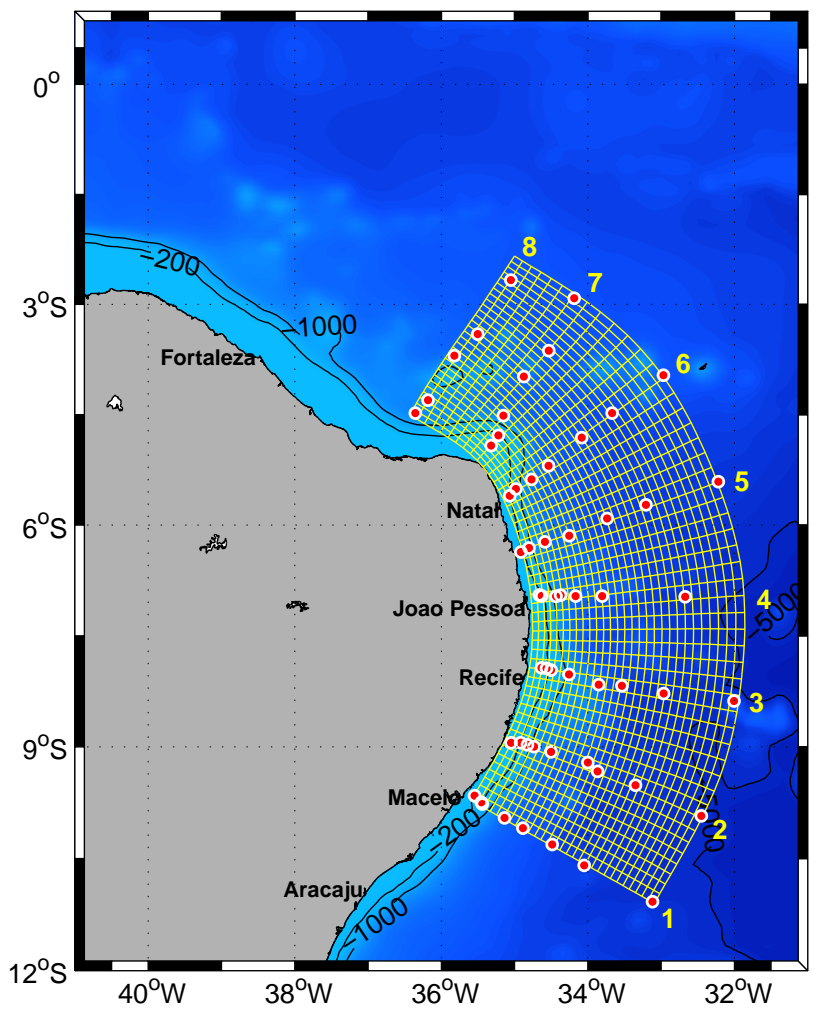

GRADE DE INTERPOLACAO - OCEANO NE II (OUT-DEZ/2004)

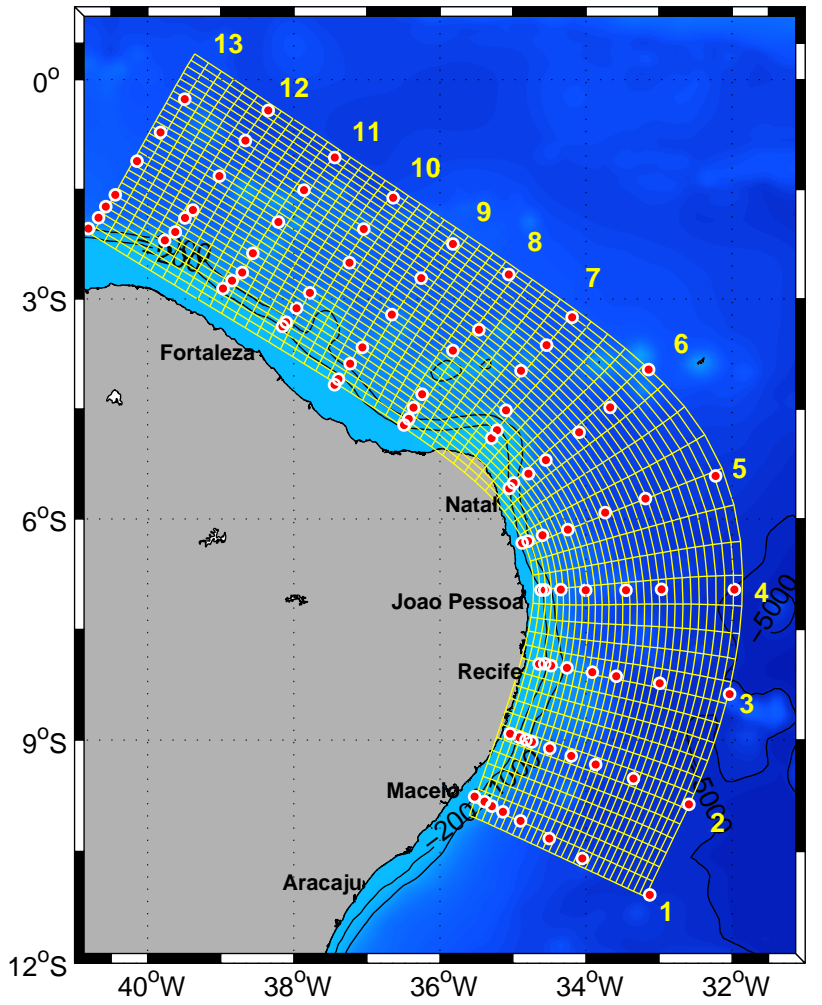

Figura 4.5: Grades curvilineares usadas na interpolação dos dados para elaboração das distribuições horizontais dos dados termohalinos e das funções de corrente, referente às comissões ONEI e ONEII. 
A AO é baseada no Teorema de Gauss-Markov, sendo geralmente usada para mapear dados não-uniformemente espaçados em uma grade regularmente espaçada [Emery E Thomson, 1998]. O método da AO caracteriza-se como um estimador ótimo, apresentando, por tanto, as seguintes características:

- é não tendencioso: a média estimada é igual à média real;

- é consistente: a estimativa melhora se aumentarmos o conjunto de dados;

- minimiza a variância;

- é suficiente: toda a informação é oriunda dos dados.

O uso da função gaussiana como função de correlação se deve ao seu formato, que condiz com a maioria das variáveis presentes na natureza e que possuem uma distribuição normal. A associação linear entre duas variáveis é avaliada usando-se a correlação.

Dois parâmetros estatísticos são fundamentais para a aplicação da AO: a variância do erro $\left(\epsilon^{2}\right)$ e o comprimento de correlação $\left(l_{c}\right)$. A variância do erro é um parâmetro de qualidade de filtragem que indica o quanto o valor de um ponto sobre a grade, coincidentemente localizado sobre uma estação, diverge do valor medido. $\mathrm{O}$ comprimento de correlação indica o quanto a distância entre as estações e um ponto sobre a grade influencia nesse ponto. Quanto maior $l_{c}$, maior a filtragem espacial.

De acordo com Carter $\mathcal{E}$ Robinson [1987], a AO corresponde a um ajuste linear por mínimos quadrados, onde as funções-peso dependem da correlação entre os dados e entre esses e os pontos de grade estabelecidos.

Podemos considerar uma função de correlação de acordo com a função de correlação gaussiana anisotrópica apresentada por Silveira et al. [2004], seguindo os fundamentos de AO descritos por Carter E Robinson [1987]:

$$
C(\Delta x, \Delta y)=\left(1-\epsilon^{2}\right) e^{-\left[\frac{(\Delta x)^{2}}{l_{x}^{2}}+\frac{(\Delta y)^{2}}{l_{y}^{2}}\right]},
$$

onde $\Delta x$ e $\Delta y$ corresponderiam aos incrementos de grade nas direções zonal e meridional, respectivamente, $l_{x}$ e $l_{y}$ os comprimentos de correlação e $\epsilon^{2}$ a variância do erro amostral aleatório. 
Como os escoamentos analisados possuem isotropia horizontal relevante, é comum a simplificação da Eq. 4.1 para uma forma isotrópica:

$$
C(r)=\left(1-\epsilon^{2}\right) e^{-r^{2} / l_{c}^{2}}
$$

onde $r=\sqrt{x^{2}+y^{2}}$ e $l_{c}$ é o comprimento de correlação horizontal na direção radial [Silveira et al., 2000a].

Os parâmetros $\epsilon^{2}$ e $l_{c}$ podem ser determinados, basicamente, de duas formas:

- (1) a partir do ajuste não-linear da função de correlação amostral à forma teórica, no caso dada pela Eq. 4.2; ou

- (2) através do conhecimento prévio da estrutura do campo investigado e das principais feições que se quer realçar. Nesse caso, são explorados diversos valores para os parâmetros, resultando em distribuições horizontais distintas. Após avaliação, são escolhidos os parâmetros e os mesmos são impostos à análise objetiva. Esse método é usualmente referido como "Análise Objetiva a priori".

Neste trabalho, os parâmetros foram obtidos através do procedimento (1). Devese ressaltar a subjetividade inerente ao procedimento (2), que pode resultar em feições irreais. Da mesma forma, cumpre observar a limitação de caráter metodológico associada ao caso (1), pois nem sempre a correlação apresentada entre os dados observados e os estimados respeita aquela assumida como gaussiana pelas Eqs. $4.1 \mathrm{e} 4.2$.

Com relação ao problema dos valores de contorno, Silveira et al. [2000a] propõem que as condições de contorno de Dirichlet sejam aplicadas durante o processo de mapeamento através da inclusão de "pseudo-dados" no esquema de interpolação por AO. Para tanto, a matriz com as coordenadas da isóbata da profundidade que se deseja mapear e valores de $\psi_{g}=0$ no contorno são adicionados à matriz contendo as coordenadas das estações e os valores de $\psi_{g}$ calculados relativamente ao NR.

Outra vantagem da AO é permitir a obtenção de mapas de erros (raiz quadrada de $\epsilon^{2}$ ) associados ao processo de interpolação. Cumpre ressaltar que o mapa de erro resultante da $\mathrm{AO}$ fornece um erro teórico, tendo em vista que o mesmo é construído com base nos parâmetros escolhidos para a AO. 
Os valores encontrados para os parâmetros variância do erro e comprimento de correlação, referentes aos dados hidrográficos da comissão ONEI, foram $\epsilon^{2}=0,2678$ e $l_{c} \approx 1,13^{\circ} \approx 125,2 \mathrm{~km}$. A Figura 4.6 representa a função de correlação gaussiana isotrópica referente à comissão ONEI, calculada de acordo com a Eq. 4.2.

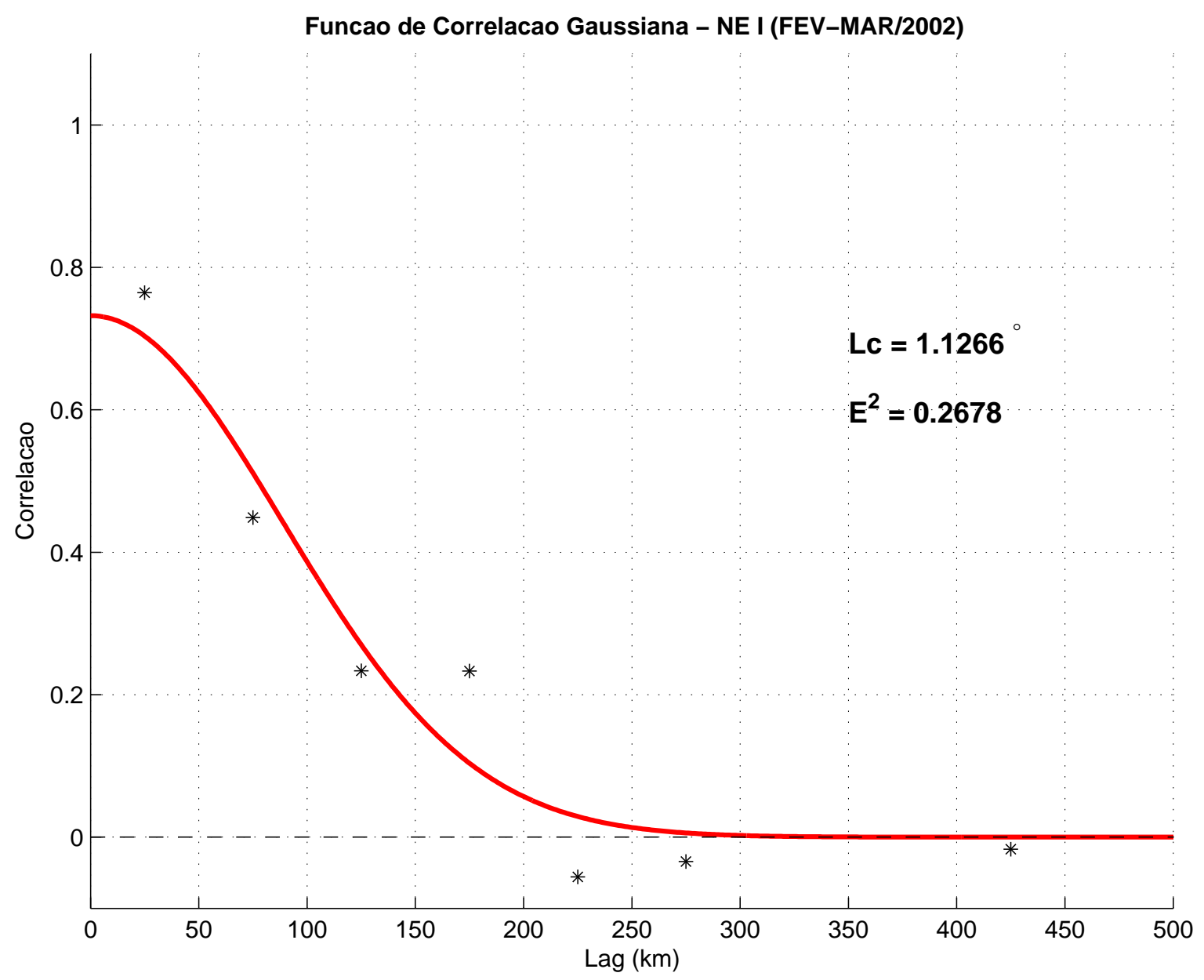

Figura 4.6: Função de correlação gaussiana isotrópica (linha vermelha), calculada de acordo com a Eq. 4.2 , e os valores de variância do erro $\left(\epsilon^{2}\right)$ e comprimento de correlação $\left(l_{c}\right)$, relativos aos dados hidrográficos da comissão ONEI $\left(\epsilon^{2}=0,2678\right.$ e $\left.l_{c} \approx 1^{\circ} \approx 125 \mathrm{~km}\right)$. 


\subsection{Resultados e Discussão}

Com o intuito de obtermos uma descrição sinótica dos padrões horizontal e vertical de escoamento da SNB ao largo da costa do nordeste, bem como de outras estruturas de mesoescala associadas à SNB, foram elaboradas distribuições verticais de velocidade geostrófica baroclínica relativa $\left(\vec{V}_{g}\right)$ e construídos campos de função de corrente geostrófica baroclínica relativa $\left(\psi_{g}\right)$ a partir dos dados de temperatura e salinidade das comissões ONEI e ONEII. A partir das distribuições verticais de $\vec{V}_{g}$, foram calculados os respectivos valores de transporte de volume e de velocidade máxima. Os transportes de volume foram calculados através da Eq. 3.21 apresentada na Seção 3.4 do Capítulo 3. Os valores de $\vec{V}_{g}$ foram obtidos a partir do MDC, com NR $=1.150 \mathrm{~m}$, para ambas as comissões.

Um dos objetivos específicos do presente trabalho foi o de obter uma descrição da circulação observada, associada ao escoamento da SNB, através da elaboração de distribuições verticais de velocidade medida por ADCP de casco, nas proximidades das latitudes de $5^{\circ} \mathrm{S}$ e $11^{\circ} \mathrm{S}$. Por esse motivo, analisamos mais detalhadamente as distribuições verticais de $\vec{V}_{g}$ referentes aos dados das radiais $1\left(\sim 11^{\circ} \mathrm{S}\right)$ e $5\left(\sim 5^{\circ} \mathrm{S}\right)$ das comissões em análise, comparando-as com as duas seções de controle apresentadas nos estudos de Schott et al. [2005] (vide Figura 1.6).

\subsubsection{Seções Verticais de Velocidade Geostrófica - ONEI e ONEII}

A SNB é uma corrente de contorno oeste tendendo, portanto, a acompanhar o contorno da margem continental. O cálculo do transporte de volume é realizado mediante a possibilidade de a velocidade não ser perpendicular à seção, pois a variação na projeção do vetor em relação à seção é compensada pela variação na área da seção. A assinatura da SNB pôde ser constatada na maioria das seções verticais de ambas as comissões. Ao analisarmos essas seções, verificamos a intensifição dessa corrente nas seções mais ao norte, com aumento de seu transporte e velocidade. Verificamos também o posicionamento de seu núcleo cada vez mais raso ao longo do seu deslocamento para norte.

A Tabela 4.1 apresenta os valores de transporte de volume (Sv) e de velocidade 
máxima $\left(\mathrm{m} \mathrm{s}^{-1}\right)$ das seções verticais de $\vec{V}_{g}(\mathrm{MDC}$ com $\mathrm{NR}=1.150 \mathrm{~m})$ correspondentes às radiais 1 e 5 das comissões ONEI e ONEII. A Tabela 4.2 apresenta valores resultantes dos estudos de Silveira et al. [1994], correspondendo aos valores de transporte de volume (Sv) e de velocidade máxima $\left(\mathrm{m} \mathrm{s}^{-1}\right.$ ) das seções verticais de $\vec{V}_{g}$ (MDC com NR $=1.000 \mathrm{~m}$ ), referentes às radiais 1 e 12 da comissão NEIII analisada por esses autores. Os valores das comissões em análise, constantes da Tabela 4.1, corroboram os valores apresentados por Silveira et al. [1994].

Tabela 4.1: Valores de transporte de volume (Sv) e de velocidade máxima $\left(\mathrm{m} \mathrm{s}^{-1}\right)$ das seções de velocidade geostrófica baroclínica relativa (MDC com NR $=1.150 \mathrm{~m}$ ), referentes às radiais 1 e 5 das comissões ONEI e ONEII.

\begin{tabular}{|c|c|c|c|}
\hline \multicolumn{4}{|c|}{ "Velocidade Geostrófica - Comissão ONEI } \\
\hline \multirow[b]{2}{*}{ Radial } & \multicolumn{2}{|c|}{ Transportes (Sv) } & \multirow[b]{2}{*}{ Velocidade $\left(\mathrm{m} \mathrm{s}^{-1}\right)$} \\
\hline & $0-500 \mathrm{~m}$ & $0-1.000 \mathrm{~m}$ & \\
\hline $1\left(\sim 11^{\circ} \mathrm{S}\right)$ & 24,4 & 29,9 & 0,64 \\
\hline $5\left(\sim 5^{\circ} S\right)$ & 14,5 & 16,9 & 0,96 \\
\hline \multicolumn{4}{|c|}{ Velocidade Geostrófica - Comissão ONEII } \\
\hline & \multicolumn{2}{|c|}{ Transportes (Sv) } & \\
\hline Radial & $0-500 \mathrm{~m}$ & $0-1.000 \mathrm{~m}$ & Velocidade $\left(\mathrm{m} \mathrm{s}^{-1}\right)$ \\
\hline $1\left(\sim 11^{\circ} \mathrm{S}\right)$ & 21,4 & 26,9 & 1,09 \\
\hline $5\left(\sim 5^{\circ} S\right)$ & 17,2 & 21,2 & 0,98 \\
\hline
\end{tabular}

Tabela 4.2: Valores de transporte de volume (Sv) e de velocidade máxima $\left(\mathrm{m} \mathrm{s}^{-1}\right)$ das seções de velocidade geostrófica baroclínica relativa (MDC com NR $=1.000 \mathrm{~m}$ ), referentes às radiais 1 e 12 da comissão NEIII analisada por Silveira et al. [1994].

\begin{tabular}{ccccc}
\hline \hline & & \multicolumn{2}{c}{ Transportes $(\mathrm{Sv})$} & \\
\cline { 3 - 4 } Radial & Estação Mais a Oeste & $0-500 \mathrm{~m}$ & $0-1.000 \mathrm{~m}$ & Velocidade $\left(\mathrm{m} \mathrm{s}^{-1}\right)$ \\
\hline 1 & $10^{\circ} 30^{\prime} \mathrm{S} ; 36^{\circ} 00^{\prime} \mathrm{W}$ & 18,9 & 23,7 & 0,50 \\
12 & $04^{\circ} 48^{\prime} \mathrm{S} ; 34^{\circ} 48^{\prime} \mathrm{W}$ & 21,8 & 24,9 & 1,00 \\
\hline
\end{tabular}


As Figuras 4.7 e 4.8 representam as seções verticais de $\vec{V}_{g}$ referentes, respectivamente, às radiais $1\left(\sim 11^{\circ} \mathrm{S}\right)$ e $5\left(\sim 5^{\circ} \mathrm{S}\right)$ da comissão ONEI. As Figuras 4.9 e 4.10 representam as seções verticais de $\vec{V}_{g}$ referentes, respectivamente, às radiais $1\left(\sim 11^{\circ} \mathrm{S}\right)$ e $5\left(\sim 5^{\circ} \mathrm{S}\right)$ da comissão ONEII.

Na Figura 4.7 (radial 1, ONEI), podemos constatar a presença da SNB com núcleo de subsuperfície em aproximadamente $300 \mathrm{~m}$, a uma distância aproximada da costa de $55 \mathrm{~km}$. Os valores de transporte de volume encontrados para essa seção, nas profundidades de $0-500 \mathrm{~m}$ e $0-1.000 \mathrm{~m}$ foram, respectivamente, de 24,4 Sv e 29,9 Sv. O valor de velocidade máxima encontrado foi de $0,64 \mathrm{~m} \mathrm{~s}^{-1}$ (Tabela 4.1).

Na Figura 4.8 (radial 5, ONEI), podemos constatar que a SNB apresenta uma configuração com núcleo de subsuperfície em aproximadamente 100 m, a uma distância aproximada da costa de $20 \mathrm{~km}$. Entretanto, claramente a corrente não foi amostrada em sua totalidade. Os valores de transporte de volume encontrados para essa seção, nas profundidades de $0-500 \mathrm{~m}$ e $0-1.000 \mathrm{~m}$ foram, respectivamente, de 14,5 Sv e 16,9 Sv. O valor de velocidade máxima encontrado foi de $0,96 \mathrm{~m} \mathrm{~s}^{-1}$ (Tabela 4.1).

Tanto na Figura 4.7 quanto na Figura 4.8 podemos observar a diminuição da velocidade do escoamento da SNB em direção à superfície, sendo que a taxa de decaimento da velocidade em direção à superfície é maior que a taxa de decaimento em direção ao fundo.

Na Figura 4.9 (radial 1, ONEII), podemos constatar a presença da SNB com núcleo de subsuperfície em aproximadamente 300 m, a uma distância aproximada da costa de $20 \mathrm{~km}$. Os valores de transporte de volume encontrados para essa seção, nas profundidades de $0-500 \mathrm{~m}$ e $0-1.000 \mathrm{~m}$ foram, respectivamente, de 21,4 Sv e 26,9 Sv. O valor de velocidade máxima encontrado foi de 1,09 $\mathrm{m} \mathrm{s}^{-1}$ (Tabela 4.1).

Na Figura 4.10 (radial 5, comissão ONEII), podemos constatar que a SNB apresenta uma configuração com núcleo de subsuperfície em aproximadamente 150 m, a uma distância aproximada da costa de $45 \mathrm{~km}$. Os valores de transporte de volume encontrados para essa seção, nas profundidades de $0-500 \mathrm{~m}$ e $0-1.000 \mathrm{~m}$ foram, respectivamente, de 17,2 Sv e 21,2 Sv. O valor de velocidade máxima encontrado foi de $0,98 \mathrm{~m} \mathrm{~s}^{-1}$ (Tabela 4.1). 

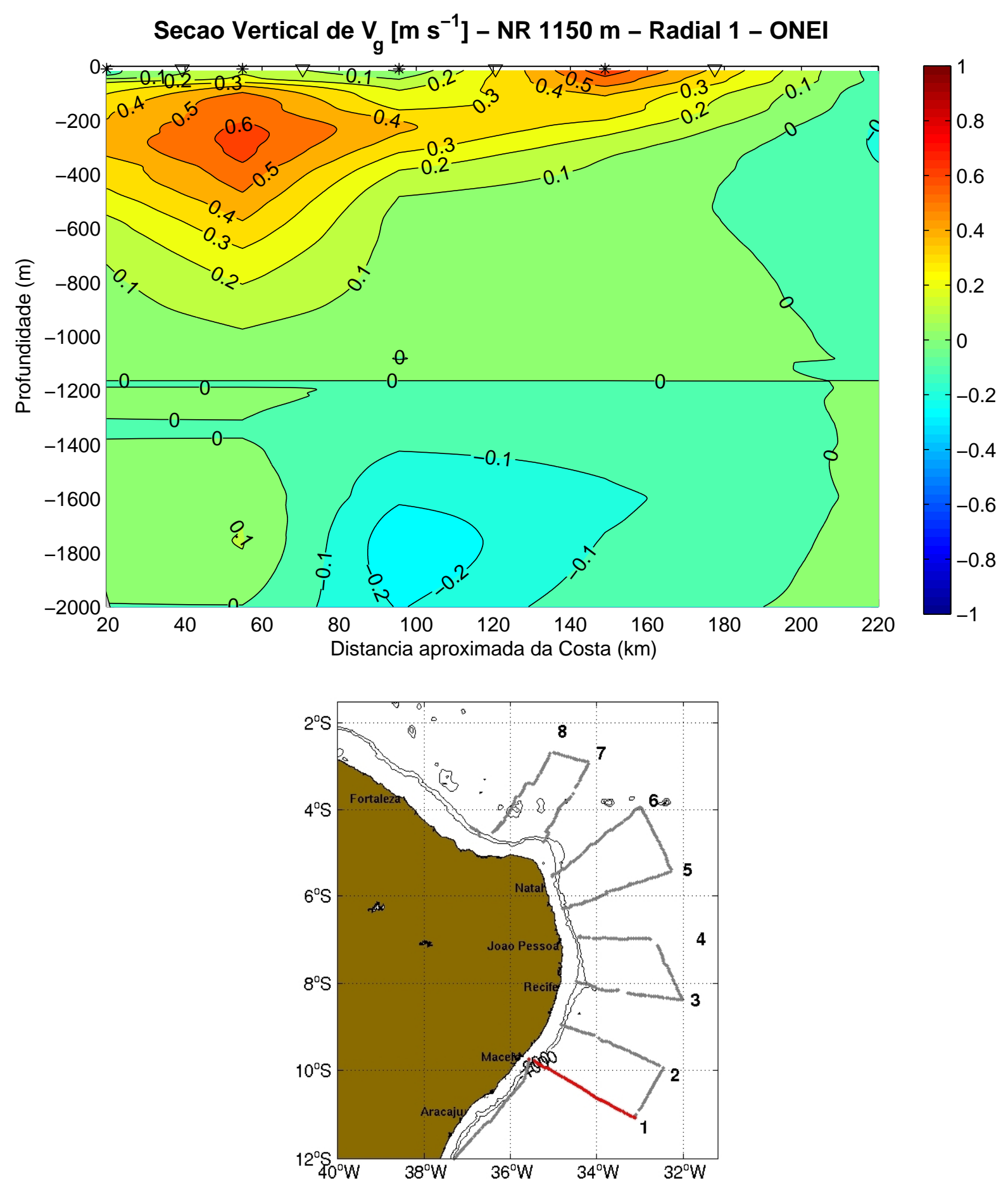

Figura 4.7: Seção vertical de velocidade de corrente geostrófica baroclínica $\left(\vec{V}_{g}\right)$, obtida a partir do MDC, com NR $=1.150 \mathrm{~m}$, referente à radial $1\left(\sim 11^{\circ} \mathrm{S}\right)$ da comissão ONEI. Os triângulos na parte superior da seção indicam as estações oceanográficas e os asteriscos, os pontos médios entre estações, para os quais são calculados as velocidades geostróficas. O intervalo entre as isotacas é de $0,1 \mathrm{~m} \mathrm{~s}^{-1}$. Valores positivos para norte. 

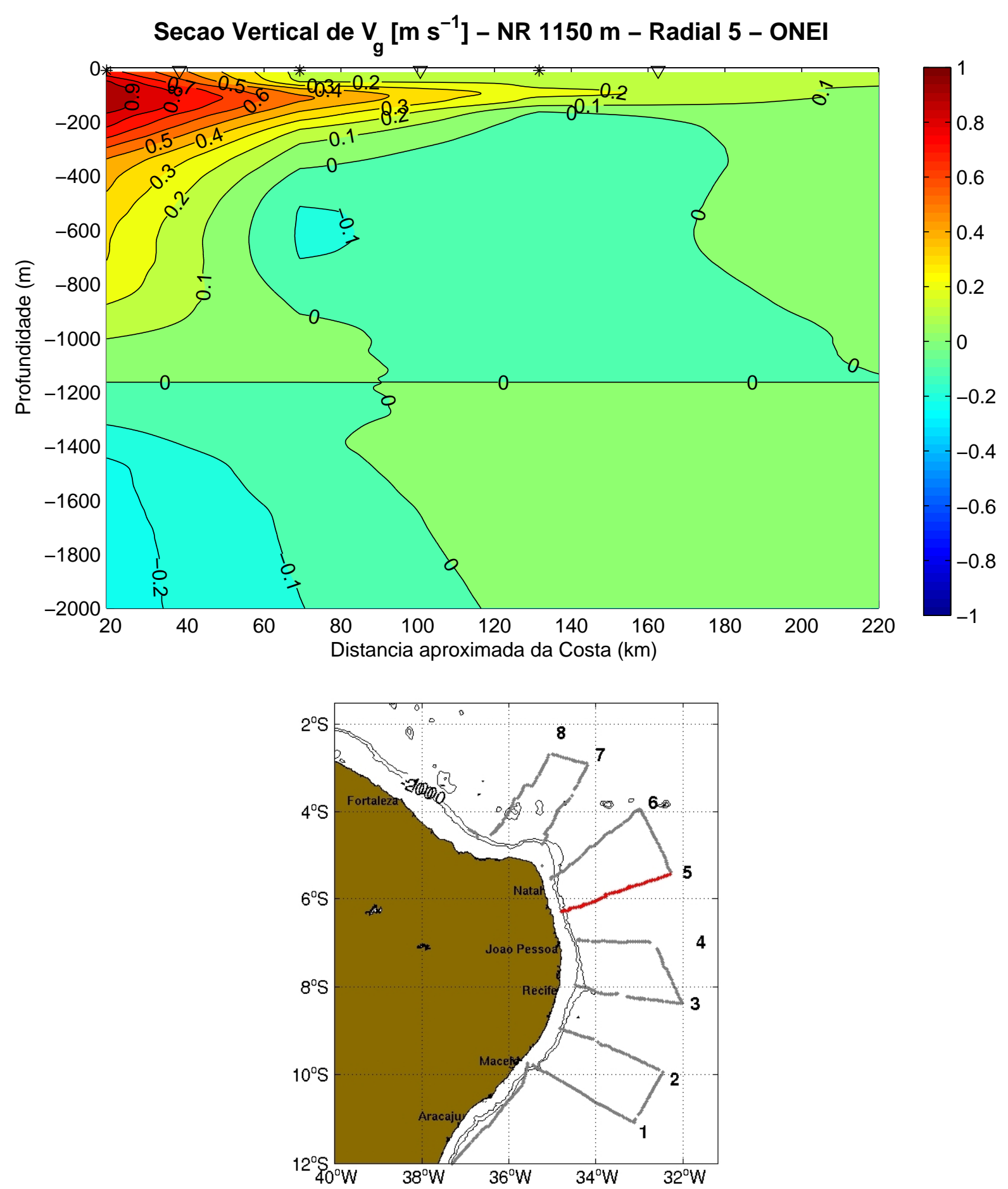

Figura 4.8: Seção vertical de velocidade de corrente geostrófica baroclínica $\left(\vec{V}_{g}\right)$, obtida a partir do MDC, com NR $=1.150 \mathrm{~m}$, referente à radial $5\left(\sim 5^{\circ} \mathrm{S}\right)$ da comissão ONEI. Os triângulos na parte superior da seção indicam as estações oceanográficas e os asteriscos, os pontos médios entre estações, para os quais são calculados as velocidades geostróficas. O intervalo entre as isotacas é de $0,1 \mathrm{~m} \mathrm{~s}^{-1}$. Valores positivos para norte. 

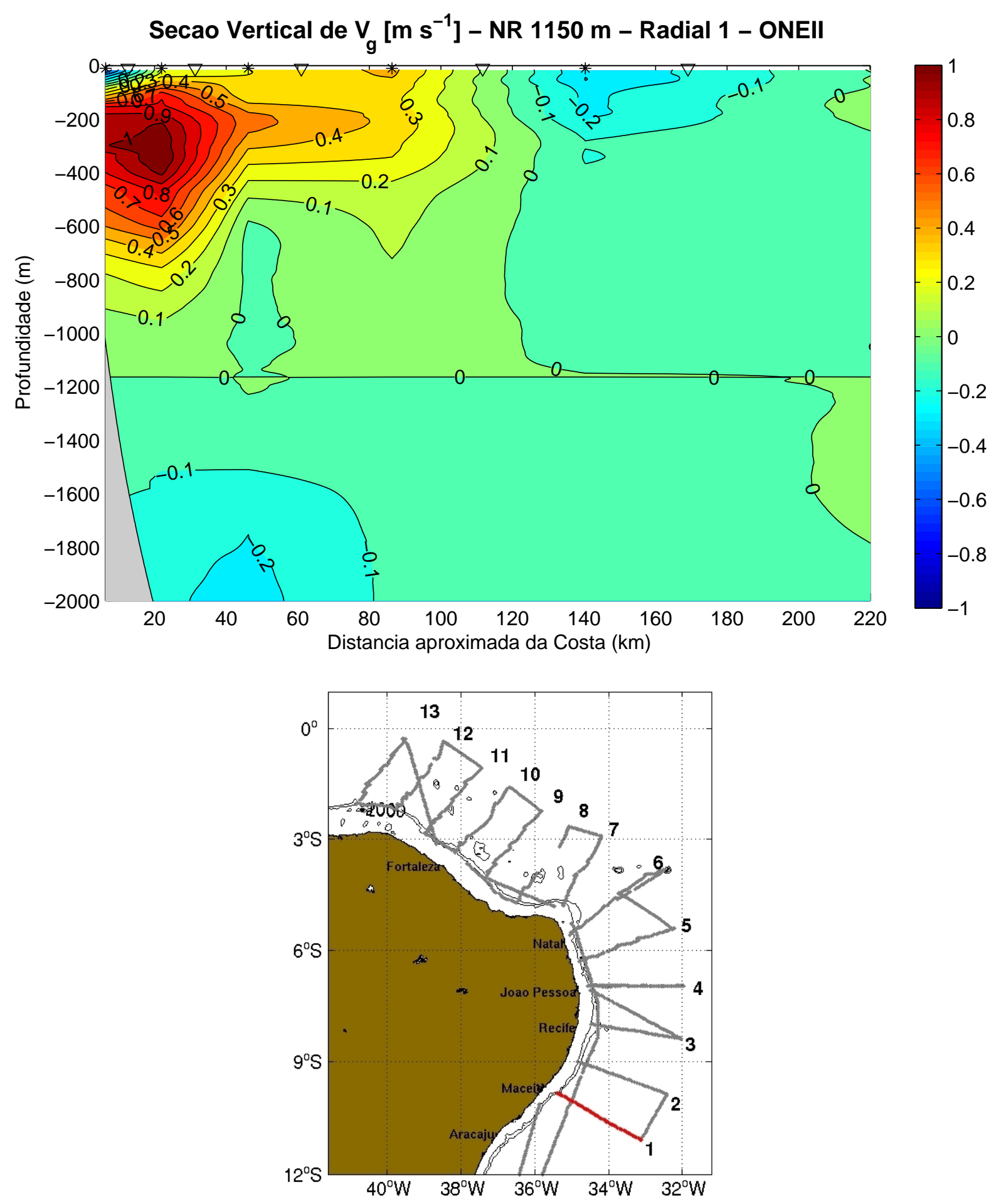

Figura 4.9: Seção vertical de velocidade de corrente geostrófica baroclínica $\left(\vec{V}_{g}\right)$, obtida a partir do $\mathrm{MDC}$, com NR $=1.150 \mathrm{~m}$, referente à radial $1\left(\sim 11^{\circ} \mathrm{S}\right)$ da comissão ONEII. Os triângulos na parte superior da seção indicam as estações oceanográficas e os asteriscos, os pontos médios entre estações, para os quais são calculados as velocidades geostróficas. O intervalo entre as isotacas é de $0,1 \mathrm{~m} \mathrm{~s}^{-1}$. Valores positivos para norte. 

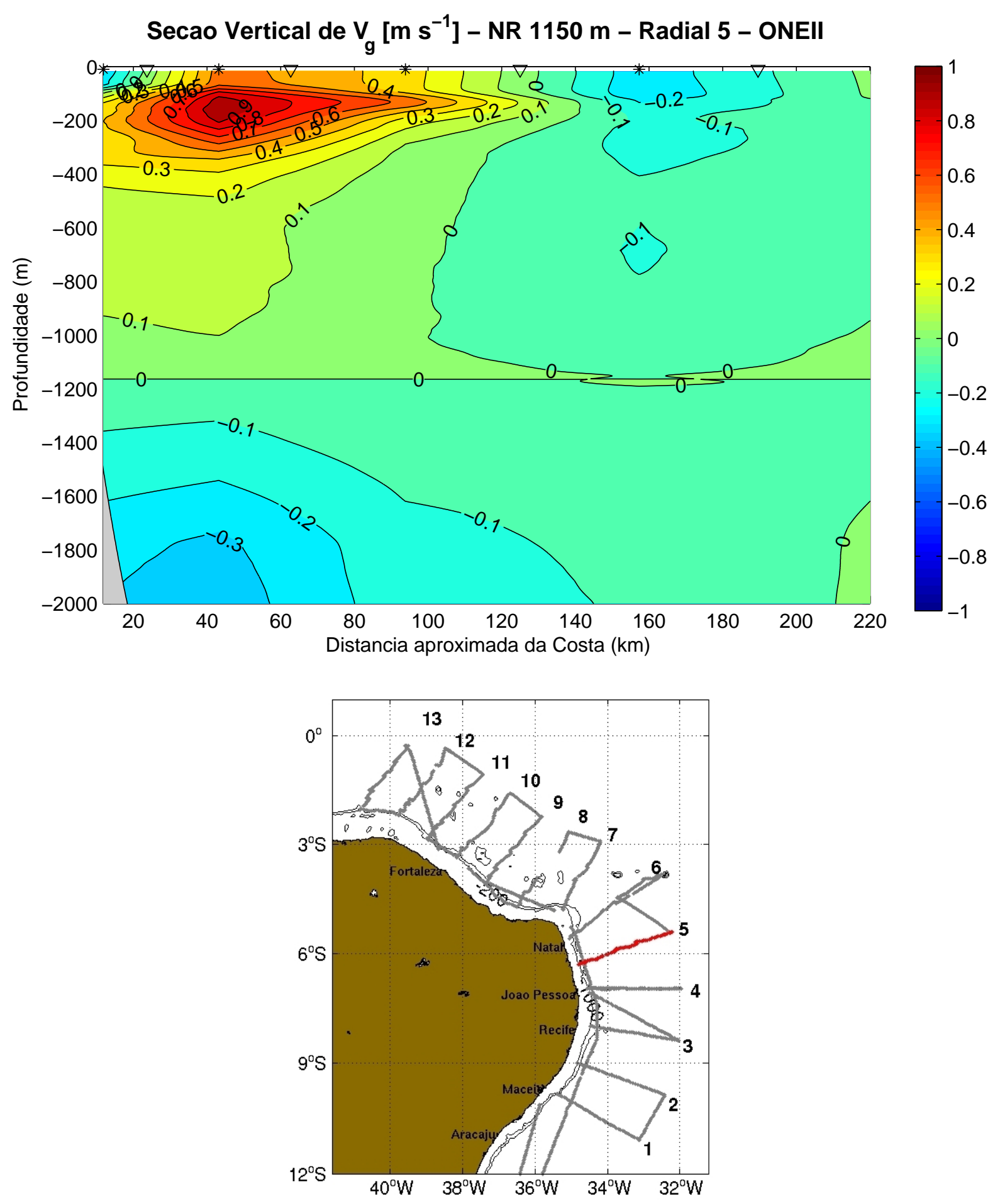

Figura 4.10: Seção vertical de velocidade de corrente geostrófica baroclínica $\left(\vec{V}_{g}\right)$, obtida a partir do $\mathrm{MDC}$, com NR $=1.150 \mathrm{~m}$, referente à radial $5\left(\sim 5^{\circ} \mathrm{S}\right)$ da comissão ONEII. Os triângulos na parte superior da seção indicam as estações oceanográficas e os asteriscos, os pontos médios entre estações, para os quais são calculados as velocidades geostróficas. O intervalo entre as isotacas é de $0,1 \mathrm{~m} \mathrm{~s}^{-1}$. Valores positivos para norte. 
Da mesma forma que o constatado para as radiais 1 e 5 da comissão ONEI, também observamos nas Figuras $4.9 \mathrm{e} 4.10$, referentes à comissão ONEII, que a velocidade da SNB diminui em direção à superfície, com taxa de decaimento em direção à superfície maior que a em direção ao fundo. Nestas figuras observamos ainda um escoamento estreito fluindo para sul, próximo à costa, entre 0 e $100 \mathrm{~m}$ de profundidade, além de um escoamento para sul entre 0 e $1.000 \mathrm{~m}$ de profundidade, com núcleo em aproximadamente $100 \mathrm{~m}$, a uma distância aproximada da costa de $160 \mathrm{~km}$.

Os valores de transporte obtidos para as comissões em análise (Tabela 4.1), referentes à assinatura da SNB, são bem próximos dos valores referentes às distribuições geostróficas apresentadas por Silveira et al. [1994] e dos valores referentes às distribuições verticais obtidas a partir de dados de LADCP por Stramma et al. [1995].

$\mathrm{O} \mathrm{NR}=1.150 \mathrm{~m}$ utilizado no presente trabalho, correspondente ao NR utilizado por Stramma et al. [1995], parece ser de fato conveniente para representar a SNB a partir de sua componente geostrófica baroclínica. Tanto assim que nos foi possível comparar os valores de transporte geostróficos com as médias seccionais obtidas por Schott et al. [2005] a partir de dados de LADCP. Esses autores encontraram valores de transporte para a SNB de $26,5 \pm 3,7 \mathrm{~Sv}$, para a seção de $5^{\circ} \mathrm{S}$, e de $25,4 \pm 7,4 \mathrm{~Sv}$, para a seção de $11^{\circ}$ S. Ao observarmos os valores da Tabela 4.1, constatamos que os transportes calculados para as duas seções de controle se encontram dentro da faixa de valores calculados por Schott et al. [2005].

Os padrões verticais geostróficos obtidos no presente trabalho se assemelham aos padrões apresentados por Silveira et al. [1994]. Entretanto, cumpre observar que os resultados obtidos mostram um processo de afloramento do núcleo da SNB entre $5^{\circ}$ $\mathrm{S}$ e $11^{\circ} \mathrm{S}$ não relatado pelos autores supracitados (vide Figura 1.4). A semelhança dos padrões verticais, bem como os valores de transporte encontrados no presente trabalho e os da literatura, encorajam-nos a proceder a análise dos padrões horizontais na seção a seguir. 


\subsubsection{Mapas de Função de Corrente Geostrófica - ONEI e ONEII}

Foram elaboradas distribuições horizontais de $\psi_{g}$ para os níveis de $32 \mathrm{~m}, 100 \mathrm{~m}$, 160 e $200 \mathrm{~m}$, referentes às velocidades $\vec{V}_{g}$ calculadas pelo MDC com NR $=1.150 \mathrm{~m}$, a partir dos dados termohalinos das comissões em análise. Nos mapas de $\psi_{g}$ de ambas as comissões, pôde-se observar o escoamento da SNB acompanhando o contorno da margem continental e, ocasionalmente, meandrando. Com relação à comissão ONEII, a existência de radiais mais ao norte possibilitou a descrição da SNB numa área mais ampla, abrangendo a região ao norte de $5^{\circ} \mathrm{S}$, região sobre a qual há controvérsia na literatura a respeito da caracterização da CNB e SNB. Os mapas de $\psi_{g}\left(\mathrm{~m}^{2} \mathrm{~s}^{-1}\right)$ referentes à comissão ONEI são apresentados nas Figuras 4.11 (níveis de $32 \mathrm{~m}$ e $100 \mathrm{~m}$ ) e 4.12 (níveis de $160 \mathrm{~m}$ e $200 \mathrm{~m}$ ). Os mapas de $\psi_{g}\left(\mathrm{~m}^{2} \mathrm{~s}^{-1}\right)$ referentes à comissão ONEII são apresentados nas Figuras 4.13 (níveis de $32 \mathrm{~m}$ e $100 \mathrm{~m}$ ) e 4.14 (níveis de $160 \mathrm{~m}$ e $200 \mathrm{~m}$ ).

Com relação à Figura 4.11, no mapa de $\psi_{g}$ para o nível de $32 \mathrm{~m}$, podemos constatar a presença de um meandramento entre as latitudes de $4^{\circ} \mathrm{S}$ e $6^{\circ} \mathrm{S}$ e a de um anticiclone entre as latitudes de $6^{\circ} \mathrm{S}$ e $8^{\circ} \mathrm{S}$, estando essas feições entre as longitudes de $32^{\circ} \mathrm{W}$ e $34^{\circ} \mathrm{W}$ indicando, possivelmente, a bifurcação do ramo central da CSE (CSEc). Nesse mapa podemos observar também um ciclone entre as latitudes de $7^{\circ} \mathrm{S}$ e $9^{\circ} \mathrm{S}$ e entre as longitudes de $33^{\circ} \mathrm{W}$ e $34^{\circ} \mathrm{W}$, correspondendo, provavelmente, ao ramo sul da CSEs girando no sentido horário, alimentando a SNB. No mapa de $\psi_{g}$ para o nível de $100 \mathrm{~m}$ (Figura 4.11), bem como nos mapas para os níveis de $160 \mathrm{~m}$ e $200 \mathrm{~m}$ da Figura 4.12. podemos observar um ciclone entre as latitudes de $4^{\circ} \mathrm{S}$ e $7^{\circ} \mathrm{S}$ e entre as longitudes de $32^{\circ} \mathrm{W}$ e $34^{\circ} \mathrm{W}$, correspondendo, provavelmente, ao ramo central da CSE (CSEc) alimentando a SSE, que também é alimentada pela SNB. Estes resultados corroboram os estudos de Silveira et al. [1994].

Nos quatro mapas de $\psi_{g}$ da comissão ONEI, ao observarmos o escoamento da SNB após contornar o Cabo Calcanhar (RN), verificamos a presença de um possível anticiclone centrado em aproximadamente $4^{\circ} 30^{\prime} \mathrm{S}$ e $36^{\circ} \mathrm{W}$. Essa feição pode ser resultante da resposta do escoamento da SNB à mudança de orientação da costa, com parte da SNB se dirigindo para o equador e parte da SNB tendendo a acompanhar o contorno da costa.

No mapa de $\psi_{g}$ da Figura 4.13 , para o nível de 32 m, o padrão da SNB é similar 
ao encontrado no mapa de $\psi_{g}$ da comissão ONEI para o mesmo nível. Entretanto, não se observa a assinatura do ramo central da CSE (CSEc). Além disso, esse mapa difere um pouco do padrão encontrado por Silveira et al. [1994], pois o anticiclone que demarca a bifurcação se apresenta mais fraco e parece que a maior parte da CSEc segue para N - NE ao norte de $6^{\circ} \mathrm{S}$. O mapa de $\psi_{g}$ para o nível de $100 \mathrm{~m}$ se assemelha ao mapa de $32 \mathrm{~m}$. Quanto aos mapas de $\psi_{g}$ para os níveis de $160 \mathrm{~m}$ e $200 \mathrm{~m}$, os padrões se assemelham aos observados nos mapas de $\psi_{g}$ da comissão ONEI para os mesmos níveis, com separação de parte da SSE em $4^{\circ} \mathrm{S}-5^{\circ} \mathrm{S}$, exatamente como descrito por Silveira et al. [1994]. A representação esquemática de Stramma E England] [1999], apresentada na Figura ??, sugere que a SSE é formada a partir de uma deflexão do ramo equatorial da CSE (CSEe). Nos padrões geostróficos obtidos para ambas as comissões, é fato que a SNB origina a SSE dominantemente.

Nos quatro mapas de $\psi_{g}$ da comissão ONEII, observamos que a SNB, ao contornar o Cabo Calcanhar (RN), em torno de $5^{\circ} \mathrm{S}$, parece se afastar da costa por inércia, sendo observado um anticiclone frontal, de forma semelhante ao observado nos quatro mapas de $\psi_{g}$ da comissão ONEI, porém com uma assinatura mais robusta e completa. Essa feição não foi ainda descrita na literatura e merece ser confirmada por evidências de medições diretas de ADCP, as quais serão apresentadas no capítulo a seguir. 
$\psi_{g}\left[m^{2} s^{-1}\right]-$ AO - NR $1150 m-$ prof $32 \mathrm{~m}$ - ONEI

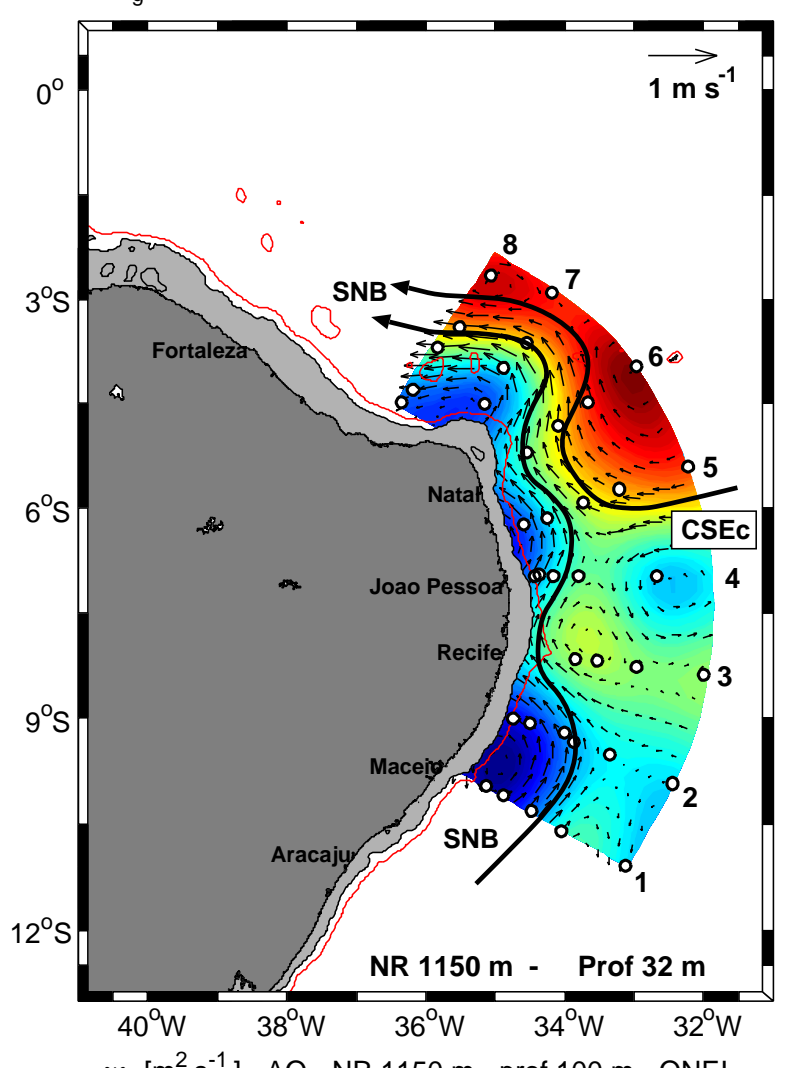

$\psi_{\mathrm{g}}\left[\mathrm{m}^{2} \mathrm{~s}^{-1}\right]-\mathrm{AO}-\mathrm{NR} 1150 \mathrm{~m}-$ prof $100 \mathrm{~m}$ - ONEI

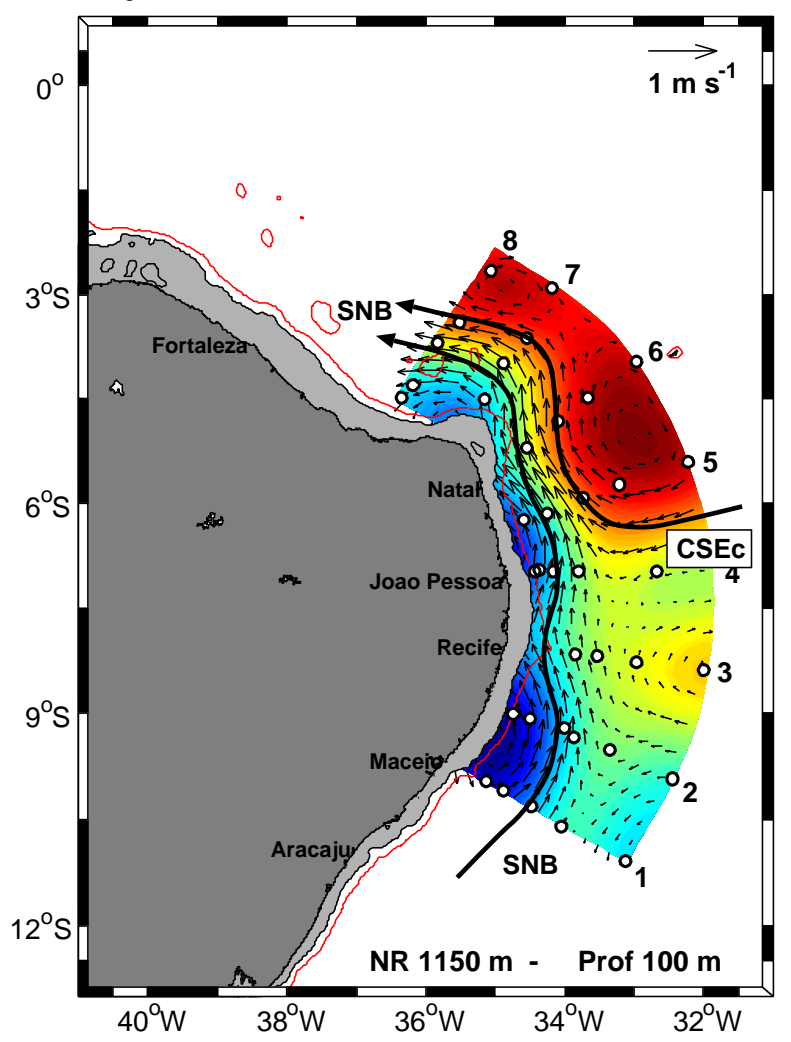

Figura 4.11: Mapas de função de corrente geostrófica baroclínica $\left(\psi_{g}\right)$ para os níveis de $32 \mathrm{~m}$ e $100 \mathrm{~m}$, referentes às velocidades calculadas pelo $\mathrm{MDC}$, com NR $=1.150 \mathrm{~m}$, a partir dos dados da comissão ONEI. Os vetores de velocidade $\left(\mathrm{m} \mathrm{s}^{-1}\right)$ estão sobrepostos aos campos de $\psi_{g}$. A máscara cinza junto à costa representa a região sobre a plataforma continental limitada pela isóbata de $100 \mathrm{~m}$ (contorno dinâmico). Linha vermelha: isóbata de $1000 \mathrm{~m}$. 

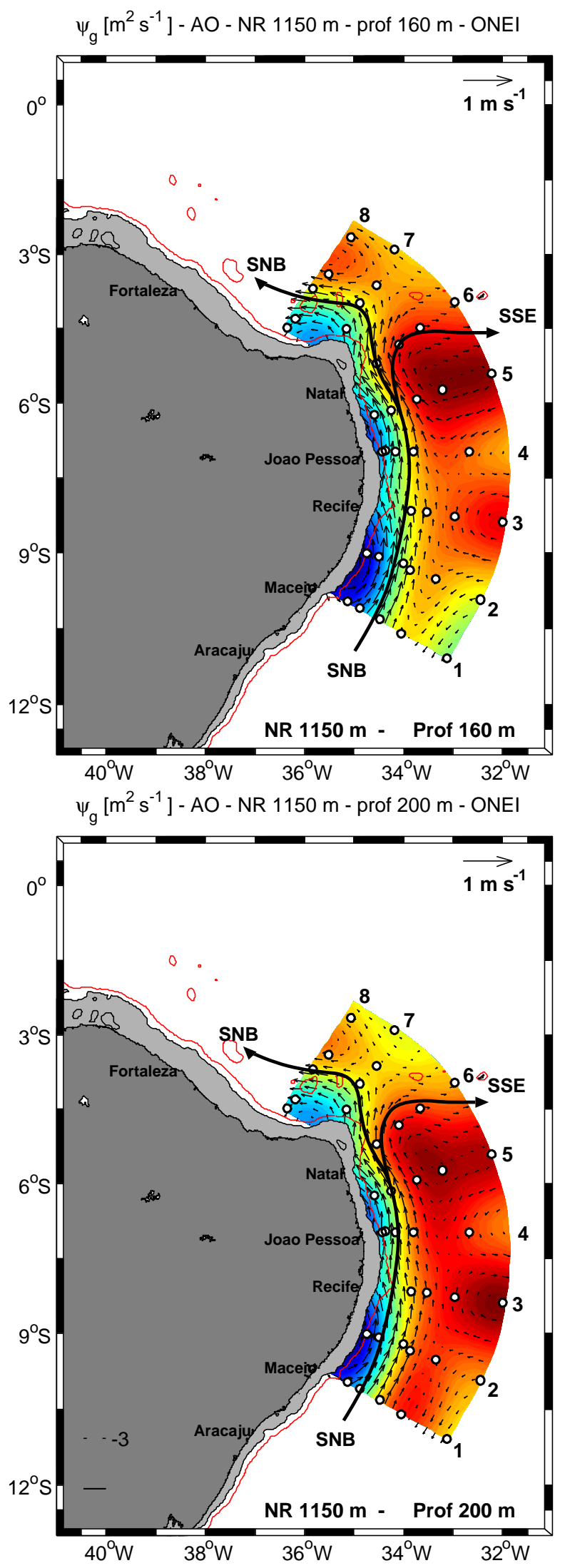

Figura 4.12: Mapas de função de corrente geostrófica baroclínica $\left(\psi_{g}\right)$ para os níveis de $160 \mathrm{~m}$ e $200 \mathrm{~m}$, referentes às velocidades calculadas pelo MDC, com NR $=1.150 \mathrm{~m}$, a partir dos dados da comissão ONEI. Os vetores de velocidade $\left(\mathrm{m} \mathrm{s}^{-1}\right)$ estão sobrepostos aos campos de $\psi_{g}$. A máscara cinza junto à costa representa a região sobre a plataforma continental limitada pela isóbata de $100 \mathrm{~m}$ (contorno dinâmico). Linha vermelha: isóbata de $1.000 \mathrm{~m}$. 

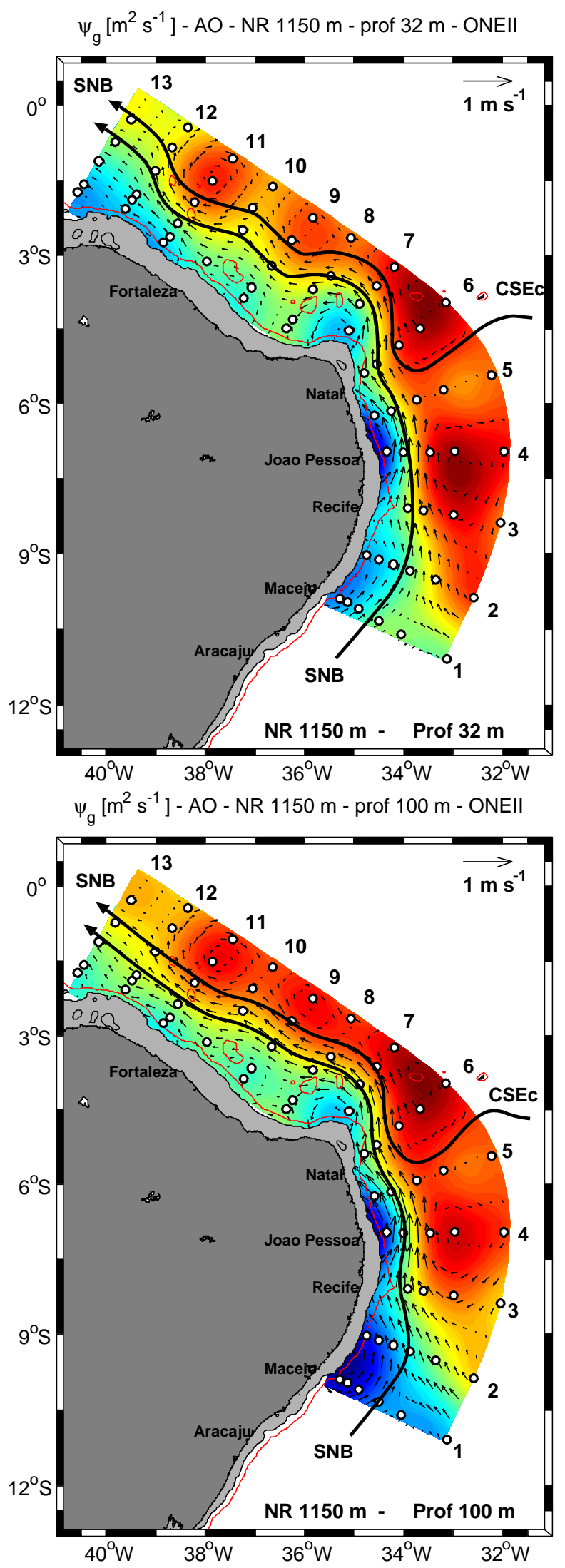

Figura 4.13: Mapas de função de corrente geostrófica baroclínica $\left(\psi_{g}\right)$ para os níveis de $32 \mathrm{~m}$ e $100 \mathrm{~m}$, referentes às velocidades calculadas pelo $\mathrm{MDC}$, com NR $=1.150 \mathrm{~m}$, a partir dos dados da comissão ONEII. Os vetores de velocidade $\left(\mathrm{m} \mathrm{s}^{-1}\right)$ estão sobrepostos aos campos de $\psi_{g}$. A máscara cinza junto à costa representa a região sobre a plataforma continental limitada pela isóbata de $100 \mathrm{~m}$ (contorno dinâmico). Linha vermelha: isóbata de $1.000 \mathrm{~m}$. 

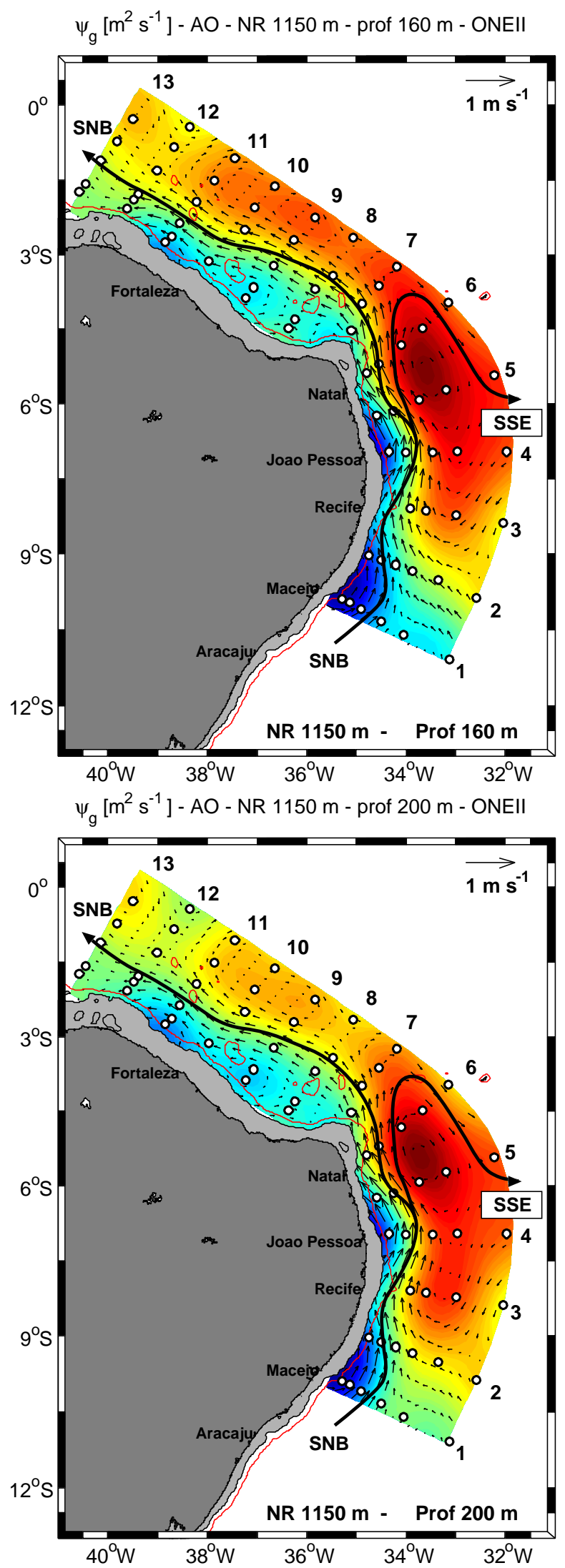

Figura 4.14: Mapas de função de corrente geostrófica baroclínica $\left(\psi_{g}\right)$ para os níveis de $160 \mathrm{~m}$ e $200 \mathrm{~m}$, referentes às velocidades calculadas pelo MDC, com NR $=1.150 \mathrm{~m}$, a partir dos dados da comissão ONEII. Os vetores de velocidade $\left(\mathrm{m} \mathrm{s}^{-1}\right)$ estão sobrepostos aos campos de $\psi_{g}$. A máscara cinza junto à costa representa a região sobre a plataforma continental limitada pela isóbata de $100 \mathrm{~m}$ (contorno dinâmico). Linha vermelha: isóbata de $1.000 \mathrm{~m}$. 


\section{Capítulo 5}

\section{Padrões de Circulação Derivados de}

\section{ADCP}

\subsection{Preâmbulo}

Os dados de ADCP das comissões ONEI e ONEII possibilitaram a aplicação do MDR para a obtenção de campos de velocidades geostróficas absolutas $\left(\vec{V}_{g_{a b s}}\right)$, com base na técnica desenvolvida por Sutton E Chereskin [2002]. Apesar de o modelo de ADCP RDI BroadBand $75 \mathbf{~ k H z}$ poder realizar perfilagens até cerca de $560-700 \mathrm{~m}$ constatamos, nos conjunto de dados de ambas as comissões, informações apenas até as profundidades de $464 \mathrm{~m}$ (ONEI) e $288 \mathrm{~m}$ (ONEII). O tratamento dos dados de velocidade foi realizado utilizando-se o pacote de programas de processamento contidos no sistema CODAS (Common Ocean Data Access System), que será detalhado na Seção 5.2 do presente capítulo. Na aplicação do MDR, buscou-se um nível suficientemente profundo para garantir o domínio da geostrofia, tendo sido escolhido o nível de 160 $\mathrm{m}$ para ambas as comissões, equivalente a, aproximadamente, duas vezes a média dos valores de profundidade média da camada de Ekman $\left(h_{E}\right)$ calculados para as comissões em análise. No presente capítulo, iremos descrever os procedimentos metodológicos utilizados na elaboração das seções verticais de velocidade observada $\left(\vec{V}_{\text {obs }}\right)$ e na construção dos campos de função de corrente observada $\left(\psi_{\text {obs }}\right)$, para ambas as comissões, bem como o estabelecimento do campo num nível a ser estabelecido como referência. 


\subsection{Metodologia}

Para obtenção dos resultados experimentais realizamos as seguintes etapas:

1. Tratamento dos dados de velocidade observada;

2. Elaboração de seções verticais de velocidade observada;

3. Construção de mapas de função de corrente observada $\left(\psi_{o b s}\right)$, através da interpolação dos dados sobre a grade curvilinear gerada, usando o método da Análise Objetiva Vetorial (AOV).

\subsubsection{Tratamento dos Dados de Velocidade Observada}

O processamento dos dados obtidos com o ADCP é um pouco mais complexo do que o realizado com os dados obtidos com o CTD, pelo fato de a velocidade ser uma grandeza vetorial. Além disso, os dados de velocidade são obtidos por um equipamento em movimento, ou seja, por um referencial que não está em repouso. Conforme mencionamos na Seção 2.3 do Capítulo 2, optamos por realizar o processamento dos arquivos .LTA (intervalo de $10 \mathrm{~min}$ ), considerando como válidos os dados com valores de percent good superiores a $50 \%$.

O percent good é um parâmetro de avaliação da qualidade dos dados de ADCP, indicando a percentagem de pulsos que atendem a determinados limiares de erros. Cada célula de profundidade apresenta quatro valores para o percent good, que terão significados diferentes, dependendo do sistema de coordenadas. Se os dados são coletados em coordenadas do feixe, então os quatro percent good indicam a porcentagem de pulsos coletados por cada feixe, cuja correlação da célula de profundidade correspondente excedeu um determinado limiar mínimo. Para os outros sistemas de coordenadas (ADCP, navio e terrestre), os quatro valores de percent good representam: 1) porcentagem de pulsos em que só foi possível utilizar três feixes para cálculo da velocidade (um feixe rejeitado); 2) porcentagem de pulsos em que o limiar de erro de velocidade não foi excedido); 3) porcentagem de pulsos em que mais de um feixe foi considerado ruim 4) porcentagem de pulsos em que todos os quatro feixes foram utilizados para cálculo de velocidade. 
O tratamento dos dados de velocidade foi realizado utilizando-se o pacote de programas de processamento contidos no sistema CODAS. Esse sistema foi desenvolvido pelo Grupo de trabalho do Dr. Eric Firing, da Universidade do Havaí, com a finalidade de uniformizar os procedimentos de processamento e armazenamento de dados de ADCP.

O sistema CODAS é constituído de um banco de dados e de um conjunto de programas de fonte aberta, escritos em linguagem $C$ e também no software MATLAB. $\mathrm{O}$ banco de dados se configura como uma forma de armazenar e acessar dados oceanográficos, sendo mais comumente usado com dados de ADCP. O pacote de programas para processamento corresponde a uma caixa de ferramentas para manipular os dados armazenados no banco de dados CODAS, estando relacionado, mais especificamente, aos procedimentos utilizados para transformar os dados de ADCP em informações úteis à ciência. O CODAS encontra-se disponível na internet, através do site da universidade.

O tratamento dos dados de velocidade pelo sistema CODAS, foi realizado, basicamente, em duas etapas:

1. Calibração dos dados de ADCP;

2. Remoção dos dados espúrios.

\section{Calibração dos dados de ADCP}

Em seus estudos, Joyce [1989] e Pollard \& Read [1989] apresentaram métodos para calibração de $\mathrm{ADCP}$, resumidamente classificados em bottom-track e water-track. Dentre as sub-rotinas contidas no pacote de processamento do sistema CODAS, encontramos sub-rotinas para determinação dos parâmetros de calibração, tanto para o método bottom-track quanto para o método water-track. Podemos definir esses métodos, resumidamente, da seguinte forma:

- Método bottom-track: consiste na comparação do deslocamento do navio, medido em relação a fundo, com o deslocamento do navio medido pelo GPS;

- Método da aceleração (water-track): consiste na comparação da aceleração relativa da água, medida pelo ADCP, com a aceleração medida pelo GPS. 
Esses métodos consistem, basicamente, na determinação de dois parâmetros:

- ângulo de desalinhamento horizontal do módulo transdutor;

- fator de escala, pelo qual os dados de ADCP devem ser multiplicados. Esse fator tenta corrigir o desalinhamento vertical de montagem do módulo transdutor $\mathrm{ADCP}$, bem como pequenos erros na geometria dos feixes originados no processo de fabricação do módulo trandutor.

De acordo com Firing [1991], os métodos bottom-track e water-track devem dar o mesmo resultado para o ângulo de desalinhamento, mas podem apresentar fatores de escala diferentes, da ordem de 0,5. Em seus estudos, Joyce [1989] estabeleceu as seguintes definições:

- Ângulo $\alpha$ : ângulo de defasagem, no sentido anti-horário, entre os sistemas de coordenadas $\left(x^{\prime}, y^{\prime}\right)$, referente aos eixos do módulo transdutor, e $(x, y)$, referente aos eixos do navio;

- fator de escala $1+\boldsymbol{\beta}$.

A Figura 5.1, representa esquematicamente os ângulos do módulo transdutor em relação ao navio, no plano horizontal (yaw) e no plano vertical (pitch), aos quais estão relacionados os parâmetros $\alpha$ e $1+\beta$, respectivamente, de acordo com Joyce [1989].

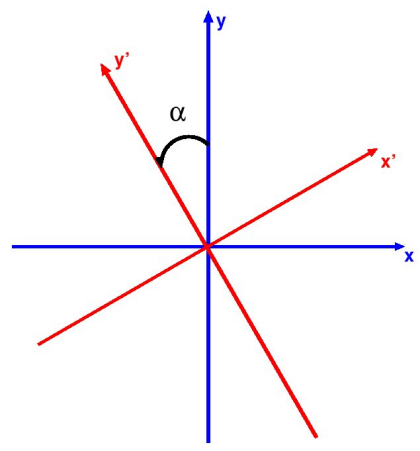

(a) Ângulo horizontal (yaw)

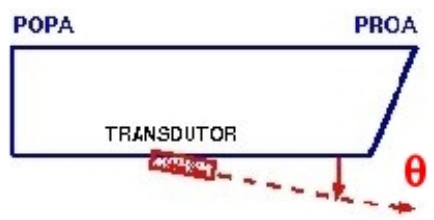

(b) Ângulo vertical (pitch)

Figura 5.1: Representação esquemática dos ângulos do módulo transdutor em relação ao navio, no plano horizontal (a) e no plano vertical (b), aos quais estão relacionados os parâmetros $\alpha$ e $1+\beta$, respectivamente, de acordo com Joyce [1989]. 
As velocidades $\left(u^{\prime}, v^{\prime}\right)$ e $(u, v)$, correspondentes aos sistemas $\left(x^{\prime}, y^{\prime}\right)$ e $(x, y)$, respectivamente, relacionam-se de acordo com as expressões

$$
\left(\begin{array}{l}
u^{\prime} \\
v^{\prime}
\end{array}\right)=\left(\begin{array}{cc}
\cos \alpha & \operatorname{sen} \alpha \\
-\operatorname{sen} \alpha & \cos \alpha
\end{array}\right)=\left(\begin{array}{l}
u \\
v
\end{array}\right)
$$

e

$$
\left(\begin{array}{l}
u \\
v
\end{array}\right)=\left(\begin{array}{cc}
\cos \alpha & -\operatorname{sen} \alpha \\
\operatorname{sen} \alpha & \cos \alpha
\end{array}\right)=\left(\begin{array}{l}
u^{\prime} \\
v^{\prime}
\end{array}\right) .
$$

Considerando a equação vetorial 2.4 apresentada na Seção 2.3 do Capítulo 2 temos, para as componentes zonal e meridional da velocidade do fluido em relação a um referencial terrestre, as seguintes expressões:

$$
\begin{aligned}
& u_{f}=u_{n}+u_{d} \\
& v_{f}=v_{n}+v_{d} .
\end{aligned}
$$

Aplicando o fator de escala $(1+\beta)$ nas Eqs. 5.3 e 5.4, temos:

$$
\begin{aligned}
& u_{f}=u_{n}+(1+\beta) u_{d} \\
& v_{f}=v_{n}+(1+\beta) v_{d} .
\end{aligned}
$$

Aplicando a Eq. 5.2 para determinarmos as componentes $u_{d}$ e $v_{d}$ em em função das componentes $u_{d}^{\prime}$ e $v_{d}^{\prime}$, e combinando com as Eqs. 5.5 e 5.6, temos:

$$
\begin{aligned}
& u_{f}=u_{n}+(1+\beta)\left[u_{d}^{\prime} \cos \alpha-v_{d}^{\prime} \operatorname{sen} \alpha\right] \\
& v_{f}=v_{n}+(1+\beta)\left[u_{d}^{\prime} \operatorname{sen} \alpha-v_{d}^{\prime} \cos \alpha\right] .
\end{aligned}
$$

Pollard E Read [1989], seguindo os cálculos de Joyce [1989], analisaram os procedimentos para determinação dos parâmetros de calibração com base em pernadas seqüênciais de ida e volta em uma mesma trajetória de navegação, realizando navegação precisa através do sistema de posicionamento GPS. Estes autores definiram as variáveis $A=1+\beta$ e $\varphi=-\alpha$, pelas quais reescrevemos as equações 5.7 e 5.8 


$$
\begin{aligned}
& u_{f}=u_{n}+A\left[u_{d}^{\prime} \cos \varphi+v_{d}^{\prime} \operatorname{sen} \varphi\right] \\
& v_{f}=v_{n}+A\left[-u_{d}^{\prime} \operatorname{sen} \varphi+v_{d}^{\prime} \cos \varphi\right] .
\end{aligned}
$$

De acordo com Pollard E Read [1989], no modo bottom-track, ao estabelecermos a condição $\vec{V}_{f}=0$, podemos determinar os valores de $\beta$ e $\varphi$. No modo water-track somente precisamos assumir que a corrente $\vec{V}_{f}$ é a mesma antes e depois do trecho de calibração, para eliminar $\vec{V}_{f}$ e resolver as duas equações, obtendo os valores de $\beta$ e $\varphi$. Assumindo o modo water-track e definindo $d \vec{V}$ como a diferença entre a velocidade após o trecho e a velocidade antes do trecho de calibração, obtemos as seguintes equações

$$
\begin{aligned}
d \vec{V}_{n} & =\vec{V}_{n}^{2}-\vec{V}_{n}^{1} \\
d \vec{V}_{d} & =\vec{V}_{d}^{2 \prime}-\vec{V}_{d}^{1 \prime} .
\end{aligned}
$$

As equações 5.9 e 5.10 resultam em

$$
\begin{aligned}
d u_{n}+A\left(d u_{d} \cos \varphi+d v_{d} \operatorname{sen} \varphi\right) & =0 \\
d v_{n}+A\left(-d u_{d} \operatorname{sen} \varphi+d v_{d} \cos \varphi\right) & =0 .
\end{aligned}
$$

Dessa forma, obtemos as expressões para as variáveis $\varphi$ e $A$ :

$$
\begin{aligned}
\tan \varphi & =\tan (-\alpha)=\frac{d v_{d} \times d u_{n}-d u_{d} \times d v_{n}}{d v_{d} \times d v_{n}+d u_{d} \times d u_{n}} \\
A & =1+\beta=\frac{-d \vec{V}_{d} \cdot d \vec{V}_{n}}{\cos \varphi d \vec{V}_{d} \cdot d \vec{V}_{d}} .
\end{aligned}
$$

Nos estudos de Osiński [2000], o ângulo de desalinhamento do módulo transdutor é descrito com base nas seguintes definições: 
- Sistema $O X^{\prime} Y^{\prime}$ : os eixos $X^{\prime}$ e $Y^{\prime}$ correspondem aos eixos do ADCP;

- Sistema OXY: os eixos X e Y correspondem aos eixos do navio;

- Sistema OEN: eixos orientados para LESTE (E) e para NORTE (N);

- $\gamma$ : ângulo de defasagem entre os sistemas OXY e OEN;

- $\lambda$ : ângulo de defasagem entre os sistemas OXY e OX'Y';

- $\phi$ : ângulo de defasagem entre $O X^{\prime} Y^{\prime}$ e OEN;

- $\Delta \gamma$ : erro na informação de $\gamma$

- $\Delta \lambda$ : erro na informação de $\lambda$.

A partir dessas definições, Osiński [2000] apresenta a ângulo de desalinhamento como o somatório dos erros de $\gamma$ e $\lambda$, ou seja, como a diferença entre o ângulo $\phi$ e a informação recebida pelo ADCP $\phi^{\prime}$ :

$$
\alpha=\Delta \gamma+\Delta \lambda=\phi-\phi^{\prime}
$$

A Figura 5.2 representa esquematicamente os sistemas de coordenadas e os ângulos de defasagem entre eles, de acordo com Osiński [2000].

Figura 5.2: Representação esquemática dos três sistemas com origem $\mathrm{O}$ no centro do módulo transdutor do ADCP: $O X^{\prime} Y^{\prime}$ (coordenadas ADCP), OXY (coordenadas do navio) e OEN (coordenadas terrestres). $\gamma$ representa a defasagem entre os sistemas OXY e OEN, $\lambda$ representa a defasagem entre OXY e OX'Y' e $\phi$ entre $O X^{\prime} Y^{\prime}$ e OEN. Obtido de Osiński [2000].

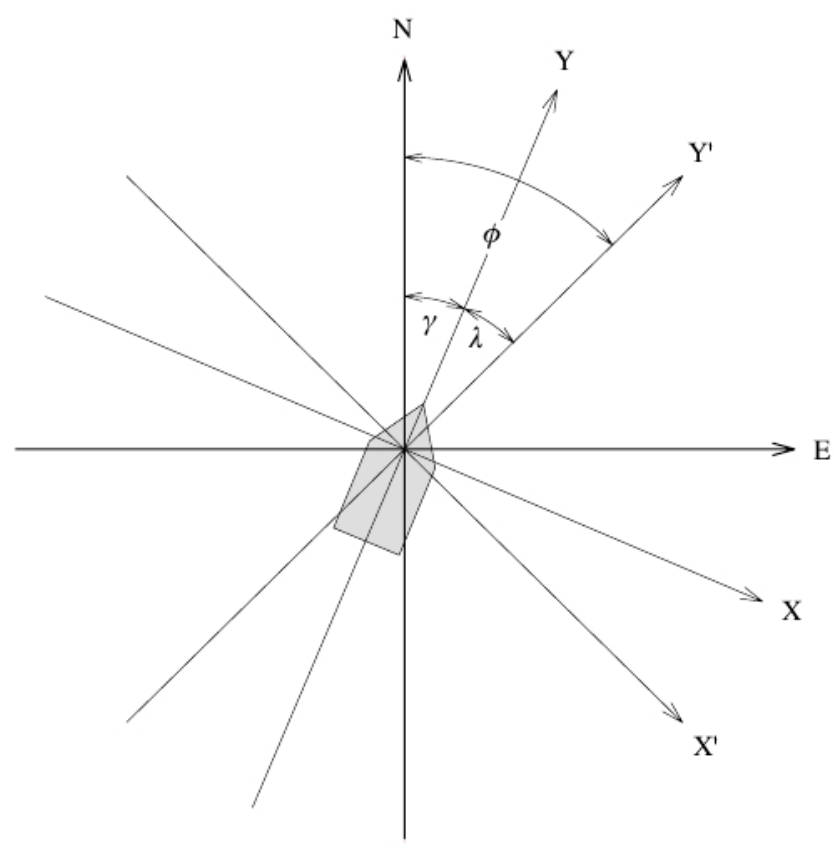


Optamos por realizar o método water-track para calibração, tendo em vista que o método bottom-track, apesar de mais eficiente, deve ser realizado em águas rasas. Obtivemos então, através do sistema CODAS, os valores de $\alpha$ e $\beta$, tendo sido escolhido uma camada específica (camada de referência) para o método water-track, a fim de avaliarmos as velocidades antes e depois das ocorrências de manobras bruscas. A camada de referência escolhida foi a décima oitava, correspondente a aproximadamente 150 $\mathrm{m}$. Os trechos de navegação escolhidos como eventos de manobras bruscas foram os seguintes:

- Estações Oceanográficas: momentos em que o navio permanece parado, em intervalos de tempo consideráveis;

- Guinadas bruscas: assumimos que a velocidade de corrente deve apresentar o mesmo valor antes e após a guinada;

- Trechos repetidos: constituem também uma boa oportunidade para realizar a calibração.

Através da calibração water-track foram obtidos os seguintes valores médios para $\alpha$ e $\beta$ :

- Comissão ONEI: $\alpha_{m e d}=0,98^{\circ}$ e $\beta_{\text {med }}=1,0036$;

- Comissão ONEII: $\alpha_{\text {med }}=1,95^{\circ}$ e $\beta_{\text {med }}=1,0024$.

A Figura 5.3 representa os pontos de calibração usados no processamento dos dados de ADCP pelo sistema CODAS, correspondentes às comissões ONEI e ONEII. 


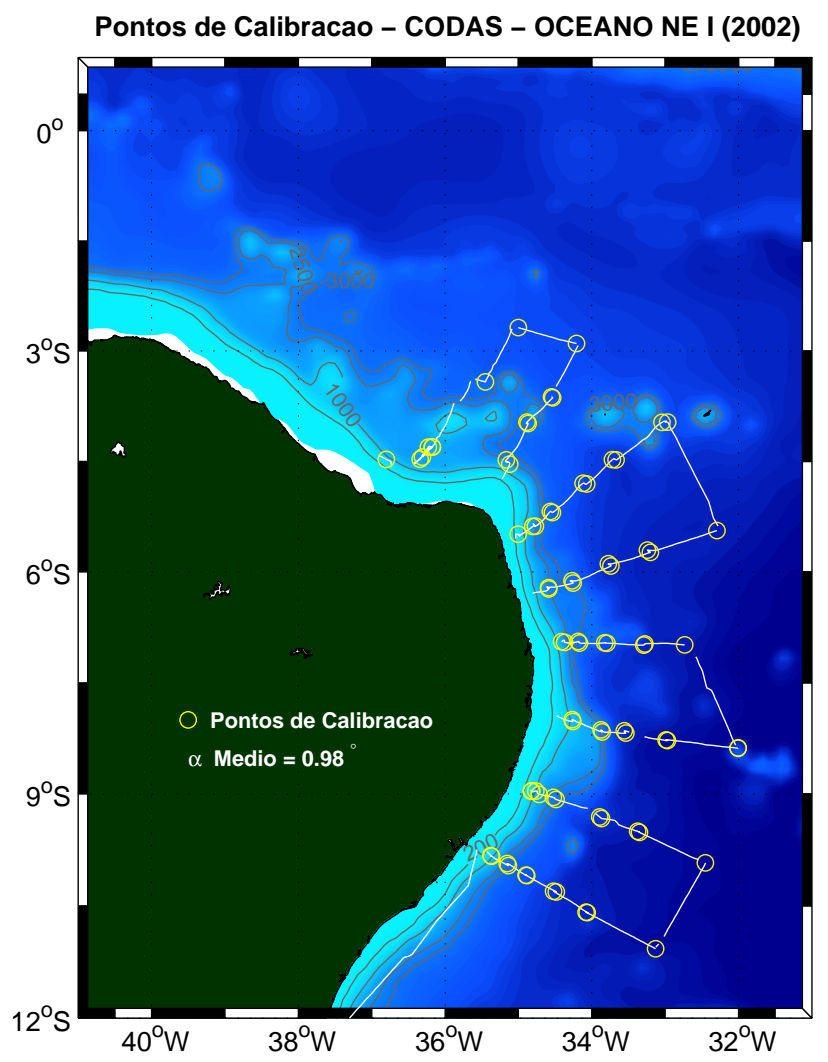

Pontos de Calibracao - CODAS - OCEANO NE II (2004)

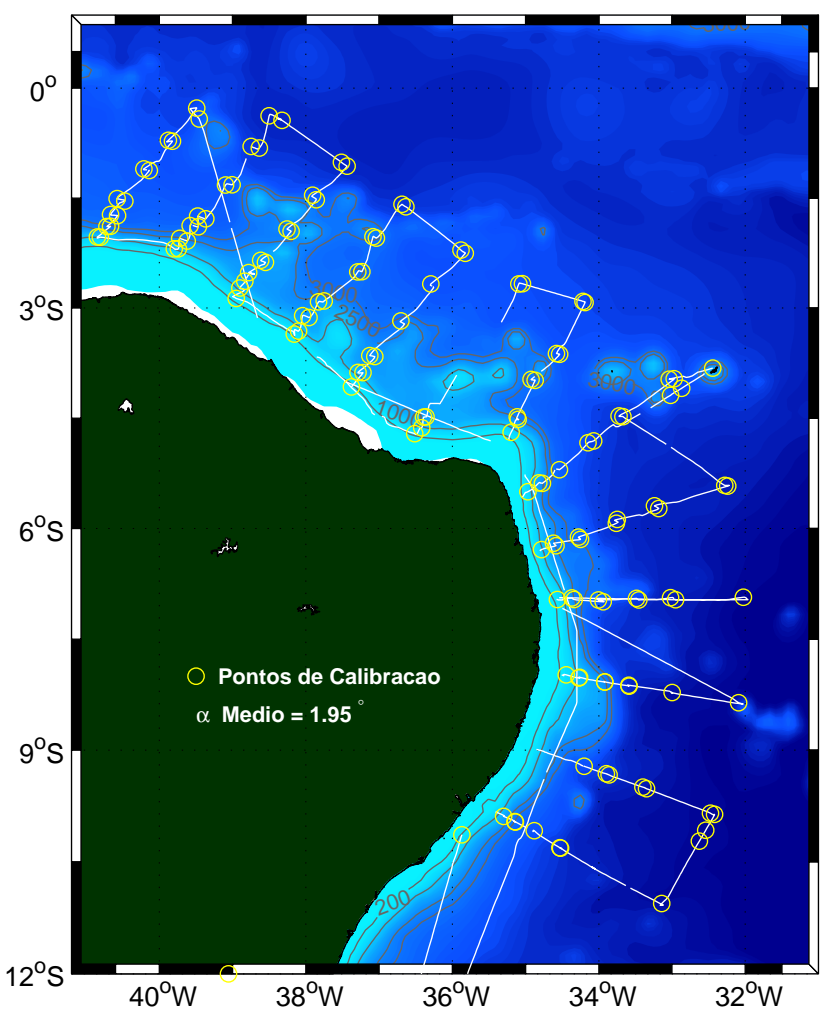

Figura 5.3: Posições dos pontos de calibração water-track, do processamento dos dados de ADCP pelo sistema CODAS, e os valores ângulo de fase médio obtidos na calibração: $\alpha$ médio $=0,98^{\circ}$, para a comissão ONEI, e $\alpha$ médio $=1,95^{\circ}$, para a comissão ONEII. 


\section{Remoção dos Dados Espúrios}

Fatores como estado do mar, transparência da água, formação de bolhas nas proximidades dos transdutores, e falhas mecânicas, dentre outros, podem afetar a qualidade dos dados coletados por ADCP. Existem formas de diagnosticar a má qualidade dos dados para a maioria dos problemas exemplificados. Dentre os parâmetros disponíveis para o diagnóstico de deficiências na qualidade dos dados, a velocidade vertical é o mais utilizado. Assumimos que nos oceanos, de uma forma geral, a velocidade vertical é muito pequena quando comparada com a horizontal. As velocidades horizontais também são usadas para diagnosticar problemas na qualidade dos dados. Assumimos, para o presente trabalho, que as velocidades com módulo superior a $2 \mathrm{~m}$ $\mathrm{s}^{-1}$ seriam consideradas como dados espúrios, fazendo com que o perfil seja descartado. A intensidade do sinal sonoro, ou intensidade do eco, é também utilizada como parâmetro para eliminar perfis. Caso a intensidade do eco não atinja valores mínimos satisfatórios, o perfil é eliminado do conjunto. Utilizamos ainda o percent good para eliminação de dados considerados espúrios, a partir do critério de se eliminar os perfis com percent good inferiores a 50\%.

\subsubsection{Seções Verticais de Velocidade Observada}

Foram elaboradas seções verticais de velocidade observada para as radiais das comissões em análise, utilizando-se interpolação por AO, de acordo com a equação

$$
C(\Delta x, \Delta z)=\left(1-\epsilon^{2}\right) e^{-\left[\frac{(\Delta x)^{2}}{l_{x}^{2}}+\frac{(\Delta z)^{2}}{l_{z}^{2}}\right]},
$$

correspondente à Eq. 4.1 apresentada na Seção 4.2.4 do Capítulo 4 . Nesse caso, $\Delta x$ e $\Delta z$ correspondem aos incrementos de grade nas direções perpendicular ao talude $\mathrm{e}$ vertical, respectivamente. Essa equação foi utilizada tendo em vista não podermos assumir a isotropia da mesma forma que a considerada para as distribuições horizontais. Das seções verticais elaboradas, analisamos como mais detalhes as seções correspondentes às radiais 1 e 5 de ambas as comissões, objetivando a comparação com as seções verticais apresentadas por Schott et al. [2005], de acordo com a figura 1.6 apresentada no item 1.2.3 do Capítulo 1. Utilizamos os valores de $\epsilon=0,02, l_{x}=100 \mathrm{~km}$ e $l_{z}=50 \mathrm{~m}$. 


\subsubsection{Mapas de Função de Corrente Observada}

Para a construção dos mapas de $\psi_{o b s}$, realizou-se a interpolação dos dados através de uma modalidade diferente de AO: a Análise Objetiva Vetorial (AOV) [Bretherton et al. 1976]. De acordo com Sutton E Chereskin [2002], para o cálculo de $\psi_{g_{a b s}}$, referenciada por dados de ADCP, deve-se escolher um nível em que as contribuições ageostróficas sejam mínimas, tendo em vista que as velocidades diretamente observadas resultam da influência de diversos movimentos que ocorrem no oceano. Como os escoamentos ageostróficos são maiores próximos à superfície, é desejável que se utilize dados correspondentes a um nível o mais profundo possível. Contudo, infelizmente, o ADCP com transmissão broadband não tem boa penetração. Sutton $\mathcal{E}$ Chereskin [2002] citam as seguintes componentes ageostróficas de baixa freqüência que interferem no cálculo de velocidade geostrófica, quando se usa a velocidade obtida com ADCP como referência:

- a deriva de Ekman, provocada pela tensão de cisalhamento do vento;

- as correntes quase-inerciais;

- as correntes de maré.

Desses três itens, os dois últimos foram filtrados naturalmente, através da interpolação por AO aplicada aos dados, pelo fato de possuírem freqüências relativamente altas quando comparadas às correntes geostróficas. Quanto à deriva de Ekman, buscou-se, de acordo com Sutton E Chereskin [2002], níveis de profundidade onde o efeito direto da tensão de cisalhamento do vento é praticamente nulo.

Como dito acima, para aplicação do MDR, o NR deve corresponder a um nível de velocidades conhecidas (no nosso caso, obtidas por ADCP), devendo ser suficientemente profundo para garantir o domínio da geostrofia, ou seja, uma profundidade onde o efeito direto da tensão de cisalhamento do vento seja praticamente nulo. Para tanto, podemos usar, como parâmetro para escolha de um nível adequado, uma estimativa da profundidade média da camada de Ekman $\left(h_{E}\right)$, que de acordo com Cushman-Roisin [1994], pode ser determinada empiricamente através de

$$
h_{E} \simeq 0,4 \frac{u_{*}}{f_{0}}
$$


onde 0,4 é o valor mais comumente aceito para a constante de Von Kármán. A variável $u_{*}$ é a velocidade de fricção turbulenta, sendo calculada através de

$$
u_{*}=\sqrt{\frac{|\vec{\tau}|}{\rho_{0}}} .
$$

De acordo com Apel [1995], o módulo da tensão de cisalhamento do vento $(|\vec{\tau}|)$ pode ser calculada por:

$$
|\vec{\tau}|=C_{d} \cdot \rho_{a} \cdot\left|V_{W}\right|^{2},
$$

onde $C_{d}$ é o coeficiente de arrasto aerodinâmico, $\rho_{a}$ é a densidade do ar e $\left|V_{W}\right|$ é a magnitude da velocidade do vento.

Foram feitas estimativas da profundidade média da camada de Ekman, uma para cada comissão hidroceanográfica, através da Eq. 5.19, considerando o período de duração das mesmas. A fim de obtermos estimativas do vento, foram utilizados os valores de tensão de cisalhamento $(\vec{\tau})$ obtidos a partir dos dados oriundos do QuickSCAT (Quick Scatterometer). O QuickSCAT é um satélite de monitoramento oceânico da NASA (National Aeronautics and Space Administration) de órbita polar e com um escaterômetro acoplado, que provê informações de velocidade e direção do vento junto à superfície do mar.

Obtivemos, então, dois valores médios de $h_{E}$, um para cada comissão: $68,5 \mathrm{~m}$ (ONEI) e 94,3 m (ONEII). Para garantir influência nula do vento, buscou-se escolher um nível que fosse maior que os valores médios encontrados para $h_{E}$ e o mais profundo possível, atentando-se para a qualidade dos dados de ADCP. Após analisarmos os dados de ambas as comissões, constatamos dados com valores de percent good superiores a $50 \%$ apenas até a profundidade de $256 \mathrm{~m}$, para a comissão ONEI, e até a profundidade de $176 \mathrm{~m}$ para a comissão ONEII, tendo sido escolhido o nível de $160 \mathrm{~m}$ para ser aplicado no MDR, para ambas as comissões. A profundidade de $160 \mathrm{~m}$ é equivalente a, aproximadamente, duas vezes a média dos valores médios de $h_{E}$ calculados para as duas comissões e, segundo Pedlosky [1987], o efeito das correntes de Ekman são negligenciáveis a essa profundidade. 


\subsection{Resultados e Discussão}

Com o intuito de obtermos uma descrição sinótica dos padrões horizontal e vertical do escoamento da SNB ao largo da costa do nordeste, bem como de outras estruturas de mesoescala associadas à SNB, foram elaboradas distribuições verticais de velocidade observada $\left(\vec{V}_{\text {obs }}\right)$ e construídos campos de função de corrente observada $\left(\psi_{\text {obs }}\right)$ a partir dos dados de ADCP das comissões ONEI e ONEII. A partir das distribuições verticais de $\vec{V}_{o b s}$, foram calculados os respectivos valores de transporte de volume e de velocidade máxima. Os transportes foram calculados de acordo com a Eq. 3.21 apresentada na Seção 3.4 do Capítulo 3, respeitando-se o limite máximo de amostragem.

Um dos objetivos específicos do presente trabalho foi o de obter uma descrição sinótica da circulação observada, associada ao escoamento da SNB, através da elaboração de distribuições verticais de $\vec{V}_{o b s}$, nas proximidades das latitudes de $5^{\circ} \mathrm{S}$ e $11^{\circ} \mathrm{S}$. Para tanto, analisamos mais detalhadamente as distribuições verticais de $\vec{V}_{\text {obs }}$ referentes aos dados das radiais $1\left(\sim 11^{\circ} \mathrm{S}\right)$ e $5\left(\sim 5^{\circ} \mathrm{S}\right)$ das comissões em análise, comparando-as com as duas seções de controle apresentadas nos estudos de Schott et al. [2005] (vide Figura 1.6.

Outro objetivo específico delineado para o presente trabalho foi o de obtermos uma descrição sinótica dos padrões verticais de circulação observada, associados ao escoamento da SNB, através da elaboração de distribuições horizontais de $\psi_{o b s}$.

O processamento dos dados de velocidade foi realizado utilizando-se o pacote de programas contido no sistema CODAS. Esse sistema padroniza, simplifica e torna mais rápido o processamento, constituindo uma poderosa ferramenta para o tratamento de dados oriundos de ADCP.

Antecipando-nos à elaboração das seções verticais por $\mathrm{AO}$, apresentamos, na Figura 5.4 referente à radial 5 da comissão ONEI, a seção de velocidade observada obtida a partir dos dados brutos (painel superior) e aquela obtida a partir dos dados processados pelo sistema CODAS (painel inferior). Nessa figura, observarmos a diferença significativa entre dados brutos e dados processados, evidenciando a importância do processamento e, principalmente, da calibração, que no nosso caso foi a do método water-track. O resultado obtido permitiu-nos observar o padrão característico da SNB, já apresentado por outros autores [Stramma et al., 1995; Schott et al., 2005]. 

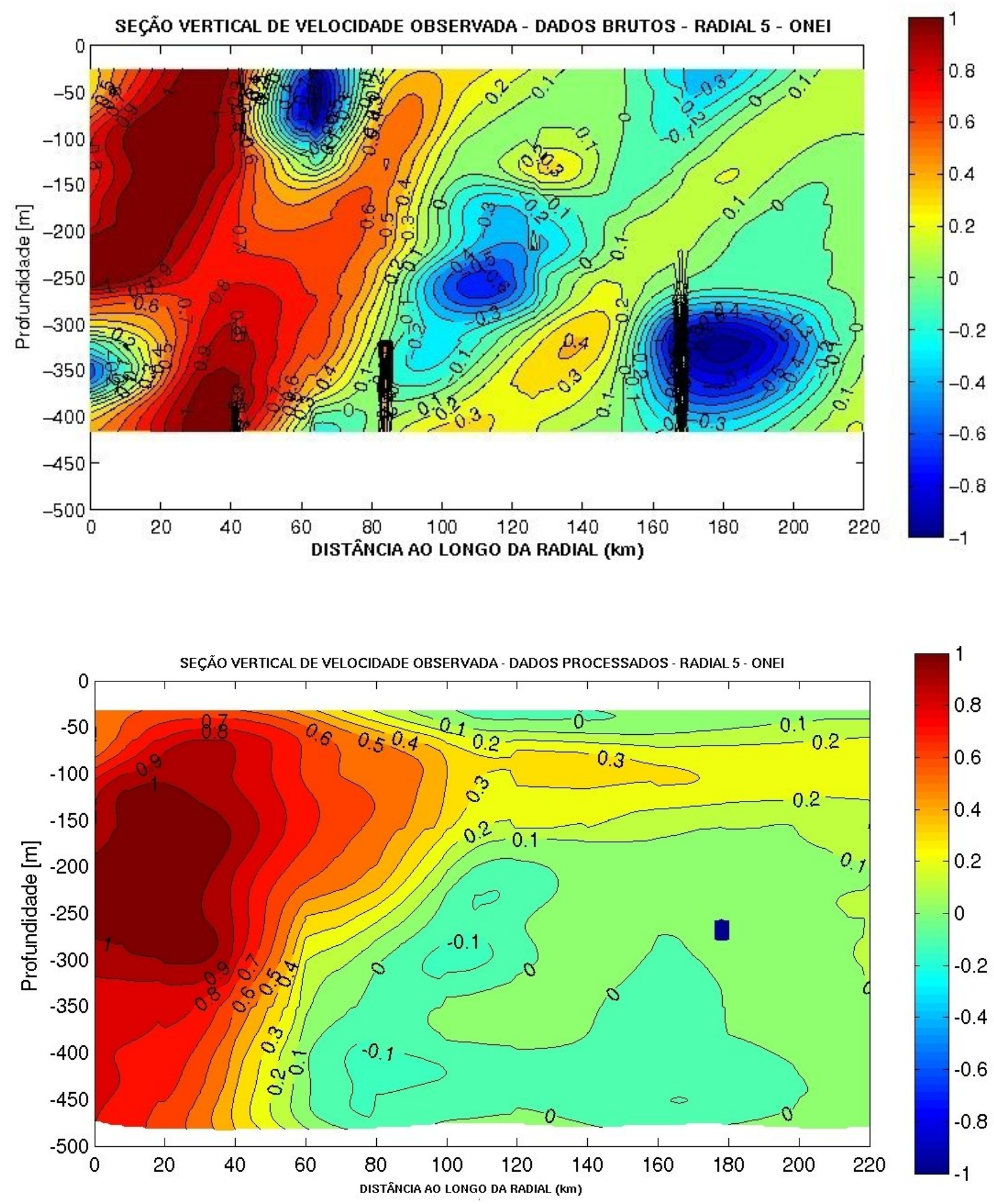

Figura 5.4: Seções verticais de velocidade observada $\left(\mathrm{m} \mathrm{s}^{-1}\right)$ obtidas a partir dos dados brutos de ADCP (painel superior) e a partir dos dados processados pelo sistema CODAS (painel inferior), exemplificando a diferença significativa entre dados brutos e processados e ressaltando a importância do processamento. Os dados processados (painel inferior) foram interpolados por $\mathrm{AO}$, e os valores com erro de interpolação superior a $30 \%$ foram desconsiderados. O intervalo entre isotacas é de $0,1 \mathrm{~m} \mathrm{~s}^{-1}$. Valores positivos para norte. Dados referentes à radial $5 \mathrm{da}$ comissão ONEI. 


\subsubsection{Qualidade dos Dados de ADCP}

Apesar de o modelo de ADCP RDI BroadBand $75 \mathrm{kHz}$ poder realizar perfilagens até cerca de 560 - $700 \mathrm{~m}$ constatamos, ao verificarmos o conjunto de dados das comissões em análise, a existência de informações apenas até as profundidades de 464 m (ONEI) e 288 m (ONEII). Da mesma forma, constatamos a existência de dados com valores de percent good superiores a 50\% apenas até as profundidades de $256 \mathrm{~m}$ (ONEI) e 176 m (ONEII). De modo geral, os dados de ADCP da comissão ONEI foram avaliados como de melhor qualidade que os da comissão ONEII.

A qualidade mais pobre dos dados da comissão ONEII é mencionada no relatório de fim de comissão do NOc Antares. Ao analisarmos os dados das radiais 2, 3, 4 e 8 da referida comissão, verificamos uma quantidade insuficiente de dados com percent good superior a $50 \%$ para elaboração das respectivas distribuições verticais.

As Figuras 5.5 e 5.6, referentes às comissões ONEI e ONEII, respectivamente, representam as distribuições horizontais dos vetores de velocidade observada resultantes do processamento pelo CODAS, sem a utilização da interpolação por AOV. Esses vetores correspondem aos dados que apresentaram percent good superiores a $50 \%$, adquiridos ao longo dos trechos de navegação apresentados nas Figuras $2.2 \mathrm{e} 5.3$, sendo mostrados nas profundidades de 32 m, 96 m, 144 m e $192 \mathrm{~m}$. Tais níveis correspondem aos níveis amostrados pelo ADCP de acordo com a "célula de profundidade" de $8 \mathrm{~m}$, utilizada em ambas as comissões, não havendo, portanto, qualquer interpolação vertical.

São bastante significativas as diferenças de posicionamento do núcleo, largura e intensidade da SNB, quando comparamos as seções da comissão ONEI com as da comissão ONEII. Os dados ADCP foram coletados durante o verão austral, na comissão ONEI, e durante a primavera austral, na comissão ONEII. Os resultados obtidos por Schott et al. [2005] indicam o mês de julho (inverno austral) como período de máximo transporte da SNB e outubro-novembro (primavera austral) como período de mínimo transporte da SNB. Como os resultados desses autores advém de linhas de fundeio, eles definiram um ciclo sazonal que mostram que os valores de transporte e velocidade já são maiores no verão austral, relativamente à primavera. Os resultados das comissões em análise corroboram os resultados obtidos por esses autores. 

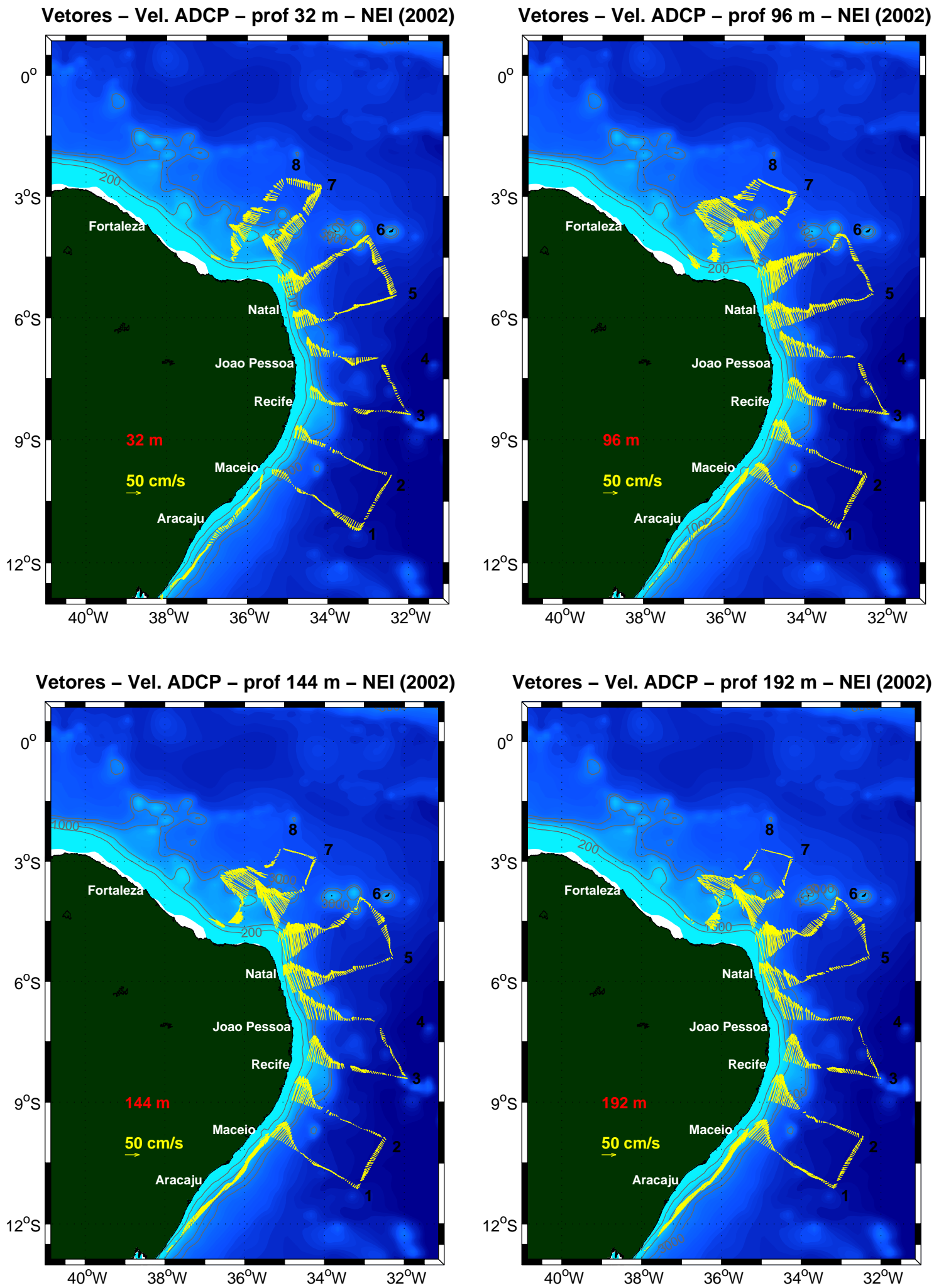

Figura 5.5: Distribuições horizontais dos vetores de velocidade observada da comissão ONEI, resultantes do processamento pelo CODAS, sem a utilização da interpolação por AOV. Esses vetores correspondem aos dados de velocidade que apresentaram percent good superiores a $50 \%$ nas profundidades de $32 \mathrm{~m}, 96 \mathrm{~m}, 144 \mathrm{~m}$ e $192 \mathrm{~m}$. Esses níveis correspondem aos níveis amostrados pelo ADCP de acordo com a "célula de profundidade" de $8 \mathrm{~m}$, utilizada em ambas as comissões. Não há interpolação vertical. 

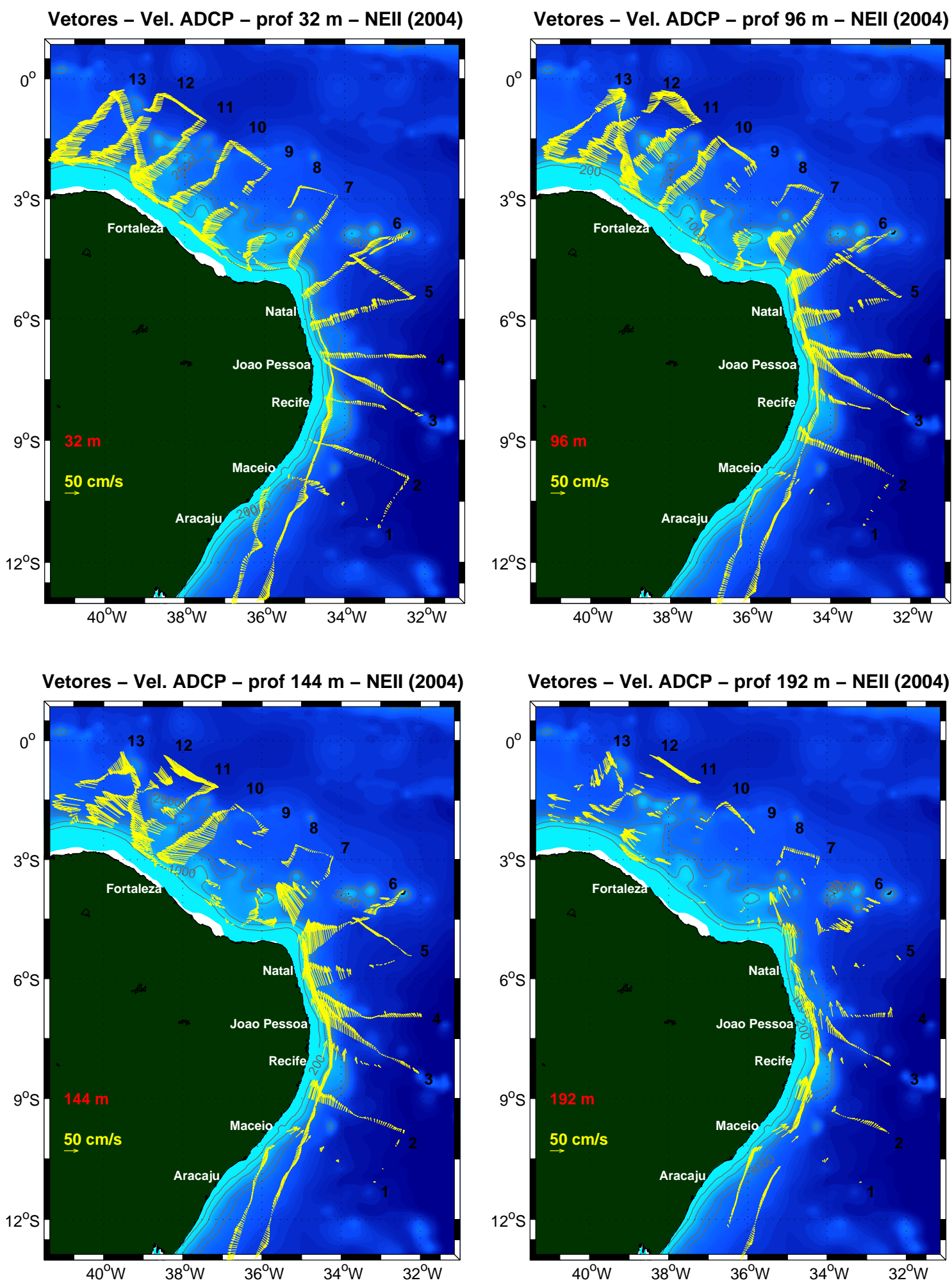

Figura 5.6: Distribuições horizontais dos vetores de velocidade observada da comissão ONEII, resultantes do processamento pelo CODAS, sem a utilização da interpolação por AOV. Esses vetores correspondem aos dados de velocidade que apresentaram percent good superiores a $50 \%$ nas profundidades de $32 \mathrm{~m}, 96 \mathrm{~m}, 144 \mathrm{~m}$ e $192 \mathrm{~m}$. Esses níveis correspondem aos níveis amostrados pelo ADCP de acordo com a "célula de profundidade" de $8 \mathrm{~m}$, utilizada em ambas as comissões. Não há interpolação vertical. 


\subsubsection{Seções Verticais de Velocidade Observada - ONEI}

A assinatura da SNB pôde ser constatada em todas as 8 seções verticais de velocidade observada referentes à comissão ONEI, tendo sido observada sua intensificação nas seções mais ao norte, com aumento de seu transporte. Foi possível verificar também o posicionamento de seu núcleo cada vez mais raso ao longo do seu deslocamento para norte. A Tabela 5.1 apresenta os valores de transporte de volume e de velocidade máxima referentes à assinatura da SNB observada nas 8 seções da comissão ONEI. Comparando esses valores com os valores de transporte apresentados por Schott et al. [2005], de $26,5 \pm 3,7 \mathrm{~Sv}$, para a seção de $5^{\circ} \mathrm{S}$, e de $25,4 \pm 7,4 \mathrm{~Sv}$, para a seção de $11^{\circ} \mathrm{S}$, constatamos que os valores de transporte das radiais 1 e 5 da comissão ONEI corroboram os valores apresentados por esses autores.

A seguir, serão apresentadas as análises referentes às radiais 1, 5, 6 e 8 da comissão ONEI. As distribuições verticais de velocidade observada foram obtidas a partir da interpolação por AO dos dados de ADCP processados pelo pacote de programas do sistema CODAS. A Figura 5.7 representa os mapas de erro de interpolação (\%) associados a essas distribuições verticais.

Tabela 5.1: Valores de transporte de volume (Sv) e de velocidade máxima $\left(\mathrm{m} \mathrm{s}^{-1}\right)$ referentes à assinatura da SNB observada nas 8 seções das radiais da comissão ONEI.

\begin{tabular}{|c|c|c|c|c|}
\hline \multicolumn{5}{|c|}{ Velocidade Observada - Comissão ONEI - Assinatura da SNB } \\
\hline \multirow[b]{2}{*}{ Radial } & \multicolumn{2}{|c|}{ Transporte (Sv) } & \multirow[b]{2}{*}{ Velocidade $\left(\mathrm{m} \mathrm{s}^{-1}\right)$} & \multirow[b]{2}{*}{ Núcleo (m) } \\
\hline & $0-200 \mathrm{~m}$ & $0-500 \mathrm{~m}$ & & \\
\hline $1\left(\sim 11^{\circ} \mathrm{S}\right)$ & 7,5 & 19,2 & 0,87 & 250 \\
\hline 2 & 7,5 & 20,2 & 1,07 & 230 \\
\hline 3 & 9,1 & 19,5 & 1,17 & 250 \\
\hline 4 & 8,8 & 15,2 & 1,18 & 200 \\
\hline $5\left(\sim 5^{\circ} S\right)$ & 13,3 & 30,6 & 1,11 & 200 \\
\hline 6 & 17,1 & 34,8 & 1,11 & 175 \\
\hline 7 & 17,9 & 29,1 & 1,41 & 140 \\
\hline 8 & 18,5 & 29,4 & 1,39 & 125 \\
\hline
\end{tabular}



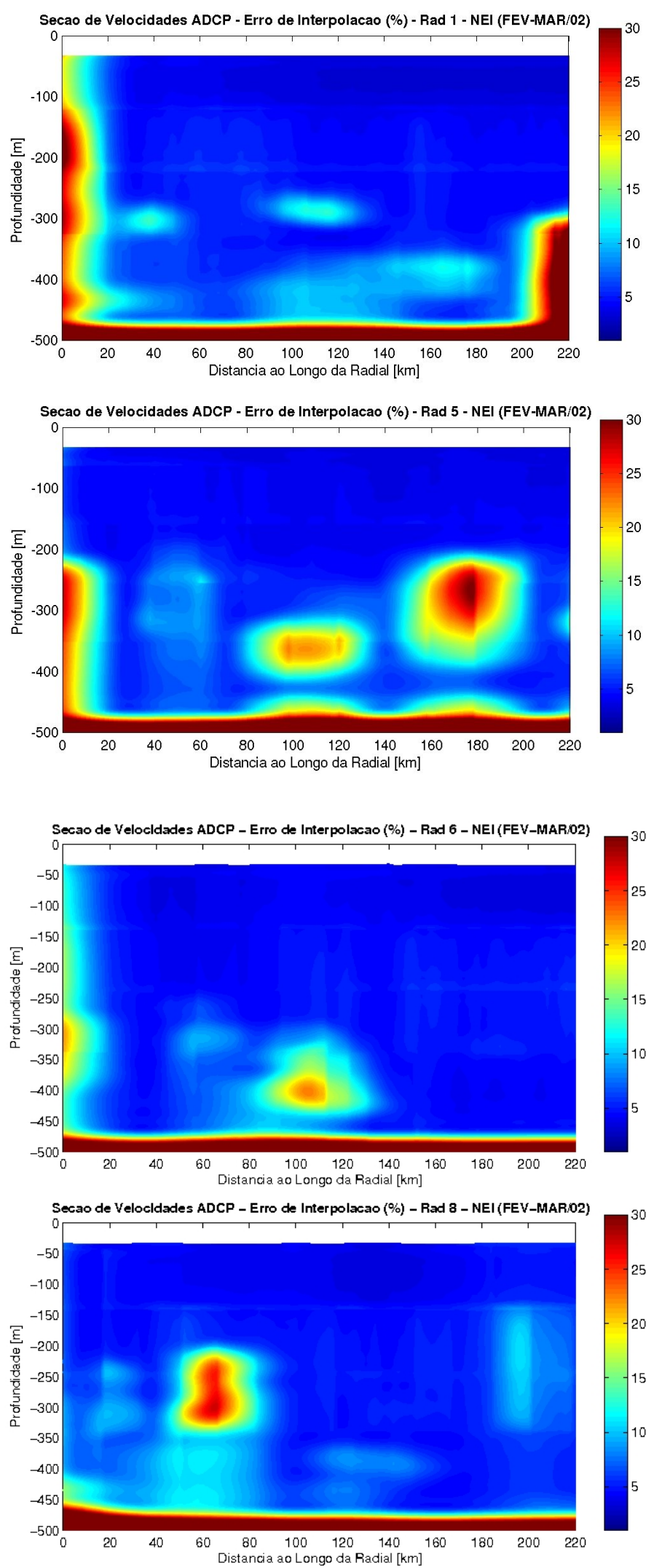

Figura 5.7: Mapas de erro de interpolação (\%) associados às seções verticais de velocidade observada referentes às radiais 1, 5, 6 e 8 da comissão ONEI. As seções verticais foram obtidas a partir da interpolação por AO dos dados de ADCP processados pelo CODAS. 
As Figuras 5.8 e 5.9 são referentes à comissão ONEI e representam as seções verticais de velocidade observada $\left(\mathrm{m} \mathrm{s}^{-1}\right)$ das radiais 1, 5, 6 e 8 . A Figura 5.8 corresponde às radiais 1 e 5 e a Figura 5.9 , às radiais 6 e 8.

Na Figura 5.8 , a seção referente à radial 1 apresenta a SNB com núcleo de subsuperfície em aproximadamente $250 \mathrm{~m}$, a uma distância aproximada da costa de $30 \mathrm{~km}$. Os valores de transporte de volume da SNB para essa seção foram de 7,5 Sv (de 0 a $200 \mathrm{~m}$ ) e 19,2 Sv (de 0 a $500 \mathrm{~m}$ ) e a velocidade máxima encontrada foi 0,87 $\mathrm{m} \mathrm{s}^{-1}$ (Tabela 5.1]. A seção referente à radial 5 apresenta a SNB com núcleo de subsuperfície em aproximadamente $200 \mathrm{~m}$, a uma distância aproximada da costa de $20 \mathrm{~km}$. Os valores de transporte de volume da SNB para essa seção foram de 13,3 Sv (de 0 a 200 m) e 30,6 $\mathrm{Sv}$ (de 0 a $500 \mathrm{~m}$ ) e a velocidade máxima encontrada foi de $1,11 \mathrm{~m} \mathrm{~s}^{-1}$ (Tabela 5.1).

A seção referente à radial 6 da Figura 5.9 apresenta a SNB com núcleo de subsuperfície em aproximadamente $175 \mathrm{~m}$, a uma distância aproximada da costa de $30 \mathrm{~km}$. Os valores de transporte de volume da SNB para essa seção foram de 17,1 Sv (de 0 a $200 \mathrm{~m}$ ) e 34,8 Sv (de 0 a $500 \mathrm{~m}$ ) e a velocidade máxima encontrada foi 1,11 $\mathrm{m} \mathrm{s}^{-1}$ (Tabela 5.1). Nessa seção podemos observar também um contrafluxo no limite leste da seção, em aproximadamente $250 \mathrm{~m}$, a uma distância aproximada da costa de $180 \mathrm{~km}$.

A seção referente à radial 8 da Figura 5.9. apresenta a SNB com núcleo de subsuperfície em aproximadamente $125 \mathrm{~m}$, a uma distância aproximada da costa de 110 $\mathrm{km}$. Os valores de transporte de volume da SNB para essa seção foram de 18,5 Sv (de 0 a $200 \mathrm{~m}$ ) e 29,4 Sv (de 0 a $500 \mathrm{~m}$ ) e a velocidade máxima encontrada foi de 1,39 $\mathrm{m} \mathrm{s}^{-1}$ (Tabela 5.1). Nessa seção podemos observar, em seu limite leste, novamente um contrafluxo com núcleo em aproximadamente $350 \mathrm{~m}$, a uma distância aproximada da costa de $180 \mathrm{~km}$. Adicionalmente, há assinatura de um possível anticiclone próximo à costa, confirmando o anticiclone observado nos mapas de função de corrente geostrófica baroclínica relativa (Figuras 4.11, 4.12, $4.13 \mathrm{e} 4.14$ ) descritos no capítulo anterior, centrado em aproximadamente $4^{\circ} 30^{\prime} \mathrm{S}$ e $36^{\circ} \mathrm{W}$.

Nas seções das radiais 1, 5, 6 e 8 podemos constatar a diminuição da velocidade do escoamento da SNB em direção à superfície, com taxa de decaimento neste sentido maior que a taxa de decaimento em direção ao fundo, semelhantemente ao observado nas seções verticais de velocidade geostrófica apresentadas no capítulo anterior. 

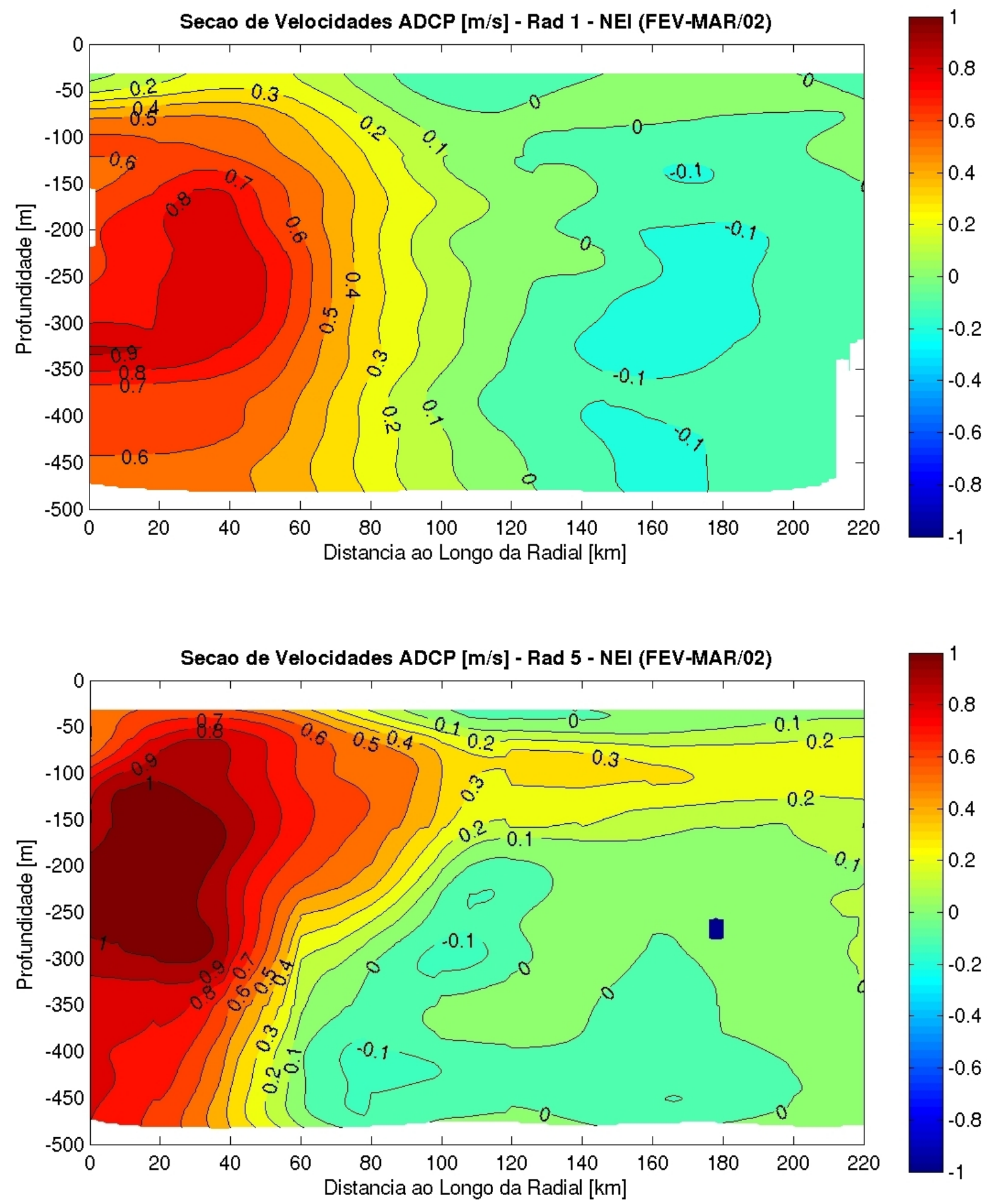

Figura 5.8: Seções verticais de velocidade observada $\left(\mathrm{m} \mathrm{s}^{-1}\right)$ obtidas a partir dos dados processados pelo sistema CODAS, referentes às radiais 1 (painel superior) e 5 (painel inferior) da comissão ONEI. As seções foram obtidas a partir de AO dos dados de ADCP processados pelo CODAS, e os valores com erro de interpolação superior a 30\% foram retirados. O intervalo entre isotacas é de $0,1 \mathrm{~m} \mathrm{~s}^{-1}$. Valores positivos para norte. 

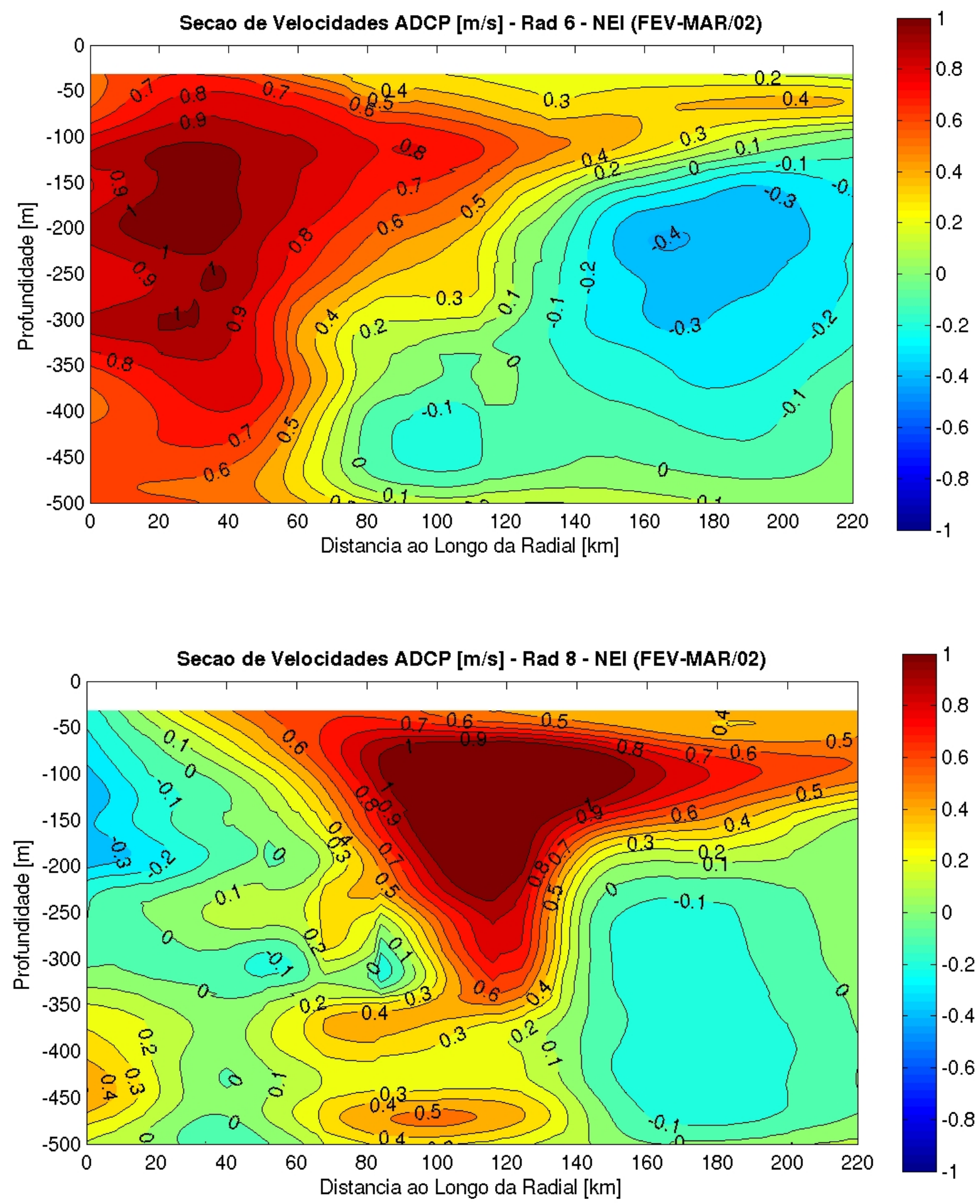

Figura 5.9: Seções verticais de velocidade observada $\left(\mathrm{m} \mathrm{s}^{-1}\right)$ obtidas a partir dos dados processados pelo sistema CODAS, referentes às radiais 6 (painel superior) e 8 (painel inferior) da comissão ONEI. As seções foram obtidas a partir de AO dos dados de ADCP processados pelo CODAS, e os valores com erro de interpolação superior a 30\% foram retirados. O intervalo entre isotacas é de $0,1 \mathrm{~m} \mathrm{~s}^{-1}$. Valores positivos para norte. 
Stramma et al. [1995], através de observações por LADCP, confirmaram a presença da SNB, com núcleo em subsuperfície em torno de $200 \mathrm{~m}$. Em seus estudos, esses autores apresentam distribuições verticais de velocidade correspondentes às latitudes de $5^{\circ} 30^{\prime} \mathrm{S}$ e $10^{\circ} \mathrm{S}$. Schott et al. [2005], a partir de dados de ADCP/LADCP, confirmaram que a SNB é bem desenvolvida em $11^{\circ} \mathrm{S}$. Em seus estudos, esses autores apresentaram distribuições verticais de velocidade nas latitudes de $5^{\circ} \mathrm{S}$ e $11^{\circ} \mathrm{S}$. As distribuições verticais de velocidade observada analisadas no presente trabalho, referentes às radiais 1 e 5 da comissão ONEI (Figura 5.8) corroboram os resultados apresentados por Stramma et al. [1995] e Schott et al. [2005].

Molinari et al. [1981] descreveram seções meridionais da SSE entre $25^{\circ} \mathrm{W}$ e $29^{\circ} \mathrm{W}$, encontrando núcleo entre $3^{\circ} \mathrm{S}$ e $5^{\circ} \mathrm{S}$, com largura de $100 \mathrm{~km}$, profundidades entre 150 $\mathrm{m}$ e $200 \mathrm{~m}$ e velocidade geostrófica (em relação a $1.000 \mathrm{dbar}$ ) de $0,2 \mathrm{~m} \mathrm{~s}^{-1}$. Silveira et al. [1994] , a partir do mapa de topografia dinâmica (relativa a 1000 m) no nível de 200 m, observaram que a SSE é alimentada pelo ramo central da CSE (CSEc) e provavelmente pela $\mathrm{SNB}$, em aproximadamente $4^{\circ} \mathrm{S}-5^{\circ} \mathrm{S}$ e $34^{\circ} \mathrm{W}$. Os contrafluxos observados nas seções de velocidade observada referentes às radiais 6 e 8 da comissão ONEI (Figura 5.9), nas porções mais afastadas da costa, provavelmente são indicativos da assinatura da SSE, corroborando os resultados de Molinari et al. [1981] e Silveira et al. [1994].

\subsubsection{Seções Verticais de Velocidade Observada - ONEII}

Conforme comentamos anteriormente, das 13 radiais da comissão ONEII, obtivemos apenas 9 seções verticais de velocidade, pois os dados relativos às radiais 2, 3, 4 e 8, foram insuficientes para elaboração das respectivas seções. A assinatura da SNB pôde ser constatada nessas seções, tendo sido observada sua intensificação nas seções mais ao norte, com aumento de seu transporte e velocidade. Como constatamos a existência de dados de ADCP apenas até a profundidade $288 \mathrm{~m}$, e só há dados com valores de percent good superiores a 50\% até o nível de $176 \mathrm{~m}$, calculamos os transportes de volume, para as 9 seções, apenas de 0 a $200 \mathrm{~m}$. A Tabela 5.2 apresenta os valores de transporte de volume $(\mathrm{Sv})$ e de velocidade máxima $\left(\mathrm{m} \mathrm{s}^{-1}\right)$ referentes à assinatura da SNB observada nessas seções. Comparando os valores de transporte obtidos por Schott et al. [2005] a partir de dados de LADCP (vide Tabela 5.3) com os valores das radiais 
$1\left(\sim 11^{\circ} \mathrm{S}\right)$ e $5\left(\sim 5^{\circ} \mathrm{S}\right)$ da comissão ONEII, constantes da Tabela 5.2, verificamos que os valores da comissão em análise, apesar de se referirem à faixa de profundidade de 0 - $200 \mathrm{~m}$ e serem provenientes de poucos dados consistentes, corroboram os valores apresentados por Schott et al. [2005].

Tabela 5.2: Valores de transporte de volume $(\mathrm{Sv})$ e de velocidade máxima $\left(\mathrm{m} \mathrm{s}^{-1}\right)$ referentes à assinatura da SNB observada nas 9 seções das radiais da comissão ONEII. Os dados relativos às radiais 2, 3, 4 e 8, foram insuficientes para elaboração das respectivas seções.

\begin{tabular}{cccc}
\hline \hline \multicolumn{5}{c}{ Velocidade Observada - Comissão ONEII - Assinatura da SNB } \\
\hline \hline \multicolumn{4}{c}{ Transporte (Sv) } \\
Radial & $0-200 \mathrm{~m}$ & Velocidade $\left(\mathrm{m} \mathrm{s}^{-1}\right)$ & Núcleo $(\mathrm{m})$ \\
\hline 1 & 12,1 & 0,73 & 220 \\
5 & 14,5 & 1,17 & 200 \\
6 & 13,7 & 1,18 & 200 \\
7 & 18,3 & 1,30 & 180 \\
9 & 19,5 & 1,22 & 130 \\
10 & 21,9 & 1,06 & 150 \\
11 & 19,9 & 0,80 & 150 \\
12 & 22,0 & 1,30 & 130 \\
13 & 18,9 & 1,22 & 130 \\
\hline
\end{tabular}

Tabela 5.3: Valores de transporte de volume (Sv) calculados por Schott et al. [2005] a partir de dados de LADCP.

\begin{tabular}{|c|c|c|c|c|}
\hline \multirow[b]{2}{*}{ Seção } & \multicolumn{3}{|c|}{$\begin{array}{c}\text { Transporte }(\mathrm{Sv}) \text { por } \\
\text { faixa de densidade }\left(\mathrm{kg} \mathrm{m}^{-3}\right)\end{array}$} & \multirow[b]{2}{*}{$\begin{array}{c}\text { Transporte }(\mathrm{Sv}) \\
\text { Total }\end{array}$} \\
\hline & $\begin{array}{c}<24,5 \\
(\lesssim 50 \mathrm{~m})\end{array}$ & $\begin{array}{c}24,5-26,8 \\
(\backsim 50-250 \mathrm{~m})\end{array}$ & $\begin{array}{c}26,8-32,15 \\
(\backsim 250-1150 \mathrm{~m})\end{array}$ & \\
\hline $11^{\circ} \mathrm{S}$ & 1,6 & 12,9 & 10,9 & 25,4 \\
\hline Desv. Padrão & 1,0 & 3,5 & 3,9 & 7,4 \\
\hline $5^{\circ} \mathrm{S}$ & 3,4 & 14,2 & 8,9 & 26,5 \\
\hline Desv. Padrão & 1,6 & 2,4 & 1,5 & 3,7 \\
\hline
\end{tabular}

A seguir, serão apresentadas as análises referentes às seções correspondentes às radiais 1 , 5, 6, 9 e 12 da comissão ONEII, obtidas a partir da interpolação por AO. A Figura 5.10 representa os respectivos mapas de erro de interpolação (\%). 
As Figuras 5.11, 5.12 e 5.13 representam as seções verticais de velocidade observada $\left(\mathrm{m} \mathrm{s}^{-1}\right)$ referentes à comissão ONEII. A Figura 5.11 corresponde às radiais 1 e 5, a Figura 5.12 corresponde às radiais 6 e 9 e a Figura 5.13, à radial 12.

Na Figura 5.11, a seção referente à radial 1 apresenta a SNB com núcleo de subsuperfície em aproximadamente $220 \mathrm{~m}$, a uma distância aproximada da costa de $15 \mathrm{~km}$. De 0 a $200 \mathrm{~m}$, os valores de transporte de volume e de velocidade máxima da SNB para essa seção foram 12,1 Sv e 0,73 $\mathrm{m} \mathrm{s}^{-1}$, respectivamente (Tabela 5.2). A seção referente à radial 5, apresenta a SNB com núcleo de subsuperfície em aproximadamente $200 \mathrm{~m}$, a uma distância aproximada da costa de $25 \mathrm{~km}$. De 0 a $200 \mathrm{~m}$, os valores de transporte de volume e de velocidade máxima da SNB para essa seção foram 14,5 Sv e 1,17 $\mathrm{m} \mathrm{s}^{-1}$, respectivamente (Tabela 5.2).

Na Figura 5.12, a seção referente à radial 6 apresenta a SNB com núcleo de subsuperfície em aproximadamente $180 \mathrm{~m}$, a uma distância aproximada da costa de 25 $\mathrm{km}$, podendo-se observar também um contrafluxo em seu limite leste com núcleo em aproximadamente $200 \mathrm{~m}$, a uma distância aproximada da costa de $200 \mathrm{~km}$. Esse contrafluxo corresponde à SSE em formação, como observado nos dados da comissão ONEI e descrito pelos padrões geostróficos de Molinari et al. [1981] e Silveira et al. [1994]. De 0 a $200 \mathrm{~m}$, os valores de transporte de volume e de velocidade máxima da SNB para essa seção foram 13,7 Sv e 1,18 $\mathrm{m} \mathrm{s}^{-1}$, respectivamente (Tabela 5.2).

A seção referente à radial 9 da Figura 5.12, apresenta a SNB com núcleo de subsuperfície em aproximadamente $130 \mathrm{~m}$, a uma distância aproximada da costa de 160 $\mathrm{km}$. De 0 a $200 \mathrm{~m}$, os valores de transporte de volume e de velocidade máxima da SNB para essa seção foram 19,5 Sv e 1,22 $\mathrm{m} \mathrm{s}^{-1}$, respectivamente (Tabela 5.2). Nessa seção também observamos a assinatura do anticiclone verificado na seção da radial 8 da comissão ONEI, confirmando a feição de mesoescala observada nos mapas de função de corrente geostrófica baroclínica relativa (Figuras 4.11, 4.12, 4.13, e 4.14), descritos no Capítulo 4

A seção referente à radial 9 foi elaborada com o intuito de confrontarmos a sua análise com a da seção referente à radial 8 da comissão ONEI, tendo em vista que a radial 8 da comissão ONEII apresentou quantidade insuficiente de dados com percent good superior a 50\%, impossibilitando a elaboração da respectiva seção. 

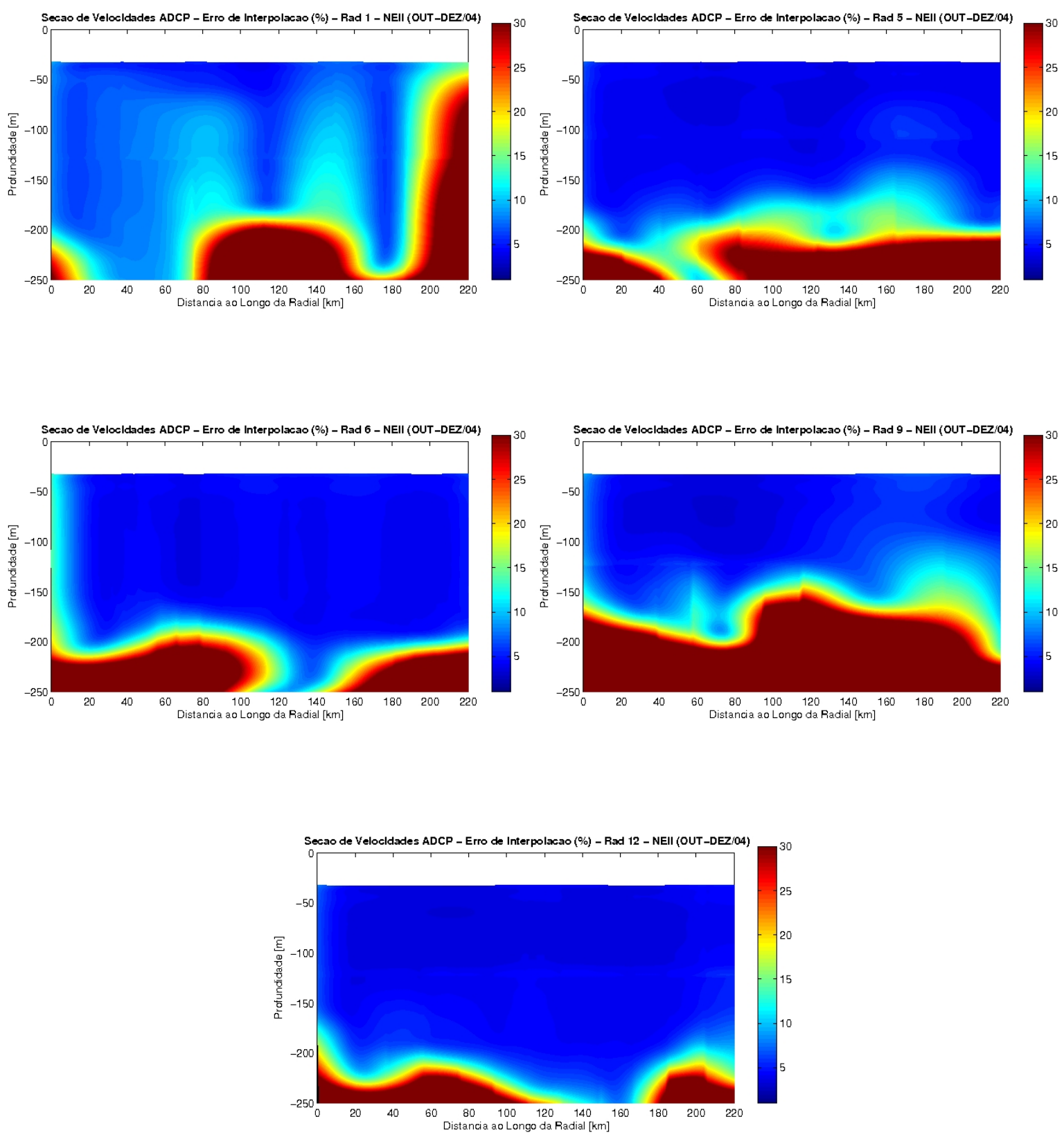

Figura 5.10: Mapas de erro de interpolação (\%) associados às seções de velocidade observada das radiais 1, 5, 6, 9 e 12 da comissão ONEII. As seções foram obtidas a partir da interpolação por $\mathrm{AO}$ dos dados de ADCP processados pelo CODAS. 

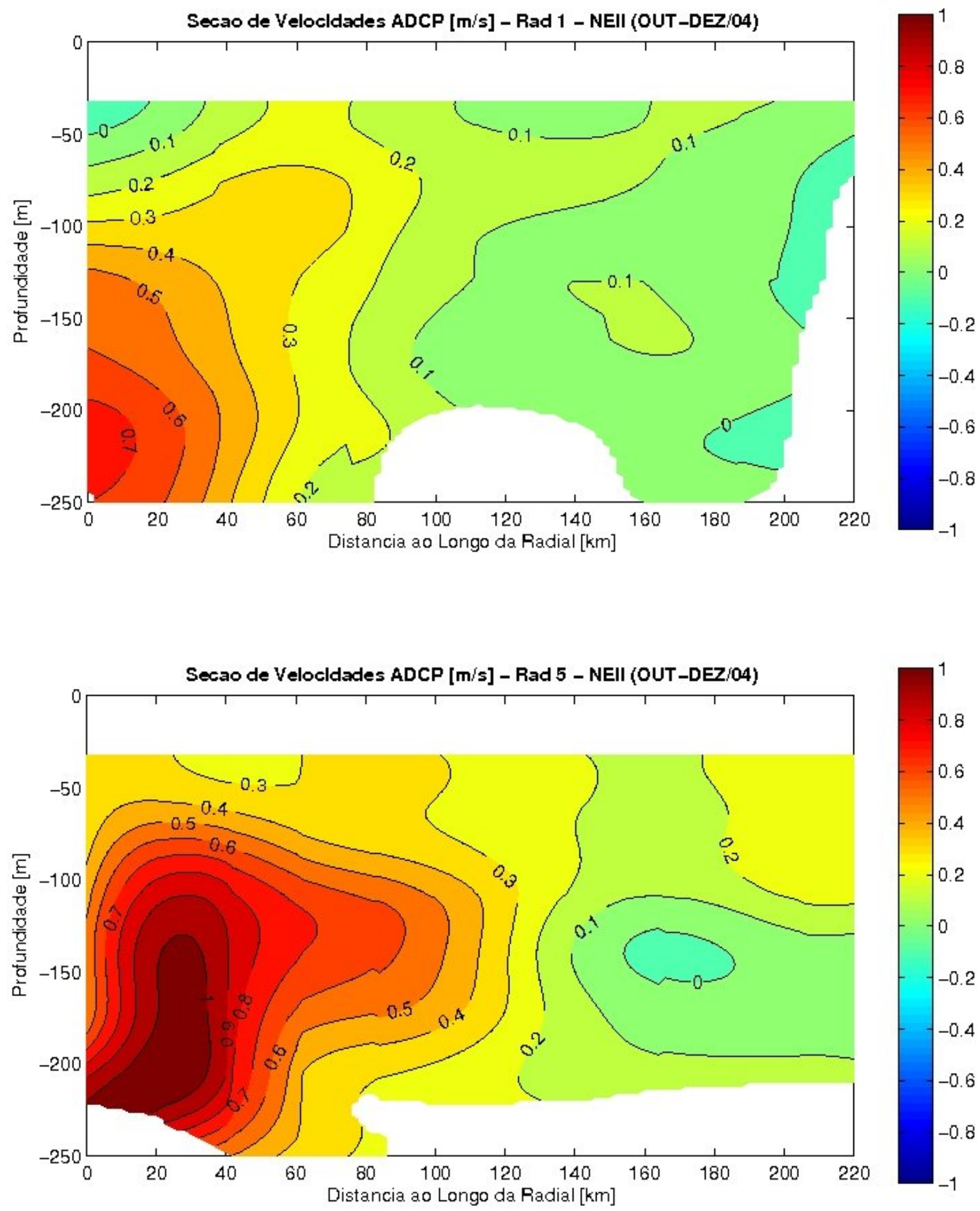

Figura 5.11: Seções verticais de velocidade observada $\left(\mathrm{m} \mathrm{s}^{-1}\right)$ obtidas a partir dos dados processados pelo sistema CODAS, referentes às radiais 1 (painel superior) e 5 (painel inferior) da comissão ONEII. As seções foram obtidas a partir de AO dos dados de ADCP processados pelo CODAS, e os valores com erro de interpolação superior a $30 \%$ foram retirados (áreas na cor branca). O intervalo entre isotacas é de $0,1 \mathrm{~m} \mathrm{~s}^{-1}$. Valores positivos para norte. 

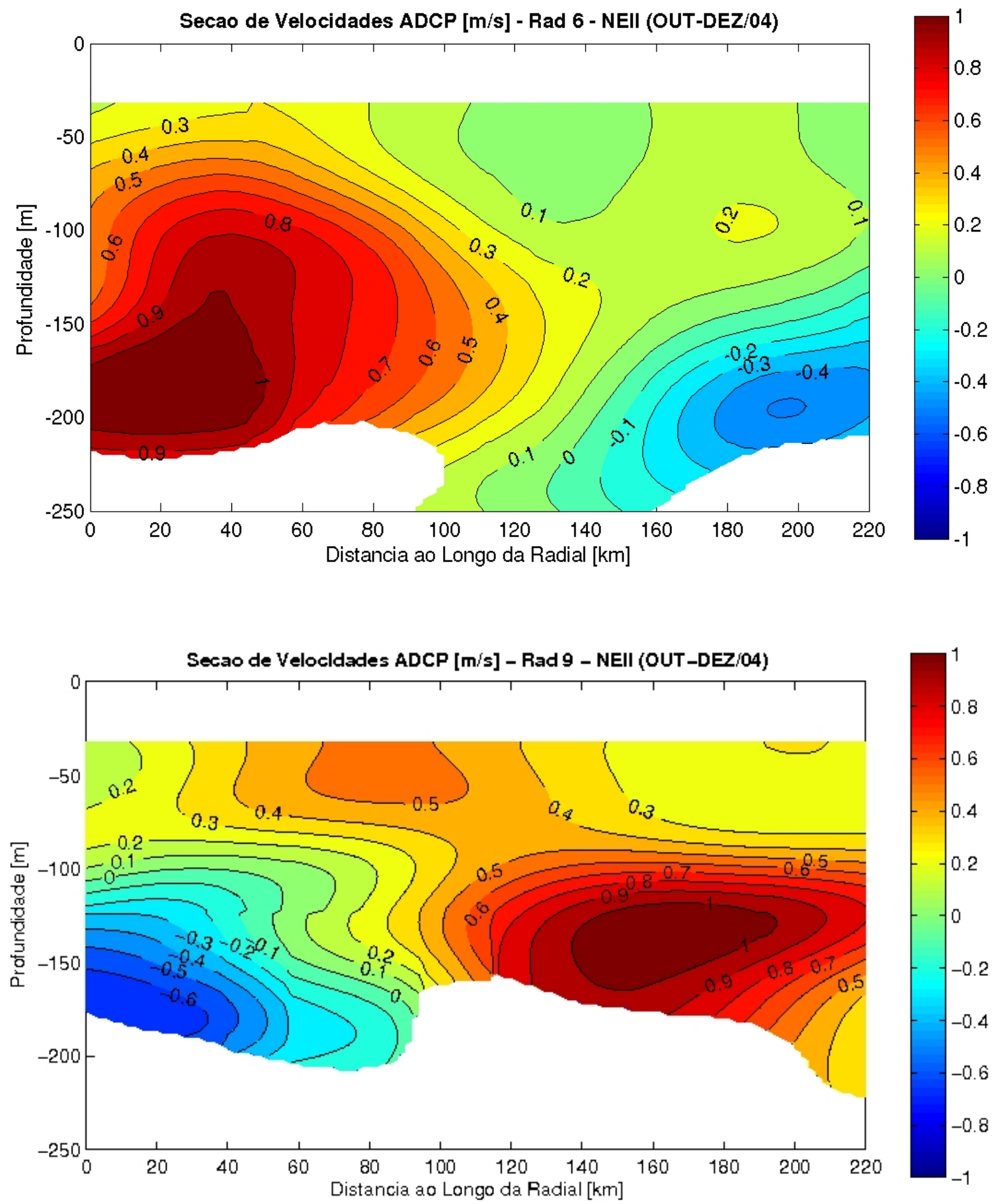

Figura 5.12: Seções verticais de velocidade observada $\left(\mathrm{m} \mathrm{s}^{-1}\right)$ obtidas a partir dos dados processados pelo sistema CODAS, referentes às radiais 6 (painel superior) e 9 (painel inferior) da comissão ONEII. As seções foram obtidas a partir de AO dos dados de ADCP processados pelo CODAS, e os valores com erro de interpolação superior a $30 \%$ foram retirados (áreas na cor branca). O intervalo entre isotacas é de $0,1 \mathrm{~m} \mathrm{~s}^{-1}$. Valores positivos para norte. 
Na Figura 5.13, a seção referente à radial 12 apresenta a SNB com núcleo de subsuperfície em aproximadamente 130 m, a uma distância aproximada da costa de 30 $\mathrm{km}$, podendo-se observar também um contrafluxo em seu limite leste, com núcleo em aproximadamente $160 \mathrm{~m}$, a uma distância aproximada da costa de $220 \mathrm{~km}$. De 0 a 200 $\mathrm{m}$, os valores de transporte de volume e de velocidade máxima da SNB para essa seção foram $22 \mathrm{~Sv}$ e 1,30 $\mathrm{m} \mathrm{s}^{-1}$, respectivamente (Tabela 5.2).

A seção referente à radial 12 é particularmente interessante por duas razões. A primeira é que as velocidades da SNB em superfície já estão muito maiores que nas seções mais ao sul, indicando um aporte adicional da CSE e o processo de "transformação" da SNB em CNB descrito por Stramma et al. [2005]. A segunda é a presença de um contrafluxo de características semelhantes àquele observado na radial 6. Entretanto, esse contrafluxo não se trata da mesma estrutura observada na radial 6 - a SSE - e sim do ramo picnoclínico e subpicnoclínico da retroflexão da CNB ao norte do equador para originar a SE e a SNE. A feição observada nessa seção corrobora os estudos de Goes et al. [2005].

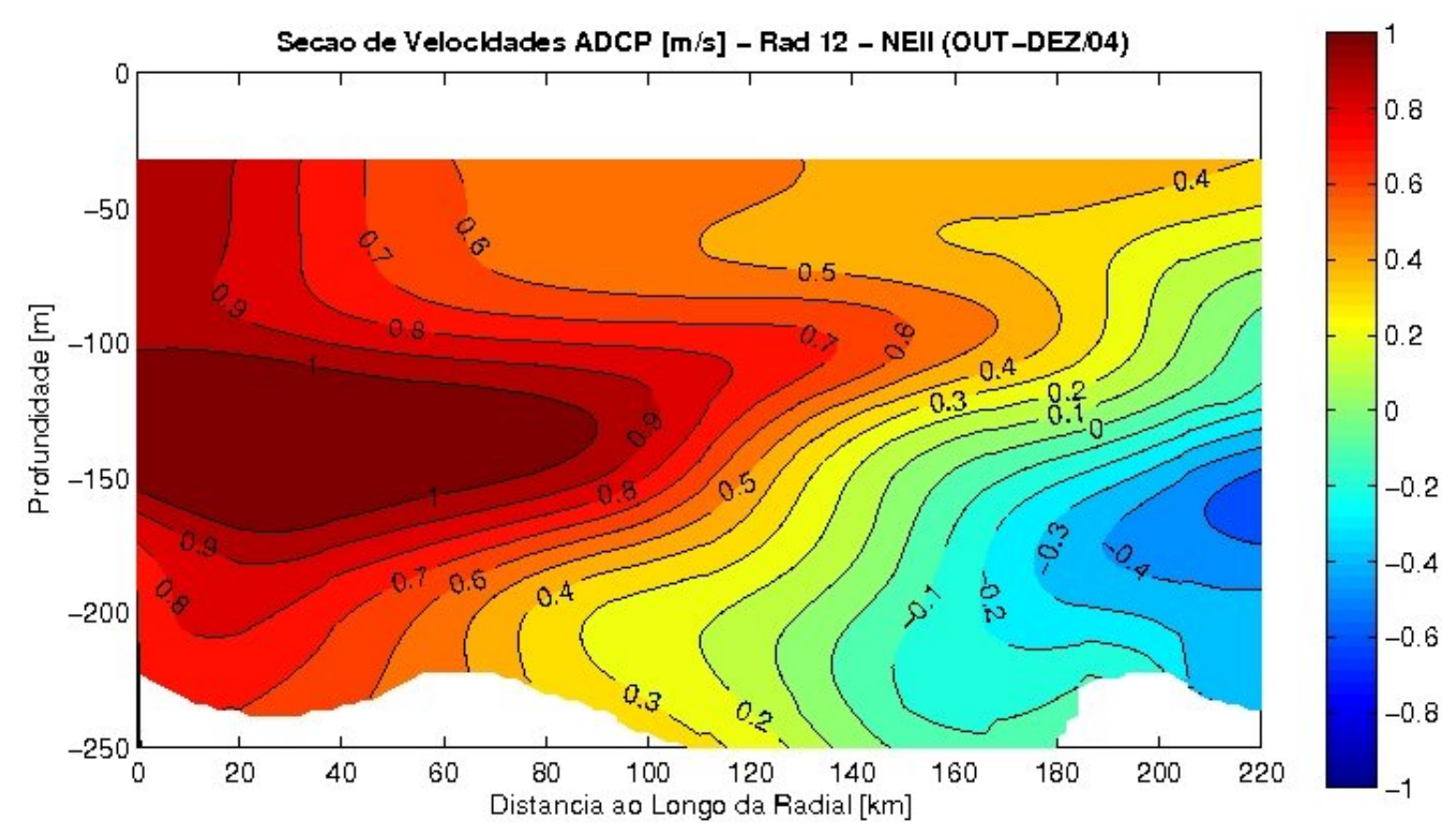

Figura 5.13: Seção vertical de velocidade observada $\left(\mathrm{m} \mathrm{s}^{-1}\right)$ obtida a partir dos dados processados pelo sistema CODAS, referente à radial 12 da comissão ONEII. A seção foi obtida a partir de $\mathrm{AO}$ dos dados de $\mathrm{ADCP}$ processados pelo CODAS, e os valores com erro de interpolação superior a 30\% foram retirados (áreas na cor branca). O intervalo entre isotacas é de $0,1 \mathrm{~m} \mathrm{~s}^{-1}$. Valores positivos para norte. 


\subsubsection{Mapa de Função de Corrente Observada - ONEI e ONEII}

Foram elaboradas distribuições horizontais de função de corrente observada $\left(\psi_{\text {obs }}\right)$ para os níveis de $32 \mathrm{~m}, 96$ e $160 \mathrm{~m}$, referentes às velocidades observadas $\left(\vec{V}_{\text {obs }}\right)$ das comissões em análise. Estas três profundidades são exatamente ou aproximadamente coincidentes com as apresentadas para os padrões horizontais de $\psi_{g}$ no Capítulo 4. Não houve qualquer interpolação vertical destes.

A Figura 5.14 representa os mapas de $\psi_{o b s}\left(\mathrm{~m}^{2} \mathrm{~s}^{-1}\right)$ referentes à comissão ONEI, para os níveis de $32 \mathrm{~m}$ (painel superior) e $96 \mathrm{~m}$ (painel inferior), e a Figura 5.15, para o nível de $160 \mathrm{~m}$. A Figura 5.16 representa os mapas de $\psi_{\text {obs }}\left(\mathrm{m}^{2} \mathrm{~s}^{-1}\right)$ referentes à comissão ONEII, para os níveis de $32 \mathrm{~m}$ (painel superior) e $96 \mathrm{~m}$ (painel inferior), e a Figura 5.17, para o nível de $160 \mathrm{~m}$. A existência de radiais mais ao norte, na comissão ONEII, possibilitou a descrição da SNB numa área mais ampla, abrangendo a região ao norte da latitude de $5^{\circ} \mathrm{S}$.

Tanto nas figuras da comissão ONEI quanto nas figuras da comissão ONEII, podemos observar o escoamento da SNB ao largo da costa, contornando o Cabo Calcanhar (RN) em aproximadamente $5^{\circ} \mathrm{S}$, com parte do escoamento seguindo para o equador e parte tendendo a acompanhar o contorno da margem continental, caracterizando um anticiclone centrado em aproximadamente $4^{\circ} 30^{\prime} \mathrm{S}$ e $36^{\circ} \mathrm{W}$, semelhantemente ao observado nos mapas de $\psi_{g}$ apresentados nas Figuras 4.11, 4.12, 4.13 e 4.14 do capítulo anterior.

No mapa de $\psi_{\text {obs }}$ para o nível de $32 \mathrm{~m}$ da Figura 5.14 (painel superior), podemos observar o aporte do ramo central da CSE (CSEc), que contribui para tornar o núcleo da SNB mais raso e sua transformação na CNB, de acordo com as análises de Stramma et al. [2005]. Com relação ao mapa para o nível de 160 m (Figura 5.15), podemos constatar a presença de um ciclone entre as latitudes de $4^{\circ} \mathrm{S}$ e $6^{\circ} \mathrm{S}$ e entre as longitudes de $32^{\circ} \mathrm{W}$ e $34^{\circ} \mathrm{W}$, correspondendo, provavelmente, ao ramo CSEc alimentando a SSE, observando-se também a SSE sendo alimentada pela SNB, corroborando os estudos de Silveira et al. [1994]. Cumpre ressaltar a boa concordância entre os padrões observados no mapa referente ao nível de 96 m (painel inferior da Figura 5.14) e no mapa para o nível de $160 \mathrm{~m}$ (Figura 5.15) e os obtidos por geostrofia para os níveis de $100 \mathrm{~m}$ (painel inferior da Figura 4.11) e $160 \mathrm{~m}$ (painel superior da Figura 4.12, respectivamente, o 
mesmo acontecendo para os mapas de $\psi_{\text {obs }}$ da comissão ONEII para os mesmos níveis. (Figuras $4.13 \mathrm{e} 4.14$ ).

No mapa de $\psi_{o b s}$ para o nível de $32 \mathrm{~m}$ da Figura 5.16, podemos constatar o mesmo fenômeno observado na Figura 5.14 para o mesmo nível, com a diferença que o ramo CSEc é visto se adicionando à SNB e já caracterizando um padrão de correntes em superfície bastante robusto. Com relação ao mapa para o nível de $160 \mathrm{~m}$ (Figura 5.17. podemos constatar a presença de um ciclone entre as latitudes de $4^{\circ} \mathrm{S}$ e $6^{\circ} \mathrm{S}$ e entre as longitudes de $32^{\circ} \mathrm{W}$ e $34^{\circ} \mathrm{W}$, da mesma forma que no mapa para o mesmo nível da Figura 5.15, porém, a partir de $39^{\circ} \mathrm{W}$, o escoamento se aproxima do contorno oeste, seguindo paralelamente à costa. Entre os meridianos de $36^{\circ} \mathrm{W}$ e $40^{\circ} \mathrm{W}$ pode ser observada uma recirculação no sentido oposto ao da SNB. Verificamos também a retroflexão da SNB na latitude aproximada de $1^{\circ} \mathrm{S}$.

A extensão da comissão ONEII permite confirmar o que foi comentado na análise da seção de velocidade observada referente à radial 12 (Figura 5.13). Nas Figuras 5.16 (painel inferior) e 5.17, observa-se claramente parte da retroflexão da CNB em níveis picnoclínicos para originar a SE/SNE, conforme descrito por Goes et al. [2005]. Na Figura 5.17 podemos observar também cessão de água da SNB através de uma recirculação ciclônica centrada em $2^{\circ} \mathrm{S}$ e $36^{\circ} 30^{\prime} \mathrm{W}$.

Pudemos verificar a assinatura da SNB em todos os padrões verticais e horizontais obtidos a partir do processamento dos dados de ADCP das comissões em análise. Os resultados obtidos com o processamento dos dados de ADCP foram coerentes com os resultados obtidos a partir dos dados termohalinos, confirmando as descrições presentes na literatura. 

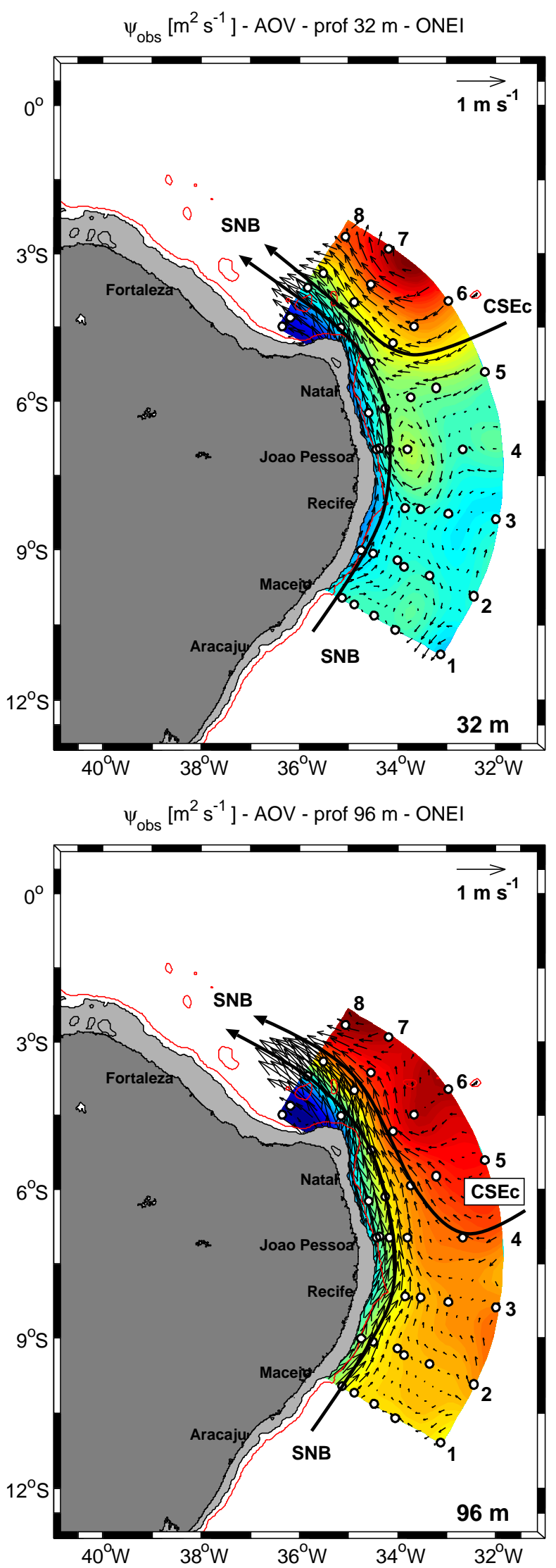

Figura 5.14: Mapas de $\psi_{\text {obs }}$, para $32 \mathrm{~m}$ e $96 \mathrm{~m}$ (ONEI). Vetores de $\vec{V}_{\text {obs }}\left(\mathrm{m} \mathrm{s}^{-1}\right)$ sobrepostos aos campos de $\psi_{o b s}\left(\mathrm{~m}^{2} \mathrm{~s}^{-1}\right)$. Máscara cinza junto à costa: região sobre a plataforma continental limitada pela isóbata de $100 \mathrm{~m}$ (contorno dinâmico). Linha vermelha: isóbata de $1.000 \mathrm{~m}$. 


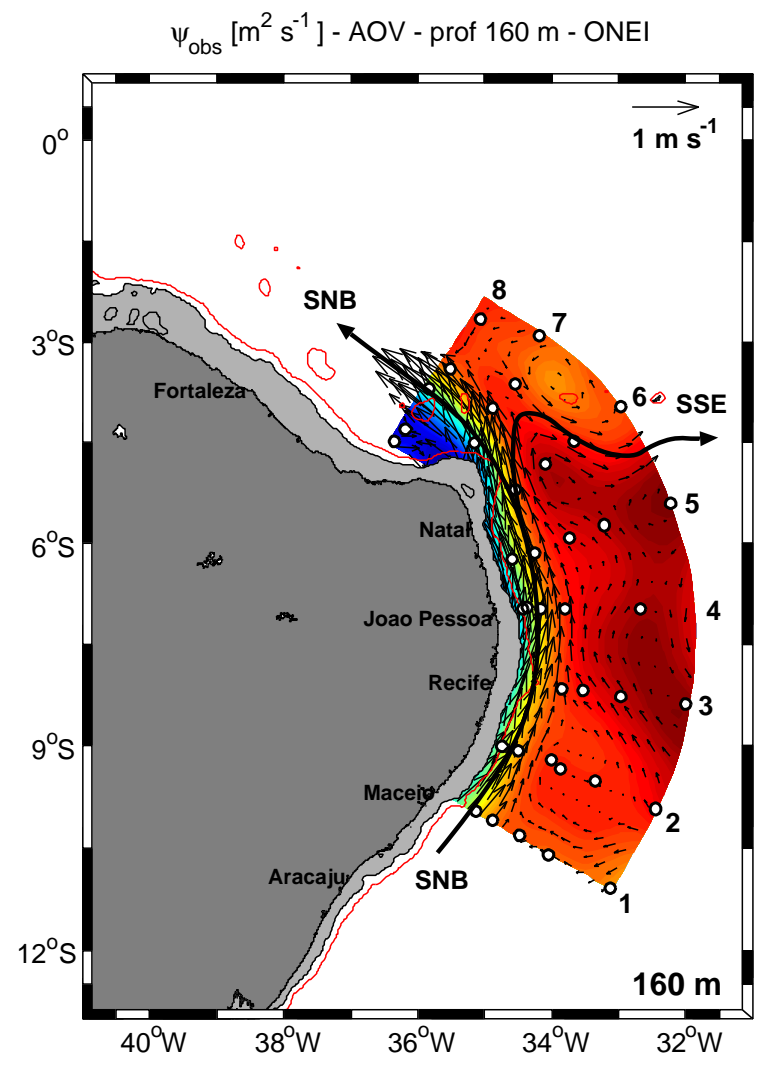

Figura 5.15: Mapa de $\psi_{\text {obs }}$ para $160 \mathrm{~m}$ (ONEI). Vetores de $\vec{V}_{\text {obs }}\left(\mathrm{m} \mathrm{s}^{-1}\right)$ sobrepostos aos campos de $\psi_{\text {obs }}\left(\mathrm{m}^{2} \mathrm{~s}^{-1}\right)$. Máscara cinza junto à costa: região sobre a plataforma continental limitada pela isóbata de $100 \mathrm{~m}$ (contorno dinâmico). Linha vermelha: isóbata de $1.000 \mathrm{~m}$. 

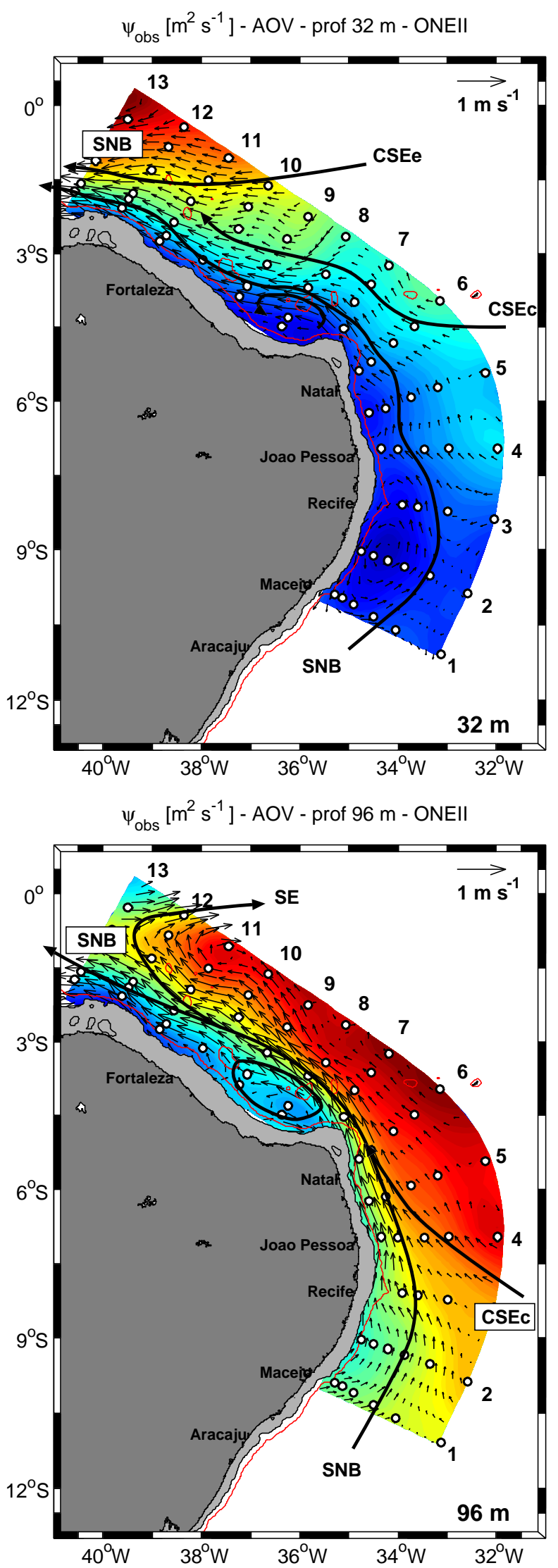

Figura 5.16: Mapas de $\psi_{\text {obs }}$, para $32 \mathrm{~m} \mathrm{e} 96 \mathrm{~m}$ (ONEII). Vetores de $\vec{V}_{\text {obs }}\left(\mathrm{m} \mathrm{s}^{-1}\right)$ sobrepostos aos campos de $\psi_{o b s}\left(\mathrm{~m}^{2} \mathrm{~s}^{-1}\right)$. Máscara cinza junto à costa: região sobre a plataforma continental limitada pela isóbata de $100 \mathrm{~m}$ (contorno dinâmico). Linha vermelha: isóbata de $1.000 \mathrm{~m}$. 


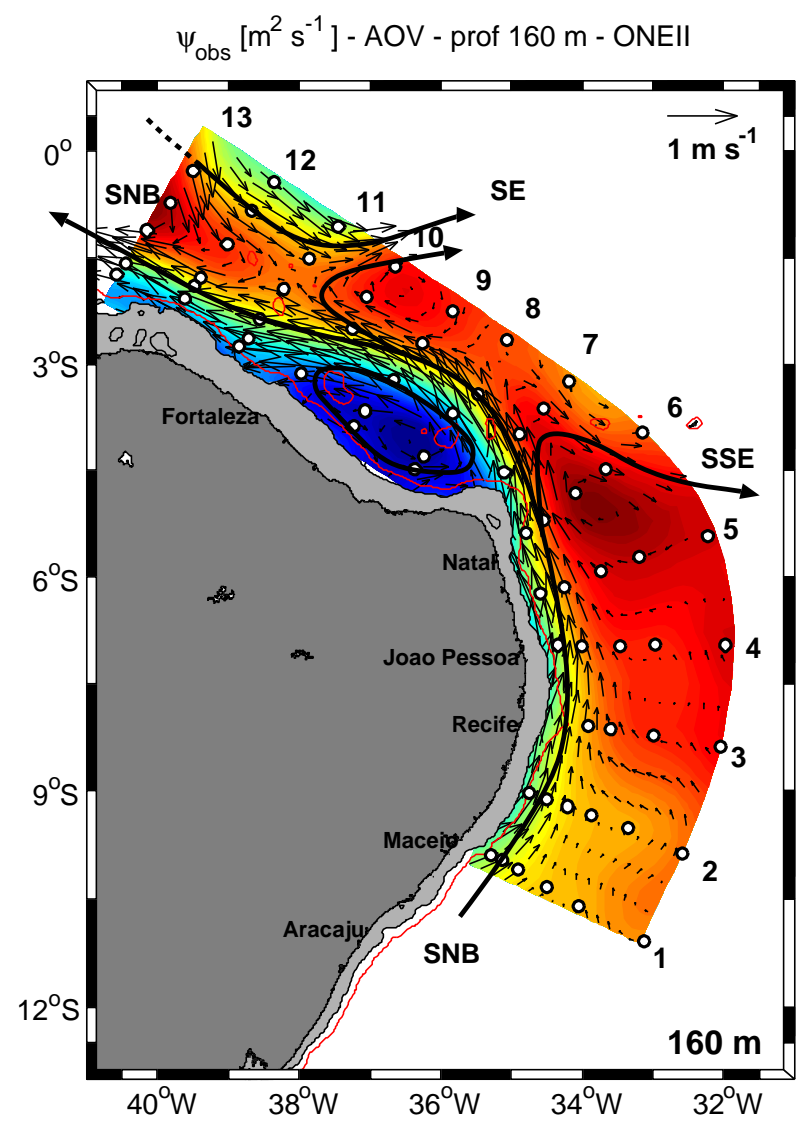

Figura 5.17: Mapa de $\psi_{\text {obs }}$, para $160 \mathrm{~m}$ (ONEII). Vetores de $\vec{V}_{o b s}\left(\mathrm{~m} \mathrm{~s}^{-1}\right)$ sobrepostos aos campos de $\psi_{o b s}\left(\mathrm{~m}^{2} \mathrm{~s}^{-1}\right)$. Máscara cinza junto à costa: região sobre a plataforma continental limitada pela isóbata de $100 \mathrm{~m}$ (contorno dinâmico). Linha vermelha: isóbata de $1.000 \mathrm{~m}$. 


\section{Capítulo 6}

\section{Padrões Horizontais Geostróficos}

\section{Absolutos}

\subsection{Preâmbulo}

Historicamente, escoamentos geostróficos têm sido calculados a partir de dados hidrográficos, através do Método Dinâmico Clássico. De fato, boa parte das informações sobre circulação oceânica são provenientes desses cálculos. Contudo, as desvantagens inerentes a esse método evidenciam a necessidade de construção de campos de circulação geostrófica absoluta para uma descrição mais realística dos escoamentos. Conforme dissemos anteriormente, a disponibilidade de dados termohalinos e de dados de velocidade de corrente, coletados simultaneamente, possibilitou que realizássemos estimativas de circulação geostrófica absoluta, através do MDR, com base na técnica desenvolvida por Sutton \& Chereskin [2002]. Foram construídos campos de função de corrente geostrófica absoluta $\left(\psi_{g_{a b s}}\right)$ utilizando-se a Eq. 3.20 apresentada na Seção 3.4 do Capítulo 3 .

Já obtivemos velocidades geostróficas baroclínicas relativas à $1.150 \mathrm{~m}$, de acordo com o apresentado no Capítulo 4 e estas foram comparadas qualitativamente com velocidades observadas no Capítulo 5 . Como constatamos boa concordância entre os resultados geostróficos e os observados, e estes resultados confirmaram as descrições presentes na literatura, é pertinente a indagação sobre o motivo de realizarmos cálculos geostróficos absolutos. 
A principal razão para esses cálculos foi o fato de dispormos de dados de ADCP apenas em níveis pouco profundos. Os padrões horizontais de circulação podem ser obtidos para qualquer profundidade. Portanto, no presente capítulo, iremos descrever os procedimentos metodológicos utilizados na construção dos campos de $\psi_{g_{a b s}}$, referentes aos dados das comissões ONEI e ONEII, bem como os respectivos resultados e análises.

\subsection{Resultados e Discussão}

Com o intuito de obtermos uma descrição sinótica dos padrões horizontal e vertical do escoamento da SNB ao largo da costa do nordeste, bem como de outras estruturas de mesoescala associadas à SNB, foram construídos campos de função de corrente geostrófica absoluta $\left(\psi_{g_{a b s}}\right)$ a partir dos dados das comissões ONEI e ONEII.

Um dos objetivos específicos do presente trabalho foi o de obter uma descrição sinótica do padrão horizontal de circulação geostrófica absoluta, associada ao escoamento da SNB, através da construção de campos horizontais de função de corrente geostrófica absoluta referenciada por dados de ADCP de casco, a fim de se obter resultados em profundidades maiores que as de alcance do perfilador de velocidade acústico. Para tanto, foram elaboradas distribuições horizontais de $\psi_{g_{a b s}}$ para os níveis de $32 \mathrm{~m}, 100 \mathrm{~m}, 200 \mathrm{~m}$ e $500 \mathrm{~m}$.

Os mapas de $\psi_{g_{a b s}}$ da comissão ONEI são apresentados nas Figuras 6.1 (níveis de $32 \mathrm{~m}$ e $100 \mathrm{~m}$ ) e 6.2 (níveis de $200 \mathrm{~m}$ e $500 \mathrm{~m}$ ). Os mapas de $\psi_{g_{a b s}}$ da comissão ONEII são apresentados nas Figuras 6.3 (níveis de 32m e 100 m) e 6.4 (níveis de $200 \mathrm{~m}$ e 500 $\mathrm{m})$.

A primeira constatação, ao verificarmos os mapas de $\psi_{g_{a b s}}$ das comissões em análise, é a existência de características híbridas advindas da combinação dos padrões de circulação geostrófica e observada. Obviamente, omitimos o mapa referente ao nível de $160 \mathrm{~m}$, tendo em vista que esse nível foi utilizado como referência para os cálculos aqui apresentados. Em contrapartida, acrescentamos o de $500 \mathrm{~m}$, profundidade de interface com as águas intermediárias. 

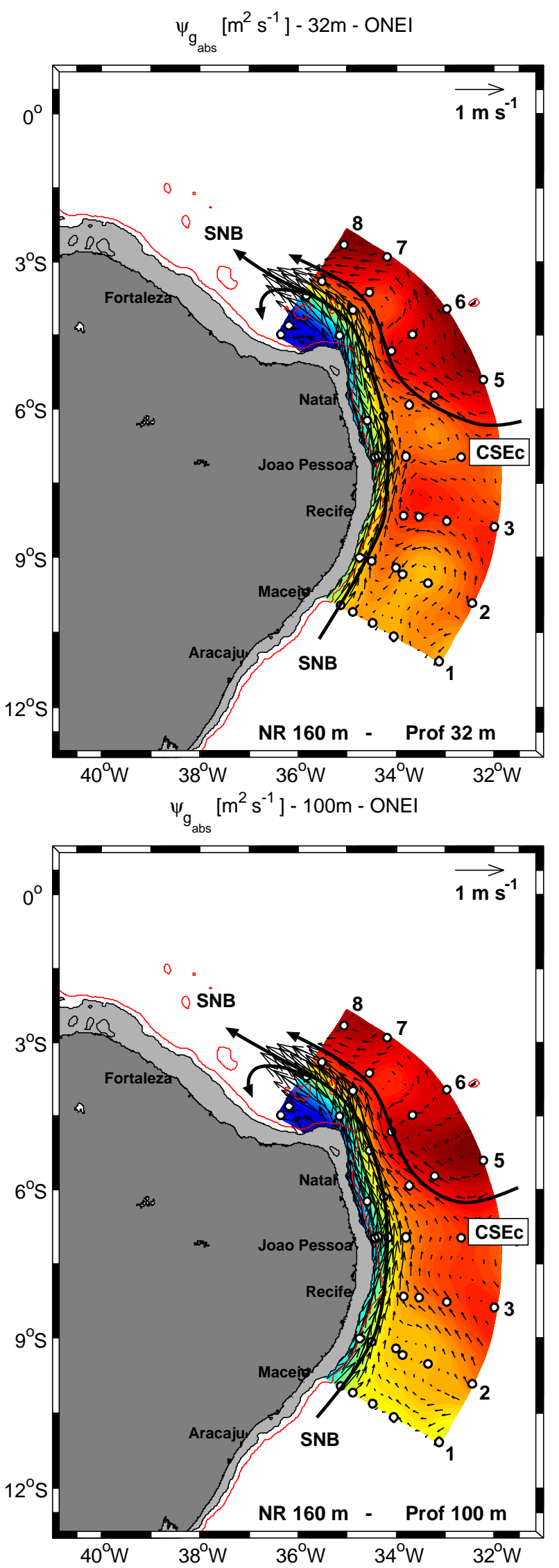

Figura 6.1: Mapas de $\psi_{g_{a b s}}$ calculados a partir do MDR com NR $=160 \mathrm{~m}$, para os níveis de 32 $\mathrm{m}$ (painel superior) e $100 \mathrm{~m}$ (painel inferior). Vetores de $\vec{V}_{g_{a b s}}\left(\mathrm{~m} \mathrm{~s}^{-1}\right)$ sobrepostos aos campos de $\psi_{g_{a b s}}\left(\mathrm{~m}^{2} \mathrm{~s}^{-1}\right)$. Dados da comissão ONEI. 

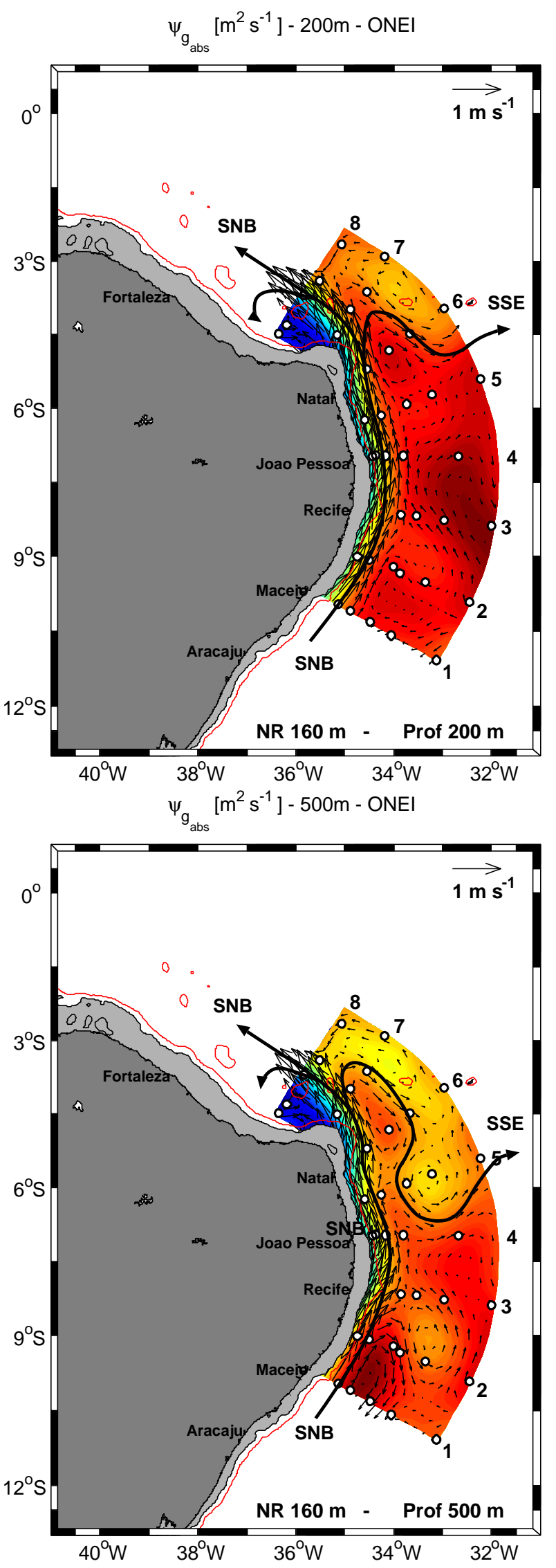

Figura 6.2: Mapas de $\psi_{g_{a b s}}$ calculados a partir do MDR com NR $=160 \mathrm{~m}$, para os níveis de 200 $\mathrm{m}$ (painel superior) e $500 \mathrm{~m}$ (painel inferior). Vetores de $\vec{V}_{g_{a b s}}\left(\mathrm{~m} \mathrm{~s}^{-1}\right)$ sobrepostos aos campos de $\psi_{g_{a b s}}\left(\mathrm{~m}^{2} \mathrm{~s}^{-1}\right)$. Dados da comissão ONEI. 
Nos mapas de $\psi_{g_{a b s}}$ de ambas as comissões podemos observar o escoamento da SNB ao largo da costa, contornando o Cabo Calcanhar $(\mathrm{RN})$ em aproximadamente $5^{\circ}$ S, com parte do escoamento seguindo para o equador e parte tendendo a acompanhar o contorno da margem continental, verificando-se o mesmo anticiclone frontal observado nos mapas de $\psi_{g}$ (Capítulo 4) e confirmado nos mapas de $\psi_{\text {obs }}$ (Capítulo 5).

Os mapas de $\psi_{g_{a b s}}$ para a comissão ONEI, nos níveis de 32 e 100 m (Figura 6.1) mostram uma SNB bem definida desde a radial 1, mais ao sul. Comparando os padrões dessas figuras com os padrões geostróficos (Capítulo 4) e os observados (Capítulo 5) para os níveis correspondentes, verificamos que se assemelham mais aos padrões observados. Em contrapartida, o ramo central da CSE (CSEc), em 32 m, aparece menos robusto que o verificado tanto no mapa de $\psi_{g}$ quanto no mapa de $\psi_{\text {obs }}$ para esse nível. Segundo Pickart E Lindstrom [1993], tal situação é possível devido a uma limitação metodológica decorrente da diferença entre as formas como as velocidades por ADCP e dados hidrográficos são amostrados. De qualquer maneira, é evidente que a SNB adquire mais velocidade e momentum na porção norte do domínio.

O mapa de $\psi_{g_{a b s}}$ para a comissão ONEI, no nível de 200 m (Figura 6.2, painel superior) mostra, de forma inequívoca e robusta, a origem da SSE dominantemente a partir da SNB, da mesma forma que os campos geostróficos baroclínicos relativos e o observado. O mapa $\psi_{g_{a b s}}$ para o nível de $500 \mathrm{~m}$ (Figura 6.2, painel inferior) exibe um ciclone vigoroso no extremo sul da região e um enfraquecimento do ramo da SNB que forma a SSE em torno de $3^{\circ} \mathrm{S}-4^{\circ} \mathrm{S}$. O decaimento da velocidade da SSE a valores da ordem de 0,1 $\mathrm{m} \mathrm{s}^{-1}$, ou menores, neste nível, é descrito por Molinari et al. [1981].

Em relação aos mapas $\psi_{g_{a b s}}$ para a comissão ONEII, no nível de 32 m (Figura 6.3 . painel superior), o padrão obtido se assemelha mais ao geostrófico (Figura 4.13, painel superior) do que ao observado (Figura 5.16, painel superior). A descrição da literatura corrobora o campo observado, onde não é vista qualquer evidência da retroflexão da CNB em nível de superfície. Sabemos que, dentro da camada de mistura, a CNB se separa da costa em torno de $6^{\circ} \mathrm{S}-7^{\circ} \mathrm{S}$ [Silveira et al., 2000a]. 

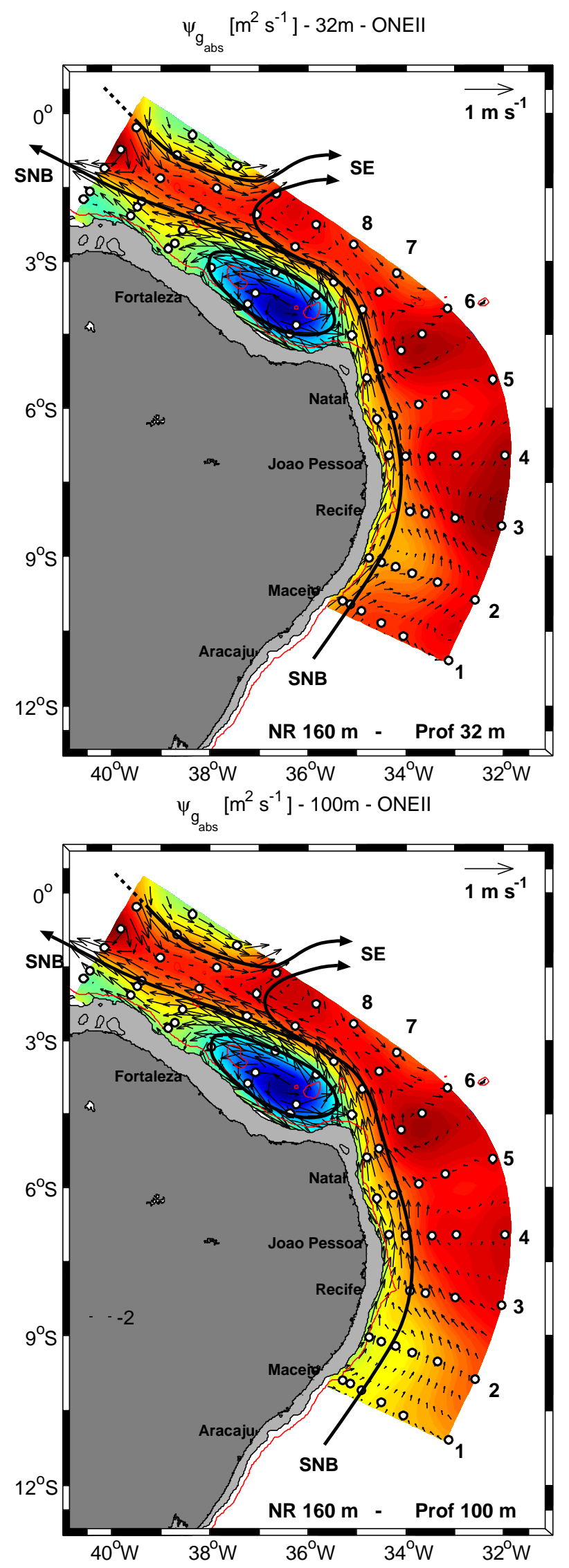

Figura 6.3: Mapas de $\psi_{g_{a b s}}$ calculados a partir do MDR com NR $=160 \mathrm{~m}$, para os níveis de 32 $\mathrm{m}$ (painel superior) e $100 \mathrm{~m}$ (painel inferior). Vetores de $\vec{V}_{g_{a b s}}\left(\mathrm{~m} \mathrm{~s}^{-1}\right)$ sobrepostos aos campos de $\psi_{g_{a b s}}\left(\mathrm{~m}^{2} \mathrm{~s}^{-1}\right)$. Dados da comissão ONEII. 

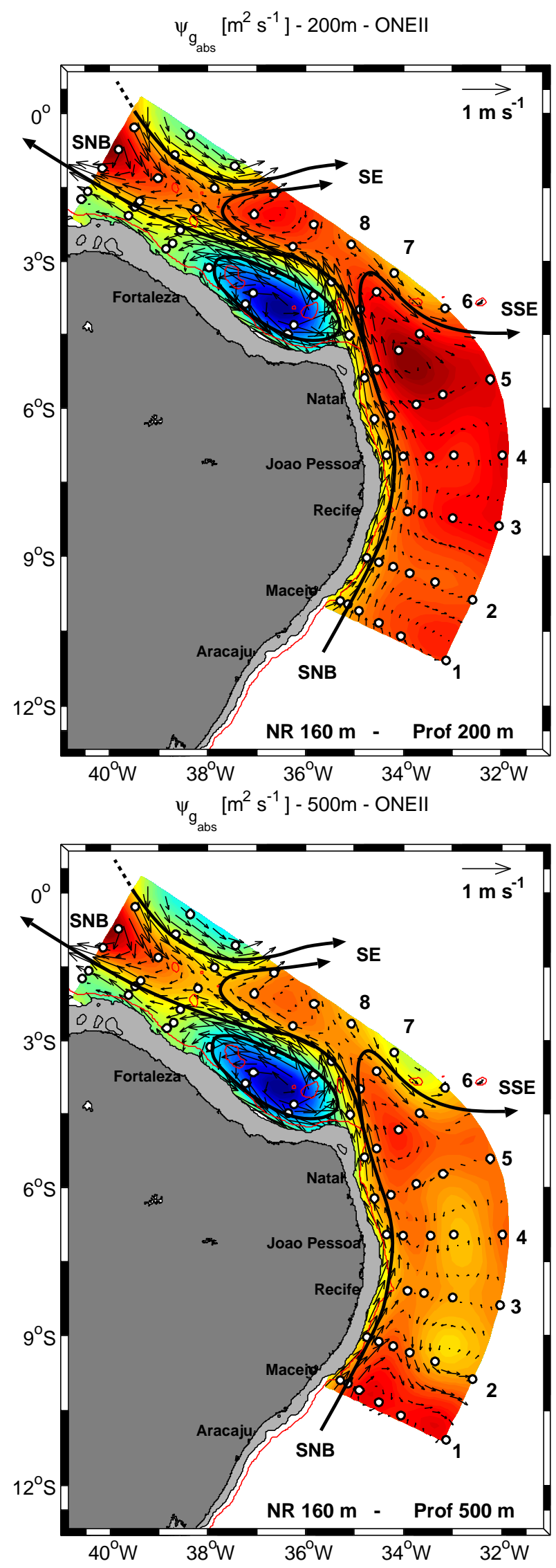

Figura 6.4: Mapas de $\psi_{g_{a b s}}$ calculados a partir do MDR com NR $=160 \mathrm{~m}$, para os níveis de 200 $\mathrm{m}$ (painel superior) e $500 \mathrm{~m}$ (painel inferior). Vetores de $\vec{V}_{g_{a b s}}\left(\mathrm{~m} \mathrm{~s}^{-1}\right)$ sobrepostos aos campos de $\psi_{g_{a b s}}\left(\mathrm{~m}^{2} \mathrm{~s}^{-1}\right)$. Dados da comissão ONEII. 
Os padrões de $100 \mathrm{~m}$ (Figura 6.3, painel inferior), $200 \mathrm{~m}$ e $500 \mathrm{~m}$ (Figura 6.4) são semelhantes e repetem o padrão de referência de 160 m, mas com diferentes intensidades de velocidade. Os mapas de circulação geostrófica absoluta, nesses níveis, exibem a SNB de forma mais organizada do que aqueles de $\psi_{g}$.

O vórtice (ou meandro) frontal de mesoescala, centrado na longitude da cidade de Macau (RN), apresentou-se de forma consistente e mais vigorosa nos campos geostróficos absolutos que nos geostróficos relativos, e sua extensão vertical coincide com a da SNB. Propomos, então, para essa estrutura, a denominação de vórtice de Macau (VM). Como há indícios dessa feição na ONEI (Figuras 6.1 e 6.2) e é claramente observado na ONEII (Figuras 6.3 e 6.4), especulamos que pode se tratar de uma estrutura quase-permanente da região. Esse vórtice seria resposta à inércia da SNB , bem como sua tentativa de conservar vorticidade, ao cruzar a abrupta mundança de orientação de costa, no Cabo Calcanhar (RN). Obviamente, mais expedições são necessárias para confirmar a suposição acima.

A Tabela 6.1, referente aos dados da comissão ONEI, apresenta os valores máximos de magnitude de velocidade não-divergente $\left(\mathrm{m} \mathrm{s}^{-1}\right)$ referentes ao núcleo da SNB nos campos de $\psi_{g}, \psi_{\text {obs }}$ e $\psi_{g_{a b s}}$, para os níveis de $32 \mathrm{~m}, 96 \mathrm{~m}$ e $200 \mathrm{~m}$, exemplificando a maior relevância dos valores obtidos a partir do MDR (geostróficos absolutos), quando comparados com os obtidos a partir do MDC (geostróficos baroclínicos relativos). Nessa tabela, podemos constatar que os valores de velocidades geostróficas absolutas aproximam-se mais dos valores de velocidade observada que os de geostróficas relativas.

Tabela 6.1: Valores máximos de magnitude de velocidade não-divergente $\left(\mathrm{m} \mathrm{s}^{-1}\right)$ referentes ao núcleo da SNB nos campos de $\psi_{g}, \psi_{o b s}$ e $\psi_{g_{a b s}}$, para os níveis de $32 \mathrm{~m}, 96 \mathrm{~m}$ e $200 \mathrm{~m}$. Dados da comissão ONEI.

\begin{tabular}{cccc}
\hline \hline \multicolumn{4}{c}{ Comissão ONEI } \\
\hline \hline \multirow{3}{*}{ Prof } & \multicolumn{3}{c}{ Velocidade não-divergente $\left(\mathrm{m} \mathrm{s}^{-1}\right)$} \\
\cline { 2 - 4 } & $\left|\vec{V}_{g}\right|$ & $\left|\vec{V}_{\text {obs }}\right|$ & $\left|\vec{V}_{g_{\text {abs }}}\right|$ \\
\hline 32 & 0,46 & 0,90 & 1,26 \\
96 & 0,54 & 1,35 & 1,27 \\
200 & 0,46 & 1,26 & 1,33 \\
\hline
\end{tabular}




\section{Capítulo 7}

\section{Considerações Finais}

\subsection{Síntese e Conclusões}

A SNB é um escoamento de características relevantes na margem continental brasileira. Contudo, ainda é escasso o conhecimento acerca dos processos de formação e da origem da SNB, bem como sobre outras feições associadas a essa corrente. Citamos, por exemplo, a inexistência de descrições de padrões horizontais de mesoescala associados à essa corrente, em termos de velocidade absoluta. Essa lacuna na literatura levou-nos a estabelecer os objetivos do presente trabalho. De acordo com os objetivos estabelecidos, foram elaboradas distribuições verticais e horizontais a partir dos dados disponíveis com o intuito de descrevermos sinoticamente o escoamento da SNB, bem como outras estruturas de mesoescala associadas a esse escoamento.

O presente trabalho foi desenvolvido a partir de dados de CTD e de ADCP, coletados simultaneamente, nas comissões ONEI e ONEII. A coleta simultânea de dados de CTD e de ADCP possibilita estimativas de velocidades geostróficas absolutas. A utilização de dados de ADCP como referência para a determinação de escoamentos geostróficos absolutos tem se tornado freqüente. Os perfiladores ADCP, quando comparados com os demais métodos de medição de velocidade de corrente, apresentam como vantagens, dentre outras, maior quantidade de dados coletados, maior qualidade dos dados coletados e maior precisão. Contudo, podemos citar, como desvantagem do perfilador ADCP, a limitação quanto à profundidade.

Estimativas de velocidades geostróficas absolutas através do MDR permitem 
que obtenhamos padrões horizontais de circulação em níveis mais profundos que os alcançados pelo $\mathrm{ADCP}$, com valores mais próximos dos valores reais, quando comparados com os valores de velocidade geostrófica baroclínica relativa.

O processamento dos dados de CTD foi realizado com base em programas desenvolvidos no ambiente MathWorks MATLAB e com o auxílio das sub-rotinas da biblioteca SEAWATER [Morgan, 1994], além de outras sub-rotinas deste software. O processamento dos dados de ADCP foi realizado através do sistema CODAS, concebido pelo Dr. Eric Firing e associados na Universidade do Havaí. Esse sistema padroniza, simplifica e torna mais rápido o processamento.

Para a construção dos mapas de função de corrente sobre as grades curvilineares geradas, bem como para a elaboração das seções verticais de velocidade observada, realizou-se a interpolação dos dados por Análise Objetiva.

Pudemos verificar a assinatura da SNB em todos os padrões verticais e horizontais elaborados no presente trabalho, tanto geostróficos quanto observados. Constatamos também uma boa concordância entre os padrões geostróficos baroclínicos relativos e os padrões observados. Citamos, como principais observações advindas de nossos resultados:

- A SNB adentra a região já como uma corrente de contorno oeste, com núcleo entre $220 \mathrm{~m}$ e $250 \mathrm{~m}$, nas proximidades da latitude de $11^{\circ} \mathrm{S}$ e com velocidades em torno de $0,8 \mathrm{~m} \mathrm{~s}^{-1}$. Tanto os campos observados como os obtidos por MDC e MDR apresentam profundidade de núcleo semelhante. Estes resultados corroboram as estimativas de LADCP obtidas por Stramma et al. [1995] e Schott et al. [2005];

- Em seu caminho para o norte, o núcleo da SNB se torma mais raso. As velocidades em superfície se tornam mais intensas devido ao aporte dos ramos da CSE. Nas proximidades da latitude de $5^{\circ} \mathrm{S}$, a profundidade, pelos três métodos de análise empregados, está em torno de $200 \mathrm{~m}$;

- Os mapas horizontais para o nível de $160 \mathrm{~m}$, obtidos a partir de medições diretas de velocidade, revelam que, em torno de $4^{\circ} \mathrm{S}-5^{\circ} \mathrm{S}$, a origem da SSE é dominantemente devido à cessão de água pela SNB, através de ramo lateral ciclônico. Tal achado corrobora os padrões geostróficos de Silveira et al. [1994] e contrariam 
os resultados de Stramma E England [1999] que apontam a SSE como originada a partir da porção picnoclínica do ramo equatorial da CSE (CSEe). Nossos mapas horizontais para o nível de $200 \mathrm{~m}$, obtidos pelo MDC e pelo MDR, confirmam os padrões derivados de ADCP de casco;

- Nas distribuições horizontais, tanto geostróficas quanto observadas, é bastante evidente a assinatura da SNB seguindo ao largo da costa e contornando o Cabo Calcanhar (RN) em aproximadamente $5^{\circ} \mathrm{S}$, bem como a assinatura de um anticiclone frontal centrado em aproximadamente $4^{\circ} 30^{\prime} \mathrm{S}$ e $36^{\circ} \mathrm{W}$. Esse anticiclone frontal pode ser decorrente da resposta do escoamento da SNB à mudança abrupta de orientação da costa, onde parte da SNB segue em direção ao equador e parte acompanha o contorno da margem continental, por inércia. Por situar-se na longitude da cidade de Macau (RN), decidimos denominá-lo Vórtice de Macau (VM);

- Os resultados apresentam efetivas evidências da "transformação" da SNB em CNB ao norte do Cabo Calcanhar (RN). Nas seções mais ao norte da comissão ONEII, em aproximadamente $1,5^{\circ} \mathrm{S}-3^{\circ} \mathrm{S}$, as velocidades observadas em superfície já atingem $0,9 \mathrm{~m} \mathrm{~s}^{-1}$ e a diferença de magnitude de velocidade observada na superfície e no núcleo, posicionado em torno de $130 \mathrm{~m}$, é de aproximadamente $0,15 \mathrm{~m} \mathrm{~s}^{-1}$. Em contrapartida, observamos que, na radial localizada nas proximidades de $11^{\circ} \mathrm{S}$, a diferença de magnitude entre os valores observados no núcleo, em torno de $220 \mathrm{~m}$, e na superfície utrapassa o valor de $0,65 \mathrm{~m} \mathrm{~s}^{-1}$;

- A extensão das radiais da comissão ONEII até as proximidades do equador nos possibilitou obter uma figura inédita vinculando sequencialmente a CNB, a SNB e a origem da SE. Entre $0^{\circ} \mathrm{S}$ e 2,5 $\mathrm{S}$, no limite oceânico da área de estudo, observamos um contrafluxo associado à ramificação picnoclínica e subpicnoclínica da retroflexão da CNB que ocorre já em hemisfério boreal. Essa retroflexão dá origem à SNE, em torno de $3^{\circ} \mathrm{S}-4^{\circ} \mathrm{S}$, não tendo sido capturada pelos dados analisados no presente trabalho, mas constante nos trabalhos de Goes et al. [2005]. Tal retroflexão também dá origem à SE, cujo núcleo se situará em torno de $100 \mathrm{~m}$. Interessantemente, nos campos derivados de ADCP e nos calculados por MDR e 
MDC, encontramos indícios de que a SNB contribui também para alimentar a SE através do ramo ciclônico em cerca de $1^{\circ} \mathrm{S}$.

\subsection{Sugestões para Trabalhos Futuros}

Os resultados apresentados no presente trabalho, evidenciaram a presença da SNB fluindo ao largo da costa brasileira, transportando águas quentes e salinas do hemisfério sul em direção ao equador, tendo sido observado também um anticiclone frontal, de provável caráter semipermanente. Em face da carência de informações acerca dos processos de formação e da origem da SNB, bem como das feições de mesoescala associadas ao escoamento da SNB, apresentamos, como sugestões:

- Realização de coleta de dados de LADCP, que permite perfilagem superfíciefundo, simultaneamente à coleta de dados de CTD, para elaboração de estimativas de corrente geostrófica absoluta. O estudo do grau de geostrofia da SNB pode ser incrementado com a utilização de um NR mais profundo que $160 \mathrm{~m}$;

- Realização de um número maior de perfilagens por $\mathrm{ADCP}$ ao sul de $10^{\circ} \mathrm{S}$, na região onde se acredita ocorrer a formação da SNB;

- Realização de um número maior de radiais e perfilagens, preferencialmente por $\mathrm{CTD}$ e LADCP, entre $5^{\circ} \mathrm{S}$ e $5^{\circ} \mathrm{N}$, para documentar-se mais precisamente a "transformação" da SNB em CNB, bem como seus padrões de retroflexão estratificadamente. 


\section{Referências Bibliográficas}

Apel, J. R., 1995: Principles of Ocean Physics. Academic Press, London, 1 edição, 634 pp.

Bretherton, F. P., E. D. Russ, \& C. B. A. Fandry, 1976: Technic for Objetive Analysis and design of oceanographic experiments applied to MODE-73. Deep-Sea Res., 23(7), $559-582$.

Bub, F. L. \& W. S. Brown, 1996: Intermediate Layer Water Masses in the Western Tropical Atlantic Ocean. Journal of Geophysical Research, 101(C5), 11,903-11,922.

Carter, E. F. \& A. R. Robinson, 1987: Analysis models for the estimation of oceanic fields. J. Atmos. Oc. Tech., 4(1), 49-74.

Cushman-Roisin, B., 1994: Introduction to Geophysical Fluid Dynamics. Prentice-Hall Inc., New Jersey, 320 pp.

Emery, W. J. \& R. E. Thomson, 1998: Data analysis methods in physical oceanography. Pergamon, Great Britain, 634 pp.

Firing, E., 1991: Acoustic doppler current profiling measurements and methods. In WOCE Operations Manual - WHP Operations and Methods, volume 3. WHP Office Report WHPO 91-1.

Ganachaud, A., 2003: Large-scale mass transports, water mass formation, and diffusivities estimated from World Ocean circulation Experiment (WOCE) hydrographic data. JGR, 108(3216), DOI:10.1029/2002JC001.565.

Gill, A. E., 1982: Atmosphere-Ocean Dynamics. Academic Press, Inc., San Diego, 1 edição, $662 \mathrm{pp}$. 
Goes, M., R. Molinari, I. C. A. Silveira, \& I. Wainer, 2005: Retroflections of the North Brazil Current during February 2002. Deep-Sea Research, Elsevier, 52(11), 647-667.

Holton, J. R., 1992: An Introduction to Dynamic Meteorology. Academic Press, San Diego, California, 3rd edição, 509 pp.

Johns, W. E., T. N. Lee, F. Schott, R. Zantopp, \& R. H. Evans, 1990: The North Brazil Current Retroflection: Seasonal Structure and Eddy Variability. Journal of Physical Oceanography, 95, 22,103-22,120.

Joyce, T. M., 1989: On In Situ “Calibration” of Shipboard ADCPs. JAOT, 6(6), 169-172.

Kundu, P. K., 1990: Fluid Mechanics. Academic Press, Inc., San Diego, California, 638 pp.

Lewis, E., 1980: The Practical Salinity Scale 1978 and its antecedents. IEEE JOURNAL OF OCEANIC ENGINEERING, OE-5(1), 3-8.

Lumpkin, R. \& K. Speer, 2003: Large-scale vertical and horizontal circulation in the North Atlantic Ocean. JPO, 33, 1902-1920.

Mayer, D. A. \& R. H. Weisberg, 1993: A Description of COADS Surface Meteorological Fields and the Implied Sverdrup Transports for the Atlantic Ocean from $30^{\circ} \mathrm{S}$ to $60^{\circ} \mathrm{N}$. Journal of Physical Oceanography, 23, 2201-2221.

Miranda, L. \& B. M. Castro Filho, 1979: Condições do movimento geostrófico das águas adjacentes a Cabo Frio (RJ). Bolm. Inst. Oceanogr., 28(2), 79-83.

Miranda, L. B., B. Castro, \& B. Kjerfve, 2002: Princípios de Oceanografia Física de Estuários. Editora da Universidade de São Paulo, São Paulo, 424 pp.

Molinari, R., 1982: Observations of eastward currents in the tropical South Atlantic Ocean: 1978-1980. Journal of Geophysical Research, 87, 9707-9714.

Molinari, R., B. Voituriez, \& P. Duncan, 1981: Observations in the Subthermocline Undercurrent of the Equatorial South Atlantic Ocean: 1978-1980. Oceanologica Acta 4, pp $451-456$. 
Morgan, P., 1994: Seawater: A library of matlab computational routines for the properties of sea water. Relatório Técnico 222, CSIRO Marine Research - Marine Laboratories.

Munk, W., 2000: Achievements in physical oceanography. In O. S. Board \& N. R. Council, editores, 50 Years of Ocean Discovery: National Science Foundation 19502000. National Academy Press, Washington, D.C., 44-50.

Osiński, R., 2000: The Misalignment Angle in Vessel-Mounted ADCP. Institute of Oceanology-Polish Academy of Sciences, 42(3), 385-394.

Pedlosky, J., 1987: Geophysical Fluid Dynamics. Springer, New York, 2 edição, 729 pp.

Peterson, R. G. \& L. Stramma, 1991: Upper-level Circulation in the South Atlantic Ocean. Progress in Oceanography, 26(1), 1-73.

Pickart, R. S. \& S. S. Lindstrom, 1993: A Comparisom of Techniques for Referencing Geostrophic Velocities. JAOT, 11, 814-824.

Pollard, R. \& J. Read, 1989: A Method for Calibrating Shipmounted Acoustic Doppler Profilers and limitations of Gyro Compasses. JAOT, 6(6), 859-865.

Pond, S. \& G. L. Pickard, 1983: Introductory Dynamical Oceanography. ButterworthHeinemann, Oxford, second edição, 329 pp.

RDInstruments, 1996: Acoustic Doppler Current Profiler - Principles of Operation - A Pratical Primer.

Rennell, J., 1832: An investigation of the currents of the Atlantic Ocean, and of those which prevail between the Indian Ocean and the Atlantic. J.G. and F. Rivington, London, 359 pp.

Rodrigues, R. R., L. M. Rothstein, \& M. Wimbush, 2007: Seasonal Variability of the South Equatorial Current Bifurcation in the Atlantic Ocean: A Numerical Study. Journal of Physical Oceanography, 37, 16-30. 
Schott, F. A., P. Brandt, M. Hamann, J. Fischer, \& L. Stramma, 2002: On The Boundary Flow Off Brazil At 5-10 S And Its Connection To The Interior Tropical Atlantic. Geophysical Research Letters, 29(17), 21(1)-21(4).

Schott, F. A., M. Dengler, R. Zantopp, L. Stramma, J. Fischer, \& P. Brandt, 2005: The Shallow and Deep Western Boundary Circulation of the South Atlantic at $5^{\circ}-11^{\circ} \mathrm{S}$. Journal of Physical Oceanography, 35, 2031-2053.

Schott, F. A., J. Fischer, \& L. Stramma, 1998: Transports and Pathways of the UpperLayer Circulation in the Western Tropical Atlantic. Journal of Physical Oceanography, 28, 1904-1928.

Silveira, I. C. A., W. S. Brown, \& G. R. Flierl, 2000a: Dynamics of the North Brazil Current Retroflection from the Western Tropical Atlantic Experiment Observations. Journal of Geophysical Research, 105(C12), 28,559-28,583.

Silveira, I. C. A., L. Calado, B. M. Castro, M. Cirano, J. A. M. Lima, \& A. S. Mascarenhas, 2004: On the baroclinic structure of the Brazil Current-Intermediate Western Boundary Current System. Geophys. Res. Lett., 31(14), L14.308.

Silveira, I. C. A., L. Calado, \& C. P. F. Francisco, 2003: Instabilidade linear de cisalhamento vertical em jatos geofísicos meridionais. Revista Brasileira de Geofísica, 21(2), 133-145.

Silveira, I. C. A., L. B. Miranda, \& W. S. Brown, 1994: On the origins of the North Brazil Current. J. Geophys. Res., 99(C11), 22.501-22.512.

Silveira, I. C. A., A. C. K. Schmidt, E. J. D. Campos, S. S. Godoi, \& Y. Ikeda, 2000b: A Corrente do Brasil ao largo da costa leste brasileira. R. bras. Oceanogr., 48(2), 171-183.

Stommel, H., 1948: The westward intensification of wind-driven ocean currents. TAGU, 29, 202-206.

Stramma, L., 1991: Geostrophic Transport of the South Equatorial Current in the Atlantic. Journal of Marine Research, 49(2), 281-294.

Stramma, L. \& M. England, 1999: On the water masses and mean circulation of the South Atlantic Ocean. J. Geophys. Res., 104(C9), 20.863-20.883. 
Stramma, L., J. Fischer, \& J. Reppin, 1995: The North Brazil Undercurrent. Deep-Sea Research Part I - Oceanographic Research Papers, 42(5), 773 - 795.

Stramma, L., Y. Ikeda, \& R. G. Peterson, 1990: Geostrophic transport in the Brazil Current north of $20^{\circ}$ S. Deep-Sea Res., 37(12), 1875-1886.

Stramma, L., M. Rhein, P. Brandt, M. Dengler, C. Böning, \& M. Walter, 2005: Upper Ocean Circulation in the Western Tropical Atlantic in Boreal Fall 2000. Deep-Sea Research, (52), 221-240.

Stramma, L. \& F. A. Schott, 1999: The Mean Flow Field of the Tropical Atlantic Ocean. Deep-Sea Research, 46, 279-303.

Sutton, P. J. H. \& T. K. Chereskin, 2002: Absolute geostrophic currents in the East Australian Auckland Current region. NZJMFWR, 36, 751-762.

Sverdrup, H. U., 1947: Wind-driven currents in a baroclinic ocean; with application to the equatorial currents off the eastern Pacific. Proc. Natl. Acad. Sci. U.S.A, 33, $318-336$.

Talley, L. D., 2003: Shallow, intermediate, and deep overturning components of the global heat budget. JPO, 33, 530-560.

Tomczak, M. \& J. S. Godfrey, 1994: Regional Oceanography: An Introduction. Pergamon, Great Britain, 422 pp.

UNESCO, 1981a: Background papers and supporting data on the International Equation of State of Seawater 1980. UNESCO Technical Papers in Marine Science, (38), 192.

UNESCO, 1981b: Background papers and supporting data on the Practical Salinity Scale 1978. UNESCO Technical Papers in Marine Science, (37), 144.

UNESCO, 1988: The Acquisition, calibration, and analysis of CTD data: a report of SCOR Working Group 51. UNESCO technical papers in marine science, (54), 94.

Urbano, D. F. \& I. C. A. Silveira, 2003: Estrutura dinâmica das contra-correntes equatoriais do Oceano Atlântico ao longo de $44^{\circ}$ W. Rev. Bras. Geof., 21(2), 145-162. 